\title{
The role of the special education administrator as perceived by principals, superintendents, and special education administrators in West Virginia
}

Katherine Leary Porter

West Virginia University

Follow this and additional works at: https://researchrepository.wvu.edu/etd

\section{Recommended Citation}

Porter, Katherine Leary, "The role of the special education administrator as perceived by principals, superintendents, and special education administrators in West Virginia" (1999). Graduate Theses, Dissertations, and Problem Reports. 3673.

https://researchrepository.wvu.edu/etd/3673

This Dissertation is protected by copyright and/or related rights. It has been brought to you by the The Research Repository @ WVU with permission from the rights-holder(s). You are free to use this Dissertation in any way that is permitted by the copyright and related rights legislation that applies to your use. For other uses you must obtain permission from the rights-holder(s) directly, unless additional rights are indicated by a Creative Commons license in the record and/ or on the work itself. This Dissertation has been accepted for inclusion in WVU Graduate Theses, Dissertations, and Problem Reports collection by an authorized administrator of The Research Repository @ WVU.

For more information, please contact researchrepository@mail.wvu.edu. 
The Role of the Special Education Administrator as Perceived by Principals, Superintendents, and Special Education Administrators in West Virginia

Katherine L. Porter

Dissertation

Submitted to the College of Human Resources and Education of West Virginia University

In Partial Fulfillment of the Requirements for the Degree of Doctor of Education

\author{
Powell Toth, Ph.D., Chair \\ Michael Sullivan, Ed.D. \\ Ronald Childress, Ed.D. \\ Phyllis Durden, Ed.D. \\ Barbara Kean, Ed.D.
}

Department of Educational Leadership Studies

Morgantown, West Virginia

1999

Keywords: special education administration, administrative tasks, role theory Copyright 1999 Katherine L. Porter 


\begin{abstract}
This study examined the expectations held by key administrative personnel within West Virginia public schools regarding the role of the special education administrator. Existing differences in perception of the administrative functions of the special education administrator in West Virginia among and within groups of superintendents, principals, and special education administrators were investigated. Forty administrative tasks organized into seven administrative activities were examined in order to identify potential areas of conflict between the school system administrators. The responses analyzed pertained to both the perceived performance and the perceived importance of each administrative task.

The West Virginia school personnel that participated in this study included: (1) all 55 county superintendents of schools, (2) all 55 persons identified as special education administrators and (3) a random sample of 150 West Virginia public school principals. The survey instrument used was the revised Newman instrument. For the current study, the Newman instrument was revised to reflect changes in special education that have occurred since the instrument was used 12 years ago in the Sullivan (1986) study. An Analysis of Variance
\end{abstract} (ANOVA) was used to answer research questions one through fourteen and an alpha level of 0.05 was set as the criteria for determining significance.

Analysis of the data indicated:

1. There were significant differences among the three groups of administrators on nine of the fourteen research questions.

2. There were significant differences among the three groups of administrators regarding the perceived performance of 28 of the 40 tasks and the perceived degree of importance of 14 of the 40 tasks contained within the seven administrative functions

3. The significant pairing included the superintendents and the principal and the special education administrator and principal. 


\section{ACKNOWLEDGMENTS}

Completion of a doctoral program is not an individual effort. In my case I want to thank my good friends and comrades in the doctoral program, Chuck Bethel and Rudy Pauley. Rudy, thanks for the push every time I seemed to need it during the dissertation process. I want to thank my committee members Dr. Phyllis Durden, Dr. Barbara Kean and Dr. Ron Childress for their great support. Special thanks are owed to Dr. Mike Sullivan for entrusting me with the replication of his dissertation and Dr. Powell Toth for his guidance and support throughout my time in the doctoral program. Thanks are also due to Dr. Mike Cunningham for his great generosity with his expertise and his time.

I want to thank my family for their support and patience. My parents, Doris Leary and Dr. Paul A. Leary, have been helpful to me in ways too numerous to list. They instilled in me the desire to have goals and the discipline to work to achieve them. Without that, I would not have been able to complete this program. My daughters, Emily and Grace, have been a source of

encouragement and support. My group of extended family and friends has encouraged me through their interest and helpfulness.

This dissertation is dedicated to my husband, David Porter. Without his encouragement I would still be thinking about enrolling in the doctoral program. His help and support during the completion of this dissertation has been immeasurable. Thanks, David. 


\section{TABLE OF CONTENTS}

page

ABSTRACT

ii

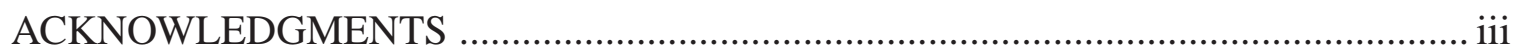

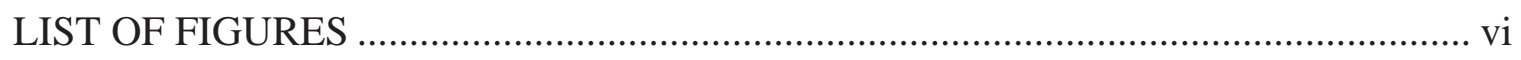

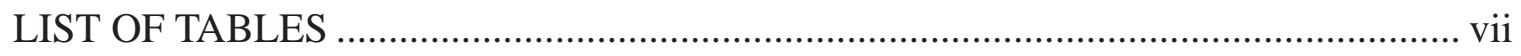

Chapter

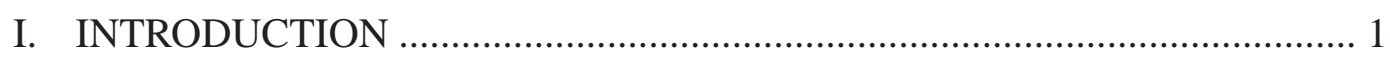

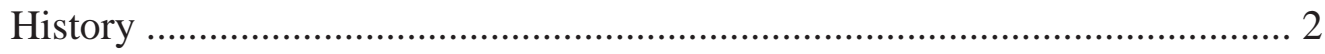

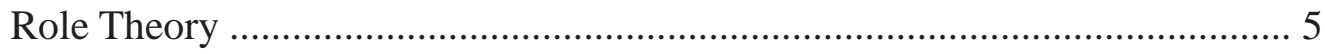

Statement of the Problem ......................................................................... 10

Definition of Terms ......................................................................... 12

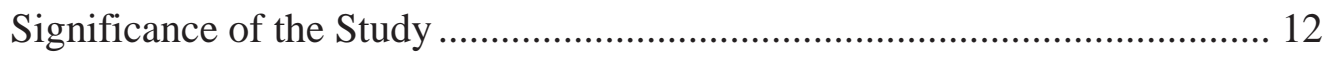

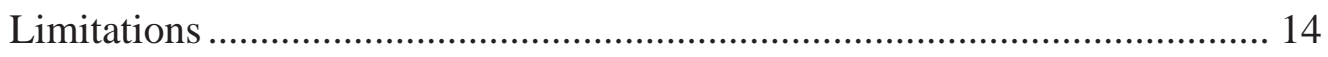

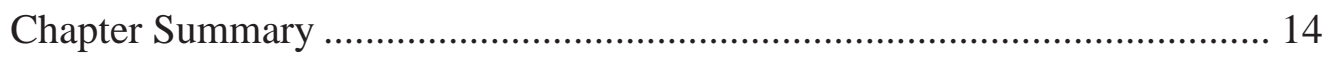

II. REVIEW OF THE RELATED LITERATURE ….................................... 15

The Special Education Administrator .................................................... 15

The Special Education Administrator and the Principal ............................ 27

The Special Education Administrator and the Superintendent .................... 32

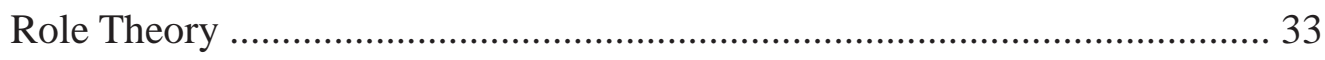

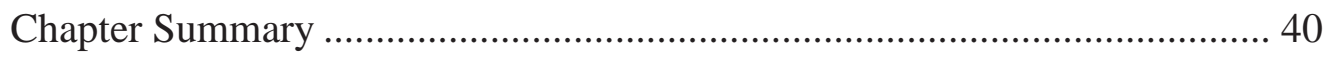

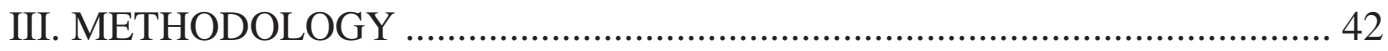

Sample and Sampling Procedures ............................................................ 42

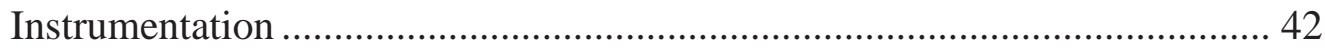

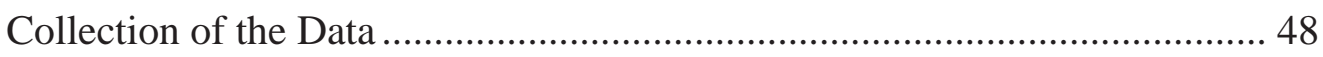

Statistical Procedures .................................................................... 49

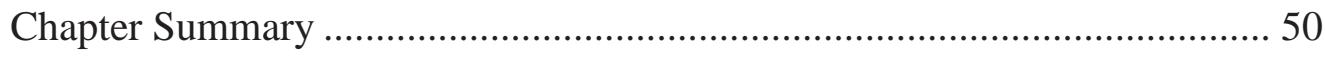


IV. PRESENTATION AND ANALYSIS OF DATA ....................................... 51

Descriptive Data ............................................................................... 51

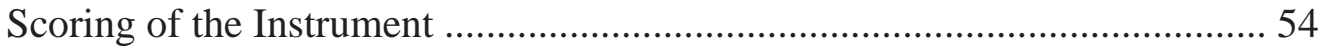

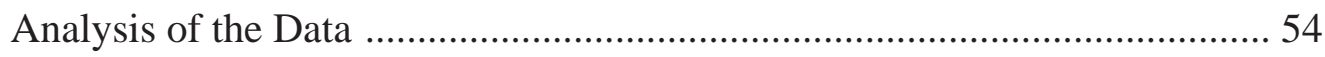

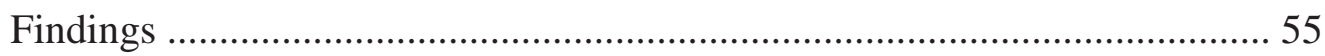

Chapter Summary ….................................................................. 114

V. SUMMARY, CONCLUSIONS AND RECOMMENDATIONS ................. 115

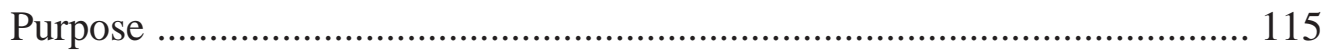

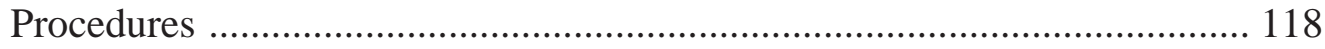

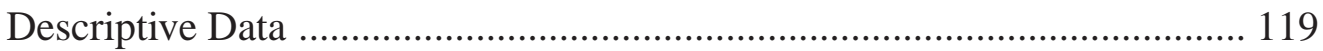

Summary of Findings ................................................................ 120

Conclusions .................................................................................... 129

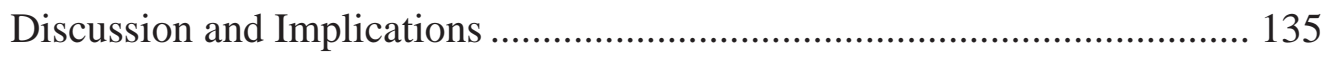

Recommendations for Further Research ............................................ 137

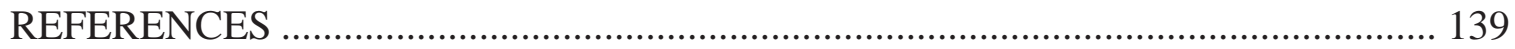

\section{APPENDICES}
A. The Revised Newman Instrument
B. Demographic Information Sheet
C. Initial Letter
D. Follow-up Letter ...
E. Demographic Tables 


\section{LIST OF FIGURES}

Figure

page

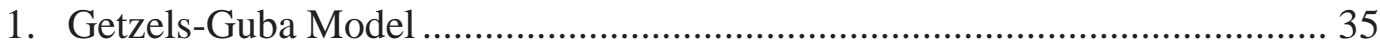




\section{LIST OF TABLES}

Table

page

1. Examples of the Newman Instrument 44

2. Sum of Squares, Degrees of Freedom, Mean Square, F Value and Levels of Significance for Question 1. 56

3. Sum of Squares, Degrees of Freedom, Mean Square, F Value and Levels of Significance for Each Task in the Planning Function as Perceived by Special Education Administrators, Superintendents and Principals (Performance)

4. Sum of Squares, Degrees of Freedom, Mean Square, F Value and Levels of Significance for Question 8.

5. Sum of Squares, Degrees of Freedom, Mean Square, F Value and Levels of Significance for Each Task in the Planning Function as Perceived by Special Education Administrators, Superintendents and Principals (Degree of Importance) ...... 60

6. Mean Differences Between Superintendents and Principals in the Staffing Function

7. Mean Difference Between Special Education Administrators and Principals in the Staffing Function

8. Sum of Squares, Degrees of Freedom, Mean Square, F Value and Levels of Significance for Question 2.

9. Sum of Squares, Degrees of Freedom, Mean Square, F Value and Levels of Significance for Each Task in the Organizing Function as Perceived by Special Education Administrators, Superintendents and Principals (Performance)

10. Sum of Squares, Degrees of Freedom, Mean Square, F Value and Levels of Significance for Question 9. 68

11. Sum of Squares, Degrees of Freedom, Mean Square, F Value and Levels of Significance for Each Task in the Organizing Function as Perceived by Special Education Administrators, Superintendents and Principals (Degree of Importance) 
12. Mean Differences Between Superintendents and Principals in the Organizing Function

13. Mean Differences Between Superintendents and Special Education Administrators in the Organizing Function

14. Sum of Squares, Degrees of Freedom, Mean Square, F Value and Levels of Significance for Question 3. 72

15. Sum of Squares, Degrees of Freedom, Mean Square, F Value and Levels of Significance for Each Task in the Staffing Function as Perceived by Special Education Administrators, Superintendents and Principals (Performance)

16. Sum of Squares, Degrees of Freedom, Mean Square, F Value and Levels of Significance for Question 10.

17. Sum of Squares, Degrees of Freedom, Mean Square, F Value and Levels of Significance for Each Task in the Staffing Function as Perceived by Special Education Administrators, Superintendents and Principals (Degree of Importance)

18. Significant Mean Differences Between Superintendents and Principals in the Staffing Function

19. Mean Differences Between Special Education Administrators and Principals in the Staffing Function

20. Sum of Squares, Degrees of Freedom, Mean Square, F Value and Levels of Significance for Question 4.

21. Sum of Squares, Degrees of Freedom, Mean Square, F Value and Levels of Significance for Each Task in the Directing Function as Perceived by Special Education Administrators, Superintendents and Principals (Performance)

22. Sum of Squares, Degrees of Freedom, Mean Square, F Value and Levels of Significance for Question 11.

23. Sum of Squares, Degrees of Freedom, Mean Square, F Value and Levels of Significance for Each Task in the Directing Function as Perceived by Special Education Administrators, Superintendents and Principals (Degree of Importance) 86 
24. Mean Differences Between Superintendents and Principals in the Directing Function

25. Mean Differences Between Superintendents and Principals in the Directing Function

26. Sum of Squares, Degrees of Freedom, Mean Square, F Value and Levels of Significance for Question 5.

27. Sum of Squares, Degrees of Freedom, Mean Square, F Value and Levels of Significance for Each Task in the Coordinating Function as Perceived by Special Education Administrators, Superintendents and Principals (Performance)

28. Sum of Squares, Degrees of Freedom, Mean Square, F Value and Levels of Significance for Question 12.

29. Sum of Squares, Degrees of Freedom, Mean Square, F Value and Levels of Significance for Each Task in the Coordinating Function as Perceived by Special Education Administrators, Superintendents and Principals (Degree of Importance)

30. Mean Differences Between Superintendents and Principals in the Coordinating Function 96

31. Mean Differences Between Special Education Administrators and Principals in the Coordinating Function 96

32. Sum of Squares, Degrees of Freedom, Mean Square, F Value and Levels of Significance for Question 6.

33. Sum of Squares, Degrees of Freedom, Mean Square, F Value and Levels of Significance for Each Task in the Reporting Function as Perceived by Special Education Administrators, Superintendents and Principals (Performance) 99

34. Sum of Squares, Degrees of Freedom, Mean Square, F Value and Levels of Significance for Question 13.

35. Sum of Squares, Degrees of Freedom, Mean Square, F Value and Levels of Significance for Each Task in the Reporting Function as Perceived by Special Education Administrators, Superintendents and Principals (Degree of Importance) 102 
36. Mean Differences Between Superintendents and Principals in the Reporting Function

37. Mean Differences Between Special Education Administrators and Principals in the Reporting Function

38. Sum of Squares, Degrees of Freedom, Mean Square, F Value and Levels of Significance for Question 7. 105

39. Sum of Squares, Degrees of Freedom, Mean Square, F Value and Levels of Significance for Each Task in the Budgeting Function as Perceived by Special Education Administrators, Superintendents and Principals (Performance)

40. Sum of Squares, Degrees of Freedom, Mean Square, F Value and Levels of Significance for Question 14. 108

41. Sum of Squares, Degrees of Freedom, Mean Square, F Value and Levels of Significance for Each Task in the Budgeting Function as Perceived by Special Education Administrators, Superintendents and Principals (Degree of Importance)

42. Mean Differences Between Superintendents and Principals in the Budgeting Function

43. Mean Differences Between Special Education Administrators and Principals in the Budgeting Function

44. Tasks in Which Significant Differences Occurred Among Principals, Superintendents and Special Education Administrators Regarding Perceived Performance and Perceived Degree of Importance Assigned to Tasks 


\section{CHAPTER 1}

\section{INTRODUCTION}

Public school education for children with handicaps has evolved in the twentieth century. In the first half of this century, education for handicapped children developed from residential schools to programs in the local community and special day programs administered by the institutions (Hartley, 1991). By the late 1960s special education became a parallel program in the public schools. The equidistant special education program consisted of a special education class model, housed in special schools or in separate classes in regular public schools (Hartley, 1991). Hartley (1991) reports that the civil rights movement of the late 1960s and early 1970s brought to the forefront of public attention the issue of appropriate education for the handicapped.

As the field of special education evolved, the need for special education administrators arose (Washington, 1996). The role of the special education administrator has been described as ambiguous and complex (Finkenbinder, 1981; Furman, 1988; Hartley \& Whitworth, 1979; Lashley, 1982; Ponder, 1994; Simpson \& Lamb, 1979; Sullivan, 1986, 1996; Sullivan \& Leary, 1991; Washington, 1996; Whitworth \& Hartley, 1982). In an organization roles are determined by expectations employees have of each other (Getzels \& Guba, 1957; Hartenian, Hadaway, \& Badovick, 1994). When roles in organizations lack clarity, role conflict can ensue (Getzels \& Guba, 1957; Hartenian et al, 1994). Role conflict, in turn, is associated with role ambiguity and reduced job satisfaction (Getzels \& Guba, 1957; Hartenian et al, 1994). Given the inexplicit nature of the role of the special education administrator and the importance of role clarity to the school organization, additional examination of the special education administrative role was warranted.

The purpose of this study was to examine expectations held by key administrators within West Virginia's school system relative to the role of the special education administrator. Existing differences in perception of the administrative functions of the special education administrator in West Virginia among and within groups of superintendents, principals and special education 
administrators were investigated.

\section{History}

A series of legislative imperatives and parent-initiated litigation led to the 1975 enactment of Public Law 94-142, The Education for All Handicapped Children Act (EAHCA) (Hartley, 1991). Public Law 94-142 has been widely credited with bringing about sweeping changes in special education (Finkenbinder, 1981; Hartley, 1991; National Association of State Directors of Special Education, 1993; Ponder, 1994; Sullivan, 1986; Whitworth \& Hatley, 1982;). Referring to Public Law 94-142, the National Advisory Committee on the Education of the Handicapped (1976) stated, "In law and as National policy, education is today recognized as the handicapped person's right" (p.143). Subsequent amendments to Public Law 94-142, made in 1990, changed the name of the act to the Individuals With Disabilities Education Act (IDEA) (National Association of State Directors of Special Education, 1993). A new version of IDEA was amended and reauthorized by Congress in 1997 (Buka, 1998). Other legislation that has impacted special education is Section 504 of the Rehabilitation Act of 1973 (National Association of State Directors of Special Education, 1993; Sullivan, 1986), the Carl D. Perkins Vocational Education Act of 1984 (Walker, 1988) and the 1990 Americans With Disabilities Act (National Association of State Directors of Special Education, 1993).

Changes in legislation relative to special education influenced changes in the role of the special education administrator (Finkenbinder, 1981; National Association of State Directors of Special Education, 1993). Prior to federal mandates, school administrators assumed the administration of special education along with other responsibilities (Washington, 1996). The mandate for educating children with disabilities prompted growth in special education programs as well as the need for qualified administrators for these programs (Washington, 1996). The need for additional administration and supervision resulted in the development of special education administration as a separate entity (Finkenbinder, 1981). 
As the role of the special education administrator has developed, one issue that is highly referenced is that the role is complex and unclear (Finkenbinder, 1981; Furman, 1988; Hatley \& Whitworth, 1979; Lashley, 1991; Ponder, 1994; Simpson \& Lamb, 1979; Sullivan, 1986, 1996; Sullivan \& Leary, 1991; Washington, 1996; Whitworth \& Hatley, 1982). Finkenbinder (1981) contended that institutions of higher education did not assume responsibility for training special education administrators until the late 1970s. Until then, administrators and supervisors nationwide received their training and experiences on the job (Finkenbinder, 1981). Given this lack of uniform training, a wide variance in the roles and functions of special education administrators ensued (Finkenbinder, 1981).

In 1969, the Wisconsin Department of Public Instruction referred to the position of the special education administrator as one that was moving "out of the infancy stage" (p.1). During the 1970s, special education was still establishing itself as a separate organizational function providing direct services to eligible handicapped students. The major concerns of special education administrators revolved around access and availability of special education programs for students (Grebner, 1989; Johnson \& Burrello, 1987). In 1982, Whitworth and Hatley stated that, "No clear conceptualization has yet emerged in many states concerning the responsibilities and competencies of special education administrators" (p.38), and in 1986, Sullivan asserted that the role of the special education administrator was ambiguous and still emerging.

By the second half of the 1980s, a nationwide movement toward school reform arose (Hirth \& Valesky, 1990). This reform movement evoked a change in the issues facing special education (Grebner, 1989; Hirth \& Valesky, 1990; Johnson \& Burrello, 1987). The main issue in special education shifted from one of access and availability to one of quality (Grebner, 1989; Johnson \& Burrello, 1987). Special education leaders, like those in regular education, are being required to show evidence of quality programs and student achievement (Grebner, 1989; Johnson \& Burrello, 1987). In fact, according to Buka (1998) the IDEA amendments of 1997 were intended to strengthen academic expectations and accountability for children with disabilities.

Reform initiatives have included a movement away from the parallel organization of 
special education to a shared responsibly for the education of all students (Lashley, 1991). The development of a more conjoined special education and regular education program became known as the Regular Education Initiative (REI) (Hirth \& Valesky, 1990). The fundamental feature of the REI is the education of students with disabilities in the regular education classroom (Hirth \& Valesky, 1990). The shift from segregating students with disabilities to one of integrating them with their peers without disabilities has become known as inclusion (Powell \& Hyle, 1997).

As school systems move toward more inclusive models, changes in schools' approaches to special education students have instigated changes in role responsibilities within the system (Lashley, 1991). Given the current school-based delivery for special education, the school principal has become critical to the success of special education programs (Goor, Schwenn, \& Boyer, 1997; Van Horn, Burrello, \& DeClue, 1992). The principal is the instructional leader for all programs within the school, including special education (Goor, Schwenn, \& Boyer, 1997). Yet, research indicates that principals' knowledge of special education needs improvement (Cline, 1981; Hirth \& Valesky, 1989,1990). McLaughlin and Kienas (1989) reported that principals have become more managers of personnel and paperwork than instructional leaders for special education. The lack of strong instructional leadership can be attributed to confusion in roles between building administrators and special education administrators (McLaughlin \& Kienas, 1989).

Although there is ample research in respect to the special education administrator and school principals, the research on special education administrators and superintendents is sparse. Meisgeier and Sloat (1970) determined that the school superintendent has the most influence on the development of the role and responsibilities of the special education administrator. A 1986 study by Sullivan examined differences in perception between special education administrators, superintendents and principals regarding the role and function of the special education administrator. Findings from the Sullivan study (1986) indicated that there was little disagreement between superintendents and special education administrators relative to the role of 
the special education administrator.

Within the last 25 years the role of the special education administrator has become increasingly complex (Hartley, 1991). The special education administrator's role has become even more complicated a special education moves from supervision in a separate program to supervision in regular education settings (Washington, 1996). Accustomed to a system of two distinct programs of special education and regular education, it is difficult for today's administrators to find the proper role in today's integrated system (Hartley, 1991). Inconsistencies and inconclusiveness concerning the special education administrators role persists and current research has been minimal (Ponder, 1994).

\section{Role Theory}

Roles and expectations are necessary to the functioning of institutions (McGregor, 1994). According to Getzels and Guba (1957), roles are the most important analytical unit of the institution and are defined in part by expectations (Getzels \& Guba, 1954,1957). Role is the personal psychological link to the organization and is combined with the expectations of others within the system (Getzels \& Guba, 1954, 1957). Combining role with expectations of others can cause an overlap of internal and external forces (Getzels \& Guba, 1954, 1957). Role conflict, role ambiguity and organizational stress can occur from these overlapping forces (Getzels \& Guba, 1954, 1957). Gmelch and Torelli (1994) use the term role conflict to describe situations that require leaders to play a role that conflicts with their value system, or to play two or more roles that are in conflict with each other. Role ambiguity is defined by Gmelch and Torelli (1994) as roles leaders must perform that are not clearly articulated in terms of behaviors or performance expectations. Any of these problems can effect personal dissatisfaction and eventually, the organization as a whole (Getzels \& Guba, 1957; Gibbs, 1990; Gmelch \& Torelli, 1994).

Getzels and Guba developed a social systems theory in 1957 that addresses role and role expectations (Getzels \& Guba, 1957). According to the Getzels-Guba model social behavior is a 
function of the interaction of role and personality (Getzels \& Guba, 1954, 1957). The GetzelsGuba model (1957) consists of a nomothetic dimension and a idiographic dimension. The nomothetic dimension is the impersonal dimension and includes the institution, the specific role under consideration and the expectations attached to that role (Getzels \& Guba, 1954,1957). The idiographic dimension is the personal dimension and includes the individual, his personality and his needs at the moment (Getzels \& Guba,1954, 1957). Burnett and Pankake (1990) assert that the nomothetic and idiographic dimensions are distinctly identifiable, yet they interact in observed behavior characterizing the total organization. Further, organizational health is dependent upon the balance between the nomothetic and idiographic dimensions applied to each person involved in the organization (Getzels \& Guba, 1954, 1957). The Gezels-Guba model identifies three types of conflict that can arise from the internal dynamics of the nomothetic and idiographic dimensions: role conflict, personality conflict, and role personality conflict (Getzels \& Guba, 1954, 1957).

Katz and Kahn are other theorists who point to the importance of role concepts in organizations (Katz \& Kahn, 1978; Ho, Vitell, Barnes \& Desborde, 1997). Katz and Kahn (1978) define role as "a set of expected activities associated with the occupancy of a given position" (p. 200). In addition to role, each person in an organization exists in relationship to other people, who constitute the role set (Katz \& Kahn, 1978). All the members of particular positions to which the focal person's position is attached may be thought of as the focal person's role set (Katz \& Kahn, 1978). The members of the role set have expectations of behaviors for the focal person and they communicate these expectations in four phases of a role episode: expectations, sending expectations, receiving expectations, behaving (Katz \& Kahn, 1978). There are four types of role conflict in the Katz and Kahn framework. Intrasender conflict occurs when incompatible expectations are received from a single role sender (Katz \& Kahn, 1978). Intersender conflict consists of incompatible expectations from two or more role senders (Katz \& Kahn, 1978). The third form of role conflict occurs when the focal person's own role expectations are in disagreement with those of one or more role senders (Katz \& Kahn, 1978). 
Finally, interrole conflict exists when pressures form one role conflict with those from another role (Katz \& Kahn, 1978).

Both the Getzels-Guba and Katz and Kahn models present role in a positive and negative light. Roles can be functional, but they can also be dysfunctional to an organization (Ho, et al, 1997). Research indicates that role conflict and role ambiguity can lead to tension, turnover, dissatisfactions, anxiety, and lower performance of employees (Ho, et al, 1997). Miles (1976) suggests that role ambiguity can lead to negative attitudes toward role senders or individuals, such as supervisor and co-workers, who are responsible for providing role clarifying information.

Given the indistinct role of the special education administrator, the potential for role conflict and ambiguity exists. Regarding the Getzels-Guba model, Sullivan (1986) advances that an administrator's behavior is affected by his personal needs, but moreover by the expectations for his role held by other individuals in the organization. Because special education administrators ordinarily occupy a position in school systems somewhere between superintendents and principals, their role is affected by behavioral expectations of others (Sullivan, 1986). When this role is complex, vague and constantly evolving, the potential for role conflict seems inevitable.

With respect to the Katz and Kahn model, Williams (1993) purported that the special education administrator's role set commonly includes the superintendent, the school board, state department personnel, regular education teachers, special education teachers, principals, related service personnel, lawyers, students, other central office personnel, other agency personnel, as well as other special education administrators. Given the variety of other roles the special education administrator interacts with, the potential for all four of Katz and Kahn's types of role conflict are readily apparent (Williams, 1993).

Research in the field of role theory calls attention to several characteristics of role conflict and role ambiguity (Hartley, 1991). The factors of role conflict and ambiguity directly relate to problems encountered by administrators in special education (Hartley, 1991). The more special education administrators learn about expectations held by others in relation to their role in the 
school system, the more likely they are to circumvent potential conflict situations (Sullivan, 1986). Therefore, the perceived role of the special education administrator within the public school system merits further inspection.

In contrast to other areas of special education, there is little research addressing competencies of administrators of special education programs (Gillung, Spears, Campbell, \& Rucker, 1992). The few studies that have addressed special education administration have concentrated on specific administrative role, personality characteristics, or role conflict (Gillung, et al, 1992). Of the studies conducted regarding this position, only one study examining the perceived role of the special education administrator has been conducted in West Virginia. In 1986, Sullivan investigated perceptions of the role of the special education administrator among and within groups of superintendents, principals, and special education administrators. Using a survey instrument developed by Newman, forty specific tasks of special education administrators were organized under seven administrative functions (Sullivan, 1986, 1996; Sullivan \& Leary, 1991). Respondents were asked to designate whether the special education administrator actually performed the tasks and the degree of importance of the task (Sullivan, 1986, 1996; Sullivan \& Leary, 1991). Three groups of West Virginia school system administrators were studied: the 55 county superintendents, the 55 identified county special education administrators, and a random sample of 150 public school principals (Sullivan, 1986, 1996; Sullivan \& Leary, 1991).

Analysis of the data indicated that there were significant differences among the subject groups relative to the perceived performance of twenty-one of the forty tasks in the instrument (Sullivan, 1986, 1996; Sullivan \& Leary, 1991). The relationship that manifested the greatest source for potential conflict was between special education administrators and principals (Sullivan, 1986, 1996; Sullivan \& Leary, 1991). Significant differences were found between special education administrators and principals on nineteen out of forty tasks (Sullivan, 1986, 1996; Sullivan \& Leary, 1991). The pairing of the special education administrator and the principal appeared to be the relationship with the potential for the most conflict, according to Sullivan's findings. 
This study will be a replication of the 1986 Sullivan study. In the time that has passed since Sullivan conducted his study, many changes have occurred in special education. Since 1986 there has been new legislation impacting special education, including the 1990 and 1997 IDEA amendments to Public law 94-142 and the Americans with Disabilities Act. The role of the special education administrator has correspondingly evolved since Sullivan's study. The Regular Education Initiative has evoked a more concerted special education and regular education program that has made the role of the principal more important in the delivery of special education programs. This evolution of legislation and the role and function of the special education administrator indicates a need for an updated inspection of this role.

Additionally, in West Virginia the role of the special education administrator has changed. Mary Nunn has worked in the West Virginia Department of Special Education for 23 years. In a recent interview, Nunn advanced that in the past five to seven years the role of the special education administrator has been altered. In many of the smaller West Virginia counties the position of the special education administrator has become a half time position (Nunn, 1998). Administrators who are responsible for the special education program may have responsibility for other county programs. Further, the newer special education administrators in West Virginia may not have a special education background (Nunn, 1998). Additional changes in West Virginia special education are a greater collaboration with regular education initiatives and more complicated legal issues (Nunn, 1998). Nunn (1998) asserted that the role of the special education administrator in West Virginia has expanded at a time when counties are making positions part-time or employing people with little special education experience.

Research into the field of special education calls attention to the changing role of the special education administrator due to changes in legislation and the inclusion movement. Changes in West Virginia have become evident to high level personnel in the West Virginia Department of Special Education. This modification of the role of the special education administrator constitutes grounds for a replication of the Sullivan study. 


\section{Statement of the Problem}

The purpose of this study was to examine the perceptions of superintendents, principals

and special education administrators within West Virginia's county school systems regarding the role of the special education administrator. Specifically, what are the existing differences, if any, of perceptions among and within groups of superintendents, principals and special education administrators of the role expectations for the special education administrator in county school systems in West Virginia? Investigation of the literature surrounding the role of the special education administrator indicated that the following questions needed to be addressed:

1. Is there a significant difference in the responses among West Virginia special education administrators, principals and superintendents to the perceived performance of the special education administrative function entitled Planning as defined by the tasks on the revised Newman instrument?

2. Is there a significant difference in the responses among West Virginia special education administrators, principals and superintendents to the perceived performance of the special education administrative function entitled Organizing as defined by the tasks on the revised Newman instrument?

3. Is there a significant difference in the responses among West Virginia special education administrators, principals and superintendents to the perceived performance of the special education administrative function entitled Staffing as defined by the tasks on the revised Newman instrument?

4. Is there a significant difference in the responses among West Virginia special education administrators, principals and superintendents to the perceived performance of the special education administrative function entitled Directing as defined by the tasks on the revised Newman instrument?

5. Is there a significant difference in the responses among West Virginia special education administrators, principals and superintendents to the perceived performance of the special 
education administrative function entitled Coordinating as defined by the tasks on the revised Newman instrument?

6. Is there a significant difference in the responses among West Virginia special education administrators, principals and superintendents to the perceived performance of the special education administrative function entitled Reporting as defined by the tasks on the revised Newman instrument?

7. Is there a significant difference in the responses among West Virginia special education administrators, principals and superintendents to the perceived performance of the special education administrative function entitled Budgeting as defined by the tasks on the revised Newman instrument?

8. Is there a significant difference in the responses among the West Virginia special education administrators, principals, and superintendents in degree of importance assigned to the special education administrative function entitled Planning as defined by the tasks on the revised Newman instrument?

9. Is there a significant difference in the responses among the West Virginia special education administrators, principals, and superintendents in degree of importance assigned to the special education administrative function entitled Organizing as defined by the tasks on the revised Newman instrument?

10. Is there a significant difference in the responses among the West Virginia special education administrators, principals, and superintendents in degree of importance assigned to the special education administrative function entitled Staffing as defined by the tasks on the revised Newman instrument?

11. Is there a significant difference in the responses among the West Virginia special education administrators, principals, and superintendents in degree of importance assigned to the special education administrative function entitled Directing as defined by the tasks on the revised Newman instrument?

12. Is there a significant difference in the responses among the West Virginia special education 
administrators, principals, and superintendents in degree of importance assigned to the special education administrative function entitled Coordinating as defined by the tasks on the revised Newman instrument?

13. Is there a significant difference in the responses among the West Virginia special education administrators, principals, and superintendents in degree of importance assigned to the special education administrative function entitled Reporting as defined by the tasks on the revised Newman instrument?

14. Is there a significant difference in the responses among the West Virginia special education administrators, principals, and superintendents in degree of importance assigned to the special education administrative function entitled Budgeting as defined by the tasks on the revised Newman instrument?

\section{Definition of Terms}

County School Systems - refers to each of the fifty-five local school districts in West Virginia. Principals - refers to a random sample of 150 principals from the fifty-five counties in West Virginia.

Role Expectations - refers to forty specific types of administrative activities organized into Gulick’s (1937) Planning, Organizing, Staffing, Directing, Coordinating, Reporting, and Budgeting (POSDCoRB) Theory by Newman.

Special Education Administrator - refers to each of the fifty-five county special education administrators.

Superintendents - refers to each of the fifty-five West Virginia county superintendents.

\section{Significance of Study}

Attempting to clarify the role of the West Virginia special education administrator may 
reduce role conflict school systems. Hartenian et al (1994) contend that if management communicates role to employees in a way that reduces the gap between expected and perceived roles, employees will experience role clarity. Sullivan (1986) maintains that the most favorable arrangement of the roles of the superintendent, the special education administrator and the principal would be described by distinct roles with few overlapping functions. A study designed to more clearly define the role of the special education administrator could diminish role conflict and ambiguity and ultimately strengthen the school system.

One outcome of the Regular Education Initiative has been a change in the role of the principal relative to special education, resulting in the building principal taking more responsibility and control for special education. School principals must have knowledge of the role of the special education administrator in order to be prepared for a partnership with them. This study will provide information useful to principals as they become special education leaders at the school level.

Role clarification regarding the special education administrator will benefit school superintendents as they establish and communicate job performance expectations to these administrators. Performance evaluation of special education administrators and principals will likely change as schools move toward inclusive educational models. Superintendents must have a clear interpretation of the role of the special education administrator and principals in order to more effectively evaluate the job performance of both.

A more precise description of the role of the special education administrator has a function in higher education. Institutions of higher education are responsible for training principals and special education administrators. Hartley (1991) and Sullivan and Leary (1991) assert that an absence of formal or consistent training for special education administrators may contribute to the ambiguity of the role. Further, in a national study, Valesky and Hirth (1990) report that only $33 \%$ of all regular administrator endorsements are required to have knowledge of special education law and no state requirements for general knowledge of special education exists for $45 \%$ of the regular education endorsements. As demand for knowledge about special 
education increases higher education can utilize information gathered concerning the role of the special education administrator to help develop needed training for principals and special education administrators.

\section{$\underline{\text { Limitations }}$}

1. This study surveyed special education administrators, superintendents, and principals in West Virginia and results may not be generalized to areas outside this representative sample.

2. The findings are limited by the reliability and validity of the revised Newman instrument.

3. The performance and importance of the seven administrative functions are measured only by the respondents' perceptions of the specific tasks assigned to each function by the Newman instrument.

4. The questionnaire format has inherent limitations according to Kerlinger (1986). It is assumed that respondents accurately completed the revised Newman instrument.

\section{Chapter Summary}

The role of the special education administrator is complex and unclear. Perceptions from superintendents and principals regarding this role are conflicting. Role conflict and ambiguity can lead to tension, dissatisfaction, and low performance by employees in organizations. It was the intent of this study to examine expectations held by key administrators within West Virginia's school system relative to the role of the special education administrator. 


\section{CHAPTER II}

\section{REVIEW OF RELATED LITERATURE}

A review of the literature indicated that the role of the special education administrator is unclear. An antecedent to this role ambiguity can be unclear expectations from others in an organization. The more special education administrators learn about expectations held by others in relation to their role in the school system, the more likely conflict can be avoided. The purpose of chapter two is to provide an overview of the literature relative to the field of the special education administrator, how this role relates to the role of the principal and the superintendent in school systems, and role theory. The chapter is divided into four sections: (1) The special education administrator's role, (2) the special education administrator and the principal, (3) the special education administrator and the superintendent and (4) role theory.

\section{The Special Education Administrator}

The special education administrator has been defined as the person whose primary purpose is to perform administrative and managerial duties needed to fully implement a comprehensive special education program (Walker, 1988). Marro and Kohl (1972) stated the following in reference to special education administrators:

If what is known about organizations in general holds true in special education, and there is no real reason to believe it does not, the central position around which organizational concerns revolve is that of the administrator of special education. This person, more than any other, will be involved either directly in decisions that will affect the lives of millions of people, the spending of billions of dollars, and the supervision of thousands of programs for students with disabilities (p.57-58).

Gearheart (1967) identified the special education administrator as "the key person on the special 
education team" (p. 297).

Attempts to isolate and identify the specific roles of the special education administrator have included both national and state-level studies (Ayer \& Barr, 1928; Baker, 1944; Furman, 1988; Johnson \& Burrello, 1987; Newman, 1970; Mackie \& Engel, 1955; Marro \& Kohl, 1972; Rude \& Sasso, 1988; Voelker, 1966; Weatherman \& Hapoz, 1975; Whitworth \& Hatley, 1982). Ayer (1928) reported on the employment of special education administrators, and found that 16 major cities employed 29 supervisors and six directors of special education. In 1944, Baker examined the position of the special education administrator and purported that special education programs were directed, for the most part, by regular education administrators. Baker (1944) went on to define the special education administrative position as one concerned with organization, administration and direction of the operation of school programs for exceptional children. In another early study designed to examine the role of the special education administrator, Mackie and Engel (1955) surveyed 103 directors and 50 supervisors of special education by exploring the functions performed, types of pupils served, and competencies needed. By summarizing their findings, Mackie and Engel (1955) were able to advance 11 tasks of the special education administration: (a) personnel competence; (b) administration and leadership; (c) evaluation and development of programs; (d) teacher recruitment and selection; (e) motivating professional development skills; (f) supervision; (g) budget and finance; (h) research; (i) coordination and community agencies; (j) legislative procedures; (k) public relations.

Voelker (1966) summarized the Mackie and Engel study and identified four major areas in which the special education administrator spends time. The four major utilizers of time for special education administrators according to Voelker (1966) were: (a) administrative duties; (b) supervisory/consultative duties; (c) direct services to children; (d) miscellaneous duties.

The first national study on the role of the special education administrator was conducted by Marro and Kohl in 1972. Using a postcard questionnaire, the researchers surveyed special education administrators who dealt directly with the superintendent or assistant superintendent in 
administering school programs. The findings of the Marro and Kohl (1972) study indicated that three out of four special education administrators were men and over one-half of the respondents were in the 39-49 age bracket. Marro and Kohl (1972) also found that the titles of the special education administrators fell into four groupings: (a) directors of special education, (b) coordinators of special education, (c) superintendents of special education, and (d) directors of pupil personnel services.

Newman (1970) surveyed 100 special education administrators regarding administrative activities. On the basis of responses generated, Newman clustered and ranked administrative tasks into five functional areas: (a) planning function, (b) organizing function, (c) directing function, (d) coordinating function, and (e) tasks needed in administration. Newman's study provided the basis for the development of the instrument described elsewhere in this document. Weatherman and Hapoz (1975) identified competencies of local directors of special education in Minnesota. Special educators identified eight competencies in the Weatherman and Hapoz study: (a) developing procedures and policies, (b) evaluating programs, (c) supervising and evaluating staff, (d) interacting with general education administrators, (e) managing office work, (f) developing public relations, and (g) helping plan and execute budgets.

Other studies have been conducted through the use of interviews. Whitworth and Hatley (1982) attempted to define the role and needed skills of the special education administrator by conducting interviews inquiring about what job functions special education administrators liked in their jobs and which functions they disliked. The largest percentage of administrators enjoyed the creative aspect of their job most of all, and the leading activity on the dislike list was the excessive amount of paperwork (Whitworth \& Hatley, 1982). Furman, (1988) in an effort to discover the characteristics of the role of the special education administrator, interviewed a special education administrator who held a staff position with respect to the organizational structure of the district. Furman reported that the special education administrator engages in two functions: management and supervision. Johnson and Burrello (1987) interviewed special education administrators in Indiana and Massachusetts and compared results from these 
geographic locations on what the administrators agreed were the critical factors in their personal and organizational success. Administrators in both areas rated the same items in the top two rankings:

1. special education must demonstrate it is providing instructionally effective programs and services that promote student growth in three areas: academic, behavioral, and social.

2. special education must be perceived as part of the entire school corporation and participate in the regular education process in such areas as personnel development. (Johnson \& Burrello, 1987, p. 11).

Another study addressed special education administrators in Colorado. Rude and Sasso (1988) examined special education administrators by asking them to rank order the 16 competencies included in the Colorado Department of Education's standards for endorsement as director of special education. The rankings for critical importance by Colorado special education administrators were: (a) management and supervision; (b) legislative and legal issues; (c) leadership and decision-making; (d) communication skills; (e) program evaluation and planning; (f) staff and program development; (g) finance and budgeting; personnel functioning; (h) assessment of curriculum-content and strategies; (i) consultative skills; (j) interagency collaboration; (k) public speaking/large group presentations; (l) preparation of grants and contracts; (m) computer literacy; (n) research skills; (o) collective bargaining expertise (Rude \& Sasso, 1988).

Regarding the role of the special education administrator in relation to the school organization, some studies reported in the literature have concentrated on the perception of the role that could lead to problems of role conflict and ambiguity (Anastasio \& Sage, 1982; Arick \& Krug, 1993; Berry \& Sistrunk, 1989; Bobay, 1973; Duncan \& Hill, 1979; Hartley, 1991; Herbert \& Miller, 1985; Mazor, 1977; Ponder, 1994; Robson, 1981; Spriggs, 1972; Sullivan, 1986; Walker, 1988). Spriggs (1972) analyzed Minnesota special education administrators and reported that responsibilities and accountability assigned to the position often exceed the authority granted 
to perform the position. Spriggs (1972) suggested that additional examination of the perceptions held by other school administrators regarding the role of the special education administrator was needed.

A number of researchers have studied the perceptions held by other school administrators regarding the role of the special education administrator in various states (Anastasio \& Sage, 1982; Berry \& Sistrunk, 1989; Bobay, 1973; Duncan \& Hill, 1979; Hartley, 1991; Robson, 1980; Walker, 1988). Bobay (1973) analyzed perceptions of Florida special education supervisors, general program supervisors and special education directors. Three roles were identified in the Bobay (1973) study as having the potential for confusion among the three groups analyzed. These roles included curriculum planning and development, counseling and guidance, and transportation scheduling for exceptional students (Bobay, 1973).

A study examining the role of the special education administrator as viewed by principals, superintendents and special education administrators was conducted by Mazor (1977) in Massachusetts. Mazor used the Newman instrument of special education administrative tasks to survey principals, superintendents, and special education administrators. Respondents were asked to indicate whether tasks were actually being performed by special education administrators and the degree of importance of each task (Mazor, 1977). Although no single function emerged as a clear source of conflict among the subject groups, post hoc analyses revealed significant differences between principals and special education administrators on six tasks performed by the special education administrator (Mazor, 1977). These six tasks were: (1) establishing special education programs, (2) establishing psychological procedures for identifying handicapped and gifted students, (3) estblishing communication with the entire school staff concerning referral and diagnostic procedures, (4) building and maintaining special education staff morale, (5) integrating special education with the entire school program, and (6) cooperating and communiating with school personnel. The relationship between the principal and the special education administrator was the one with the potential for the most conflict (Mazor, 1977). 
Duncan and Hill (1979) attempted to clarify the role of the special education administrator by comparing school superintendents', special education administrators' and special education teachers' perceptions of the role of the special education administrator in North Dakota. Information generated from the Duncan and Hill study indicate that special education administrators, superintendents and teachers have considerable differences in perceptions of the role of the special education administrator.

A study of the role perceptions of those persons primarily responsible for the delivery of services to meet the needs of handicapped students was conducted in Indiana public schools (Robson, 1980). Role descriptions were solicited from a group of people composed of the director of special education, the elementary school principal, the superintendent, the regular classroom teacher, and the special education teacher (Robson, 1980). Robson (1980) created a survey of 41 specific administrative tasks that respondents were asked to rate on a five point scale the amount of responsibility they expected from the principal or director of special education. Robson's findings indicated that among the respondent group the significant differences occurred between role perceptions and role expectations relative to pupil concerns. Robson reported that overall there was a discrepancy between what people expected of the special education administrator and what the special education administrator thought should be done.

In a study conducted in New York state, Anastasio and Sage (1982) inquired about the role expectations of the special education administrator within groups of superintendents, principals, and administrators of special education. Information collected by Anastasio and Sage was organized into a framework of role dimensions. The role dimension types of special education administrators employed by Anastasio and Sage in their study were (a) advocate, (b) facilitator-trainer, (c) policy planner, (d) moniter-evaluator, and (e) program manager. The role of facilitator-trainer was the dimension most distinctly recognized by all three groups (Anastasio \& Sage, 1982). Anastasio and Sage reported that no great discrepancy emerged within the groups of superintendents, principals, and special education administrators regarding the role of the special education administrator. 
In 1988, Walker made inquiries into the role of the special education administrator's position in Texas public schools. Walker (1988) surveyed a random sample of 114 special education administrators to determine which tasks revealed in the literature as critical were perceived as a high priority by special education administrators. By comparing his results to a national study by Lindeberg (1987), Walker (1988) was able to conclude that of the 12 tasks perceived to be very high priority by the Texas special education administrators, eight of these tasks were also identified by national leaders in the field of special education. Walker (1988) asserted that the consistency between national leaders and Texas special education leaders in agreement of high priority tasks suggested that there were tasks common to those people involved in the administration of special services across the United States.

Berry and Sistrunk (1989) investigated the relationship between self-perceived supervisory behaviors and their actual supervisory behaviors as perceived by special education teachers. The conclusions from the Berry and Sistrunk study were that special education teachers and their supervisors did not vary significantly in their perceptions of supervisors' actual behaviors, but that there was a significant difference between teachers' perceptions of supervisors' behaviors and teachers' preference for supervisory behaviors of supervisors. In a 1991 study by Hartley, the perceived role of the special education administrator was compared by examining principals and special education administrators. Utilizing instruments that ranked the importance of special education administrator tasks, Hartley discovered that principals and special education administrators had distinct differences in the perception of the role of the special education administrator.

One study regarding the perceived role of the special education administrator has been conducted on a national level (Herbert \& Miller, 1985). Herbert and Miller (1985) examined the attitudes of a national group of special education supervisors toward their jobs and tried to discern to what extent the supervisors experienced role conflict. From a series of in-depth interviews, Herbert and Miller (1985) established that there was conflict in the role of the special education supervisor. By more closely examining how the supervisors coped with this conflict, 
Herbert and Miller (1985) identified five supervisory styles of the special education administrator. These five styles were referred to by Herbert and Miller as The Activist, The Good Example,The Politician, The Communication Specialist, and The Counselor. Herbert and Miller further clarified the supervisory styles of special education administrators by reporting that The Communication Specialist experienced the lowest amount of role conflict, while The Politician and The Good Example experienced a moderate amount of role conflict and The Activist and The Counselor experienced high role conflict. According to Herbert and Miller, one reason The Activist and The Counselor had high role conflict is they emphasized the technical assistance of the job, almost to the exclusion of administrative responsibilities.

One method for examining the evolution of the role of key personnel such as the special education administrator is by recounting the development of training programs for these positions (Sullivan, 1986). According to Connor (1963), one of the first courses in special education administration was offered at Teacher's College, Columbia University around 1906-07. Kirk (1957) was one of the first researchers to mention the need to explore a graduate level training and degree program in special education. According to Kirk, basic requirements should consist of a master's degree, teaching certificate in an area of exceptionality, and two years teaching experience. In 1966, the Council for Exceptional Children produced a set of professional standards targeted to improve preparation programs for special education administrators (Lamb \& Burrello, 1979). Conner (1966) examined the national trend for training programs and recommended a minimum program culminating in a Master's degree.

In 1970, Newman discovered that there was a definite effect in the amount of special education training held by the special education administrator and his ability to preform the administrative function of planning and directing in-service training. The same study cited the impact of the lack of special education teaching experience or training upon both the evaluation of exceptional education teachers and special education curriculum development.

Forgone and Collings (1975) conducted a national questionnaire study to determine the status of the state certification-endorsement requirements of special education administrators. 
Data regarding certification were categorized into three areas: no certification, general education certification, and special education administration certificate (Forgone \& Collings, 1975). It was found that for special education administrators: (a) 23 states required no certificationendorsement at all, (b) 18 states required a general education administrative certificate, (c) three states required completion of an approved program and (d) six states required certificationendorsement in special education (Forgone \& Collings, 1975). In a 1985 study, Prillaman and Richardson assessed the extent to which state certification-endorsement requirements for special education administration changed in the ten year period since PL 94-142 became law. The most significant finding was that only four states and the District of Columbia reported requiring neither special education nor general education administration certification-endorsement for special education administrators. This contrasted markedly with the 23 states requiring no state certification in the 1975 Forgone and Collings study.

Stile and Pettibone (1980) conducted a study of the status of training/certification of special education administrators. Their findings indicated that $51 \%$ of the states offered separate certification for special education administrators. Stile, Abernathy, and Pettibone (1986), conducted a five year follow-up study by surveying all 50 states and the District of Columbia's state certification offices. The greatest change occurred in the number of offices reporting a special education requirement for a general education credential (Stile, Abernathy, \& Pettibone, 1986). The researchers suggested that this may have indicated an increased awareness of the need for special education training by general administrators (Stile, Abernathy, \& Pettibone,1986).

Valesky and Hirth (1992) surveyed all state directors of special education to examine state requirements for certification endorsements of school administrators to determine whether they required a knowledge of special education law specifically, and special education in general. This study found that only $33 \%$ of all regular administrator endorsements were required to have a knowledge of special education law and that no state requirement for a general knowledge of special education existed for $45 \%$ of the regular administrator endorsements (Valesky \& Hirth, 1992). 
A descriptive study of special education administrators' policies and practices was conducted in 1993 by Arick and Krug. This study attempted to identify priorities for training (Arick \& Krug, 1993). Of the randomly selected special education directors, 1468 completed surveys were received (Arick \& Krug, 1993). The results of the study were organized into four areas: (a) current and projected administrative personnel needs; (b) preparation quality of special education administrative personnel; (c) training needs of special education administrative personnel; and (d) description and analysis of the administrative policies/practices regarding mainstreaming student with disabilities (Arick \& Krug, 1993). A projected shortage of special education administrative personnel by 1998 was found to affect 789 of the 1,444 school districts responding to this item (Arick \& Krug, 1993). The results of this survey found the majority of special education directors had training and experience in the field, $64 \%$ had certification in teaching special education, $58.3 \%$ had certification in administration of special education, and $65 \%$ had two or more years experience teaching special education (Arick \& Krug, 1993). Additionally, the highest rated general administrative training need was creating strategies for facilitating collaboration and the highest rated special education training need was adaptation of curricula and instruction for students (Arick \& Krug, 1993). The policy/practice with the highest rating was the item titled: Regular classroom staff need to receive training to collaborate with special education in order to adapt instruction (Arick \& Krug, 1993).

The perceived adequacy of training of Mississippi special education directors and special education directors nationwide was investigated by Ponder in 1994. Using the Special Education Directors' Skills Survey, Mississippi and national respondents rated pre-service training they received in skill areas of job responsibility (Ponder, 1994).Using the same scale and skill areas, respondents rated the training perceived to be necessary to be special education directors (Ponder, 1994). The difference between training received and training necessary for each skill area was compared between Mississippi respondents and national respondents. The results indicated significant differences in the skill areas of curriculum development/curriculum evaluation for special education students and educational assessment of special education 
students (Ponder, 1994).

In West Virginia two studies have addressed special education administration. One called attention to training (Thouvenelle, Deloria, \& Blasche, 1984) and the other to the perceived role of the special education administrator (Sullivan, 1986). In 1984 the West Virginia Department of Education commissioned a study to determine the factors that could have been contributed to the dispersion in the percentages of exceptional students served among county school districts in West Virginia (Thouvenelle, Deloria, \& Blasche, 1984). The study identified formal training in education administration and/or teaching of handicapped students as primary facts related to the existence of quality special education programs within individual school districts (Thouvenelle, Deloria, \& Blasche, 1984).

Only one study examining the perceived role of the special education administrator has been conducted in West Virginia. In 1986, Sullivan investigated perceptions of the role of the special education administrator among and within groups of superintendents, principals, and special education administrators. Forty specific tasks of special education administrators were organized under seven administrative functions on a survey instrument developed by Newman (Sullivan, 1986, 1996; Sullivan \& Leary, 1991). Respondents were asked to designate whether the special education administrator actually performed the tasks and the degree of importance of the task (Sullivan, 1986, 1996; Sullivan \& Leary, 1991). Three groups of West Virginia school system administrators were studied: the 55 county superintendents, the 55 identified county special education administrators, and a random sample of 150 public school principals (Sullivan, 1986, 1996; Sullivan \& Leary, 1991).

Significant differences were noted among the subject groups relative to the perceived performance of 21 of the 40 tasks in the instrument (Sullivan, 1986, 1996; Sullivan \& Leary, 1991). The relationship that manifested the greatest source for potential conflict was between special education administrators and principals (Sullivan, 1986, 1996; Sullivan \& Leary, 1991). Significant differences were found between special education administrators and principals on 19 out of 40 tasks (Sullivan, 1986, 1996; Sullivan \& Leary, 1991). According to Sullivan's findings, 
given the number of tasks in which principals and special educaiton administrators differed in responses on the survey, the pairing of the special education administrator and the principal appeared to be the relationship with the potential for the most conflict.

Since the Sullivan study (1986), in West Virginia the role of the special education administrator has continued to change. In a recent personal interview, Mary Nunn, Assistant Director in the West Virginia Office of Special Education, who has worked in the West Virginia Office of Special Education for 23 years, reported that the role of the special education administrator in West Virginia has evolved since the passage of PL 94-142 in 1975. The passage of PL 94-142 evoked an increase in special education programs in West Virginia and subsequently a need for special education administrators (Nunn, 1998). At that time, Nunn (1998) stated "The job was just dumped on someone in the central office." As the special education programs grew, administration of county special education programs became a full time job and the administrators needed an administration and special education background (Nunn, 1998). The focus in special education at that time in West Virginia was on creating programs and access to education for handicapped students (Nunn, 1998).

In the past five to seven years, Nunn (1998) purported that the role of the special education administrator in West Virginia has changed. The role of the special education administrator has expanded at a time when counties are making special education administration positions part-time or employing people with little special education background (Nunn, 1998). In many of the smaller counties in West Virginia, the person who has the responsibilities of special education administration may also be responsible for other programs such as Title One programs or curriculum and supervision for the county (Nunn, 1998).

The reduction of personnel with responsibility for special education programs in West Virginia comes at a time when the special education program has become more complicated (Nunn, 1998). More litigation in the area of special education and the trend on the federal level toward more accountability for quality special education programs were illustrations of how the position of the special education administrator has become more complicated, according to Nunn 
(1998). The other example advanced by Nunn (1998) regarding the growing complexity of the special education administrator's role in West Virginia, is the move towards collaboration with regular education programs. Some West Virginia regular education initiatives which involve special education programs are: (a) the Education First grant program; (b) the School to Work initiative; (c) the requirement that all students, except the most severely disabled, take the Stanford Achievement Test; and (d) the newly adopted instructional goals and objectives that are the curriculum for all students (Nunn, 1998). Nunn (1998) asserted that the role of the West Virginia special education administrator is one that requires an administrator who is well informed on national and state educational reform efforts that effect all students, including special education students.

Studies which have examined the role of the special education administrator have concluded that this professional suffers from the lack of a clear role description. Differences in how others in the school organization perceive the role, as well as the differences in training required for the role, are illustrations of the unclear nature of the role of the special education administrator. In West Virginia, the role of the special education administrator has evolved since the passage of PL 94-142. The role started in 1975 as an extra responsibility for a central office administrator who may have had no background in special education. As the profession grew in importance, the role responsibilities became greater and a background in special education was essential. Today, counties in West Virginia are reducing personnel responsible for special education programs at a time when the role has become more complicated. Clearly, the role of the special education administrator is uncertain and ever changing, as evidenced by the review of the literature and the reported situation in West Virginia. Further efforts to clarify the role of the special education administrator are warranted.

\section{The Special Education Administrator and the Principal}

According to a survey of the Education Commission of the States in 1974, special 
education was perceived by governors to be the number one challenge to states (Davis, Wholeben, \& Ellis, 1979). A more recent study by Hill (1993) was conducted to determine how much time is spent by high school principals on specific tasks. Special education was the third most time consuming category in this study and, in terms of daily frequency, it was the second most time consuming category (Hill, 1993).

Prior to the passage of PL 94-142 most handicapped students received special education services in separate schools or separate classrooms in regular education schools (Hartley, 1991). Much of the research done at that time regarding the school principal and special education was concerned with principals of regular education schools that housed separate special education classrooms (Hartley, 1991). Swain and Underwood (1965) and School (1968) alleged that quality special education programs need the cooperation and support of the principal. In 1973, Schultz conducted research that led him to declare that the special education administrator is the person who must ensure that the principal recognizes and prepares for special education as one component of the school curriculum. In contrast to Schultz, Payne and Murray (1974) were of the opinion that the principal, as individual program leader, should be considered the most important influence in integrating the exceptional student in the regular classroom.

As schools attempted to meet the least restrictive environment continuum of special education services mandated by the 1975 PL 94-142, the role of the principal was revised (Powell \& Hyle, 1997; Valesky \& Hirth, 1992). The principal became more responsible for special education at the building level (Valesky \& Hirth, 1992). The role of the principal regarding special education was altered in a more profound fashion beginning in the mid-1980s with the school reform movement (Valesky \& Hirth, 1992).

The trend toward greater accountability for special education by regular education school administrators was supported by what has become known as the Regular Education Initiative (Valesky \& Hirth, 1992). Madeline Will, former assistant Secretary for Special Education and Rehabilitative Services at the United States Department of Education, in a report entitled Educating Students with Learning Problems: A Shared Responsibility (1986), outlined a 
partnership between regular and special education. One of Will's (1986) proposed strategies was to empower principals to control all special education programs and resources at the building level. According to Will (1986), "The principal must be empowered to create programs that can build individualized education plans based on the needs of children, plans shaped to fit the availability of resources" (p.14). Valesky and Hirth (1992) asserted that if principals are to control all special education programs and resources at the building level, they must possess extensive knowledge of special education.

The 1990 changes to PL 94-142 that became the Individuals with Disabilities Education Act (IDEA), and the 1997 amendments to IDEA, required that students with disabilities be educated in general education classes with peers who are not disabled to the maximum extent appropriate (Buka, 1998; Powell \& Hyle, 1997). The education of special education students in regular education classrooms became known as inclusion (Powell \& Hyle, 1997). This change from segregating students with disabilities to one of integrating them with their peers without handicaps required adjustments in the structure and delivery of both regular and special education programs (Powell \& Hyle, 1997). Powell and Hyle (1996) suggested that the building level administrator was the pivotal role in the process of successful inclusion. In order to achieve successful inclusion, the principal must have a well informed knowledge base of special education and must be supportive of special education activities (Powell \& Hyle, 1997).

A review of the literature regarding special education administration and the school principal indicated that research since the Regular Education Initiative and the move toward inclusion has concentrated on principals' involvement in the inclusion process (Powell \& Hyle, 1997), principals' attitudes regarding inclusion (Downing, Eichinger, \& Williams, 1997; Van Horn, Burrello. \& DeClue, 1992), and training in special education issues (Goor, Schwenn, \& Boyer, 1997; McLaughlin \& Kienas, 1989). Powell and Hyle (1997) utilized multiple case studies to examine what principals in three secondary schools did to facilitate the change to inclusive schools. Data were compared to the seven criteria considered by Scruggs and Mastropieri (1994) to be essential to successful inclusion programs (Powell \& Hyle, 1997). Then 
the data were compared to the six components advanced by Fullen $(1982,1991)$ as necessary for successful school change (Powell \& Hyle, 1997). Analysis of the data indicated that none of the secondary schools examined had a successful inclusion program according to the Scruggs and Mastropieri criteria (Powell \& Hyle, 1997). Additionally, two of the principals studied did not engage in any of Fullen's $(1982,1991)$ six components for successful change. The third principal engaged in all strategies except restructuring (Powell \& Hyle, 1997). Powell and Hyle (1997) concluded that principals did very little to facilitate the change to inclusive schools.

Van Horn et al. (1992) and Downing et al. (1997) both gathered information through the use of the structured interview to assess educators' perceptions toward inclusive education. Van Horn et al. (1992) analyzed perceptions of elementary and high school principals relative to inclusion. Five conclusions emanated from the Van horn et al (1992) study: (a) The beliefs and attitudes of the principals' toward special education are the key factor influencing their behavior toward students with disabilities; (b) The most important role the principal plays in the inclusion of special education students into the school is that of symbolic leader; (c) Principals are reactive rather than proactive in the delivery of special education services; (d) principals rely on the central office special education staff for direct support and consultation rather than direct involvement with building programs; and (e) The contextual factors surrounding the school appear to make a difference in the work of the principal, but they do not appear to have a significant impact on the acceptance of special education students and programs in the school.

Downing et al. (1997) attempted to discern differences in perception of inclusive education by interviewing principals, regular education teachers and special education teachers from three types of educational settings: (a) full inclusion, (b) partial integration, and (c) no inclusion educational experience. Findings from this study revealed that regardless of the professional role or level of implementation of inclusion, similar responses were solicited regarding perceptions of inclusion.

Training principals in special education issues is a subject that has emerged since the regular Education Initiative and the inclusion movement (Goor et al., 1997). Two models for 
comprehensive training of principals to become more effective leaders of special education programs are presented by McLaughlin and Kienas (1989) and Goor et al. (1997). McLaughlin and Kienas (1989) developed a model program called the Administrator's Roundtable that was designed to increase leadership of school principals in special education. The program consisted of monthly sessions where principals discussed relevant topics, professional materials and information was distributed, and site visits to model special education programs were conducted (McLaughlin \& Kienas, 1989). Evaluation of the program based on an questionnaire given before attending the Roundtable meetings and after a year of attending meetings, indicated that the roundtable meetings had a positive impact on principals' awareness and knowledge in the area of special education policies and practices (McLaughlin \& Kienas, 1989).

Goor et al. (1997) described the fundamental components of a comprehensive training program to help principals become more effective in the role of leaders of special education programs at the building level. In contrast to programs that only concentrate on knowledge and skills, the model presented by Goor et al (1997) first addressed beliefs that affect behavior relative to special education. After essential beliefs regarding special education have been established then the training program can address knowledge, skills and reflective behaviors (Goor et al., 1997). Goor et al. (1997) also presented a format for principal preparation programs with examples of learning activities.

One additional issue regarding special education administration and principals, advanced by Elliot and Riddle (1989), is that a consequence of the changing role of administrators' responsibilities between regular and special education could be the elimination of the special education director as a separate administrative position. Many states fund special education based on the amount of time a student receives special education, therefore, if a student spends more time in regular classes, it is possible that state funding for special education could decrease (Elliot \& Riddle, 1989). As school principals assume more responsibility for administering special education programs, one predicted change, asserted by Elliot and Riddle (1989), is the combining of the special education director position with other regular education administrative 
duties at the central office level.

Based on information obtained in a personal interview with Mary Nunn (1998), Assistant Director in the West Virginia Office of Special Education, the position of the special education administrator in some West Virginia counties has recently been combined with other administrative duties at the central office level. While Nunn (1998) did not report the reason for this combining of positions is the inclusion movement or less state funding for special education, it is interesting to note the similarities in the prediction made by Elliot and Riddle in 1989 and the information advanced by Nunn regarding the role of the special education administrator.

It appears evident in the review of the literature regarding the principal and special education, that principals have a major impact on the success of special education programs. The Regular Education Initiative, the inclusion movement, and the 1990 IDEA and 1997 amendments to IDEA legislation have clearly had an impact on the role of the principal relative to special education programs. The specific roles and responsibilities of the special education administrator and the school principal have changed. Because both are key personnel in the delivery of special education programs, perceptions of these roles should be identified and understood if programs for exceptional children are to be effectively provided.

\section{The Special Education Administrator and the Superintendent}

While the role of the special education administrator and the principal are important to special education programs in the school organization, the superintendent is ultimately responsible for these programs (Sullivan, 1986). As the chief administrator of the school district the superintendent must accept responsibility for the successful operation of every aspect of the school system (Mazor, 1977). Early references to the superintendent regarding special education by Grieder and Rosenstengel (1954) advanced that the duty of the superintendent as the executive officer of the school system is to implement the system's special education program. Graham (1956) asserted that the influence of the superintendent is a crucial factor in the role 
definition of the special education administrator.

Bruno (1961) declared that the creation of a position of an administrator of special education should be considered when the special education program expanded to the extent that supervisory responsibilities are comparable to other administrative services in the school system. Bruno's observation was prophetic, given the rapid growth of special education programs that occurred with the passage of PL 94-142 in 1975 that created this very circumstance (Sullivan, 1986).

Equally important to the superintendent understanding the role of the special education administrator is the special education administrator understanding what tasks the superintendent expects him to undertake (Mazor, 1977). A review of the literature relative to the superintendent and the special education administrator disclosed studies that examined the perceived role of the special education administrator (Anastasio \& Sage, 1982; Duncan \& Hill, 1979; Mazor, 1977; Sullivan, 1986). Anastasio and Sage (1982), Mazor (1977), and Sullivan (1986) all report no great discrepancy between the special education administrator and the superintendetns regarding the role of the special education administrator. Contradicting these findings, the Duncan and Hill (1979) study reported considerable differences in perceptions of the role of the special education administrator.

In West Virginia, the role of the special education administrator is defined to a great degree by the influence of the superintendent (Sullivan, 1986). Not only must the special education administrator understand the superintendent's expectations of his role and the tasks he is to perform, the special education administrator must keep the superintendent informed of new trends and mandates impacting special education (Sullivan, 1986). A well defined understanding of the roles of the superintendent and the special education administrator is important to the functioning of the special education program. 


\section{Role Theory}

Given the evident lack of a clear definition of the role of the special education administrator, the potential exists for role conflict. Role conflict is a concept associated with role theory (Clouse, 1989). Role theory is a field of inquiry that has developed in this century (Clouse, 1989). Clouse (1989) asserted that while some concepts of role theory were expounded in the early 1900s, the basic definitive work occurred during the 1950s and 1960s. Role theorists espouse the idea that the behavior of an individual is shaped by the demands and roles of others, by perceived approval of behaviors, and by the individual's own understanding and assumptions of what his behavior should be (Clouse, 1989). The role analyst is concerned with studying these factors in the context of families, informal and work groups, school groups, organizations, communities and societies (Clouse, 1989).

Role has been described as "the most important analytic unit of the institution" (Getzels, Lipman, \& Campbell, 1968, p 59). Getzels and Guba (1957) reported that the following generalizations may be made pertaining to the nature of roles: (a) Roles represent positions, offices, or statuses within the institution (b) Roles are defined in terms of role expectations. (c) Roles are institutional givens, (d) The behaviors associated with a role may be thought of as lying along a continuum from "required" to "prohibited", (e) Roles are complementary; they derive meaning from other related roles in the institution (p. 426-427).

In the late 1950s Getzels and Guba pioneered several studies in pursuit of a theory in education administration (Clouse, 1989). Getzels and Guba attempted to develop a theory of administration as a social process that clearly delineated the role of the individual within the organizational setting (Clouse, 1989). The Getzels-Guba model involves two major classes of phenomena: the institution and the individual (Getzels \& Guba, 1957; Getzels et al, 1968). The institution is defined by certain roles and expectations that will fulfill the goals of the system (Getzels \& Guba, 1957; Getzels et al, 1968). The individual is defined by personalities and needdispositions (Getzels \& Guba, 1957; Getzels et al, 1968). According to Getzels and Guba, the 
institution, role and expectation, which together constitute the nomothetic, or normative dimension of activity in a social system; and the individual, personality, and needs-disposition, which together constitute the idiographic, or personal dimension in a social system, interact to define social behavior. The nomothetic and idiographic dimensions are distinctly identifiable, yet they interact in observed behavior characterizing the total organization (Getzels \& Guba, 1957; Getzels et al, 1968). Further, organizational health is dependent upon the balance between the nomothetic and idiographic dimensions applied to each person in the organization (Getzels \& Guba, 1957; Getzels et al, 1968). The model being described may be represented pictorially as indicated in figure 1.

Figure 1. The Getzels-Guba Model

(NOMOTHETIC DIMENSION)

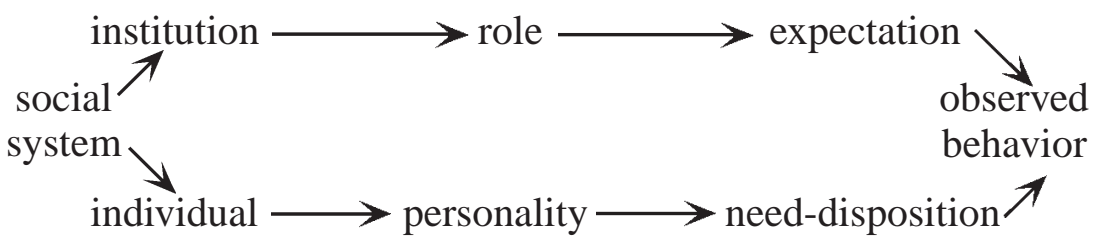

(IDIOGRAPHIC DIMENSION)

The nomothetic axis shown at the top of the diagram consists of institution, role and role expectations (Getzels \& Guba, 1957; Getzels et al, 1968). The social system is defined by its institutions; each institution by its constituent roles; each role by the expectations attached to it (Getzels \& Guba, 1957; Getzels et al, 1968). The idiographic axis shown at the bottom of the diagram consists of individual, personality, and need-disposition (Getzels \& Guba, 1957; Getzels et al, 1968). Social behavior is a result of the interactions between the nomothetic dimensions and the idiographic dimensions (Getzels \& Guba, 1957; Getzels et al, 1968). The social behavior of an individual will result as the individual attempts to cope within an environment composed of patterns of expectations for his behavior in ways consistent with his own independent pattern of 
needs (Getzels \& Guba, 1957; Getzels et al, 1968).

The Getzels-Guba model can be used to predict possible conflict areas in an organization (Clouse, 1989). A role-personality conflict can occur as a function of discrepancies between the pattern of expectation of a given role and the pattern of needs-disposition of an individual (Getzels \& Guba, 1957; Getzels et al, 1968). The individual is faced with the decision to choose whether he will fulfill individual needs or institutional requirements (Getzels \& Guba, 1957; Getzels et al, 1968).A second type of conflict is role conflict (Getzels \& Guba, 1957; Getzels et al, 1968). Role conflicts occur when a role incumbent is required to conform simultaneously to a number of expectations which are considered to be mutually exclusive (Getzels \& Guba, 1957; Getzels et al, 1968). A third conflict area is a conflict between personality and needs disposition (Getzels \& Guba, 1957; Getzels et al, 1968). One effect of such personal disequilibrium is to keep the individual at odds with the institution (Getzels \& Guba, 1957; Getzels et al, 1968). This may mean that the individual cannot maintain a stable relationship with a given role or he habitually misperceives the expectations placed upon him (Getzels \& Guba, 1957; Getzels et al, 1968). A fourth conflict area is role-expectations conflict (Getzels \& Guba, 1957; Getzels et al, 1968). This type of conflict occurs when two sets of expectations for the same role are in opposition (Getzels \& Guba, 1957; Getzels et al, 1968).

Other theorists who point to the importance of role concepts in organizations are Katz and Kahn (1978). In an earlier study, Kahn, Wolfe, Quinn, Snoek, \& Rosenthal (1964) defines a person in an organization as an "array of roles which he plays in the particular set of organizations and groups to which he belongs" (p.8). Katz and Kahn (1978) advanced that each person in an organization exists in relationship to other people, who are referred to as the focal person's role set. All the members of particular positions to which the focal person's position is attached may be thought of as the focal person's role set (Katz \& Kahn, 1978). Katz and Kahn reported four types of role conflict in their framework. Intrasender conflict occurs when incompatible expectations are received from a single role sender (Katz \& Kahn, 1978). Intersender conflict consists of incompatible expectations from two or more role senders (Katz \& 
Kahn, 1978). The third form of role conflict occurs when the focal person's own role expectations are in disagreement with those of one or more role senders (Katz \& Kahn, 1978). Finally, interrole conflict exists when pressures form one role conflict with those from another role (Katz \& Kahn, 1978).

Further, Katz and Kahn (1978) asserted definitions for role conflcit and role ambiguity. Role conflcit is when expectations for an individual are in conflict and role ambiguity is when unclear or vague expectations exist in an organization (Katz \& Kahn, 1978). Katz and Kahn (1978) have asserted that role conflict and ambiguity can be important aspects of organizational stress. Research findings indicate that role conflict and ambiguity can lead to tension, turnover, dissatisfactions, anxiety, and lower performance of employees, unsatisfactory work group performance, and unfavorable attitudes toward role senders (Ho, et al.,1997; Van Sell, Brief, \& Schuler, 1981).

Many organizational studies have been conducted wherein different kinds of occupations have been examined using role analysis and related role concepts (Clouse, 1989). An early study was conducted by Getzels and Guba (1954) which focused on the role conflict experienced by Air Force officers while assuming the multiple positions of officer and instructor. In the field of education administration several studies have examined role (Campbell, Bridges, Corbally, Nystrand, \& Ramsey, 1971; Downey, 1970; Gorton, 1972; Johnson, 1971; McGregor, 1994; Naegley, Evans \& Lynn, 1969).

Naegley, Evans, and Lynn (1969) discussed the role-image of leadership and concluded that the behavior of an administrator is combined with the image of expectancy of his role by those in a group. The findings from the Naegley, Evans, and Lynn (1969) study indicate that unless roles are clearly defined and understood and there is a procedure for feedback concerning the extent to which role expectancies are being met, considerable dissatisfaction may result. Further, unresolved role conflict can bring about lower levels of competence and effectiveness in an individual (Naegley, Evans \& Lynn, 1969).

Gorton (1972), in an interpretation of the Getzels-Guba model, suggested that as long as 
the administrator's need dispositions are compatible with the expectations of others, conflict will be minimal. When need dispositions and expectations clash, role conflict is likely (Gorton, 1972). Additionally, the administrator needs to learn the expectations of individuals or groups whose evaluation of him may impair or enhance his effectiveness (Gorton, 1972).

Other researchers inquiring about role conflict were Campbell, Bridges, Corbally, Nystrand, and Ramsey (1971). Campbell et al., purported that, for the most part, the presence of role conflict is signaled by the existence of incompatible expectations for performance. Incompatible expectations mean that there are simultaneous demands for behaviors which are mutually exclusive, contradicting, or inconsistent (Campbell et al., 1971). Incompatible expectations for an administrator's performance occur in three basic ways: (a) Role conflict that arises between two roles held by the same person, (b) Role conflict that develops when two or more groups have incompatible expectations for the same role, and (c) Role conflict that occurs when contradictory expectations are held by members of the same group for the occupant of the same role (Campbell et al., 1971).

In 1971, Johnson compared the role expectations held by supervisors, teachers, and elementary school principals for the supervisor of classes for the mentally retarded. Johnson (1971) examined both general leadership and curriculum leadership behaviors. Results of the study indicated no significant differences among perceptions of general leadership behaviors, but did display a potential for conflicts in curriculum leadership behaviors (Johnson, 1971). In the Johnson study (1971) building administrators viewed the supervisors of classes for elementary retarded as another administrator, while teachers viewed the supervisor's primary function as that of a resource or consultant person.

Another study relative to special education was also conducted in 1971. Downey (1971) used the leader behavior dimensions, initiating structure and consideration, identified by Halpin (1966), to study behaviors of special education administrators. Downey (1971) advanced that administrators of special education in larger districts appeared to exhibit more initiating structure. Given the foregoing, the magnitude and complexity of the special education 
administration function should be adjusted accordingly if either the initiating structure or consideration is considered to be an important component of the role of the special education administrator.

A more recent study regarding the Getzels-Guba model and education administration, was conducted by McGregor in 1994. McGregor attempted to determine the perceived roles and role expectations of eight Ontario superintendents responsible for curriculum implementation. The study used the Getzels-Guba model to analyze whether the role and role expectation of the superintendents responsible for curriculum implementation were understood more in terms of a manager of a system of curriculum implementation or in terms of an executor of policy of curriculum implementation (McGregor, 1994). Using the case study format for gathering data, McGregor (1994) concluded that the Getzels-Guba model was adaptable for this type of study. The eight superintendents displayed a dichotomous role, with one role being the manager of curriculum implementation and the other role involving executing policy relative to curriculum (McGregor, 1994). Additionally, the political aspect of their role expectations was increasing for these superintendents, conflicts involving personal values were the most difficult for the superintendents and the superintendents prefered their managerial role over their political role (McGregor).

Research in the field of role theory calls attention to several qualities of role conflict and role ambiguity (Hartley, 1991). The factors of role conflict and ambiguity directly relate to problems confronting special education administrators (Hartley, 1991). Given that the special education administrator has a significant role in the overall education system, the need for a clear perception of what is expected of him by various key groups becomes more apparent (Mazor, 1977). Because the position of the administrator of special education is generally designated somewhere between the superintendent and principals in the school organization, the position occupies a role that is affected by behavioral expectations of others (Sullivan, 1986). If the special education administrator experiences role conflict, it may affect not only himself but also the group with whom he is in conflict (Mazor, 1977). Therefore, the more the special education 
administrator learns about expectations held by others regarding his role, the more likely he is to either avoid or minimize conflict situations (Sullivan, 1986).

The significance of the literature reviewed relative to role theory and the role of the special education administrator is that the presence of role conflict may affect the job performance of the special education administrator, the productivity of the staff with whom the perceived role conflict exists, and ultimately services delivered to special education students. In order for quality special education programs to exist, a high level of cooperation and understanding of individual roles should occur between the building administrator, the special education administrator, and the superintendent.

\section{Chapter Summary}

This chapter reviewed the literature relative to the role of the special education administrator. Several studies attempted to isolate and identify the specific tasks and function of the special education administrator (Ayer, 1928; Baker, 1944; Furman, 1988; Johnson \& Burrello, 1987; Newman, 1970; Mackie \& Engel, 1955; Marro \& Kohl, 1972; Rude \& Sasso, 1988; Voelker, 1966; Weatherman \& Hapoz, 1975; Whitworth \& Hatley, 1982). Other studies presented evidence that an unclear view of the role of the special education administrator persists (Anastasio \& Sage, 1982; Arick \& Krug, 1993; Berry \& Sistrunk, 1989; Bobay, 1973; Duncan \& Hill, 1979; Hartley, 1991; Herbert \& Miller, 1985; Mazor, 1977; Ponder, 1994; Robson, 1980; Spriggs, 1972; Sullivan, 1986; Walker, 1988).

In West Virginia the role of the special education administrator has changed (Nunn, 1998). When PL 94142 was first mandated, the position of the special education administrator in West Virginia was an emerging role (Nunn, 1998). As the locus in the field of special education evolved to one of quality, as opposed to access to programs, the position of the special education administrator in West Virginia became a full-time position, occupied by a professional special educator (Nunn, 1998). Today, counties in West Virginia are limiting personnel in the 
administration of special education by sharing the responsibility for this program with other obligations (Nunn, 1998). The special education administrator in West Virginia today must have knowledge of regular education programs and reform efforts in order to collaborate more with regular education (Nunn, 1998).

This chapter also examined literature documenting the importance of the role of the principals and superintendent in the delivery of special education services. The changing role of the principal was clearly denoted in the literature regarding the special education administrator and the school principal (Powell \& Hyle, 1997; Valesky \& Hirth, 1992). As schools move toward more inclusive models, the school principal has become critical to the success of the special education program (Lashley, 1992). But it has been asserted that school principals are lacking in knowledge pertaining to special education (Powell \& Hyle, 1997; Valesky \& Hirth, 1992). As the roles of the special education administrator, the principals and the superintendent evolve, it becomes imperative for a common perception of the role of the special education administrator to exist in order to meet the growing mandates for quality educational services for handicapped students.

The conceptual models proposed by Getzels and Guba (1957) and Katz and Kahn (1968) have been reviewed. These models provide a method for analyzing the factors which influence an administrator's behavior. Campbell et al. (1971) note that the presence of role conflict is frequently signaled by the existence of incompatible behavioral performance expectations held by other key persons. If one is to minimize conflict, it is necessary to identify and understand potential conflicting situations.

The role of the special education administrator is complex and ambiguous. Perceptions regarding this role from superintendent and principals are conflicting. In an organization roles are determined by expectations employees have of each other. Unclear roles can lead to role conflict and role ambiguity. In turn, role conflcit and role ambiguity can lead to reduced job satisfaction. A clear interpretation of the role of the West Virginia special education administrator could diminish role conflict and ambiguity and ultimately strengthen the school system. 


\section{CHAPTER III}

\section{METHODOLOGY}

This study examined the expectations held by key administrative personnel within West Virginia public schools regarding the role of the special education administrator. Existing differences in perception of the administrative functions of the special education administrator in West Virginia county school systems among and within groups of superintendents, principals, and special education administrators were investigated. The methodology and design used to conduct the research are described in this chapter.

\section{Sample and Sampling Procedures}

Representatives from each of the 55 West Virginia county school systems were used as public school subjects in this study. The school personnel chosen to participate in this study included: 1. All 55 county superintendents of schools 2. All 55 persons identified as special education administrators in the Directory of Special Education Administrative Personnel (1997) published by the West Virginia Department of Education and 3. A random sample of 150 West Virginia public school principals.

\section{Instrumentation}

Four previous studies concerning the role of the special education administrator have employed the instrument used in this study (Bobay, 1973; Mazor, 1977; Newman, 1970; Sullivan, 1986). The instrument was developed by Karen S. Newman when she studied tasks actually and ideally performed by special education administrators. Newman organized a total of 40 tasks and assigned them to seven types of administrative activities identified by Urwick's 
(1937) POSDCoRB Theory (Planning, Organizing, Staffing, Directing, Coordinating, Reporting, and Budgeting). The instrument dealt with the tasks actually being performed, the tasks which ideally should be performed and the ranking of tasks within each separate administrative activity (Newman, 1970). Newman (1970) designed and validated her questionnaire by combining the judgment of experts with statistical analysis (Ross, 1941). Textbooks, articles, and research studies in the field of special education administration were reviewed in order to obtain a master list of the tasks performed by the administrator of special education (Newman, 1970). These tasks were reviewed by both her doctoral committee and five additional experts in the field of special education (Newman, 1970). Suggestions and comments from these people were incorporated into the development of the instrument (Newman, 1970). As a check on the readability and validity of the instrument, Newman (1970) had a group of general and special education administrators complete the questionnaire. Newman's format allowed individuals to record their perceptions of the actual performance of the 40 administrative tasks. Additionally, the subjects groups were given the opportunity to rate the importance of these administrative tasks (Newman, 1970).

In a 1973 study conducted by Bobay, a minor change was made to the Newman instrument. Rather than having the subjects rank each task 1-6 as Newman did, Bobay (1973) requested that each respondent rank each task by circling one of the following responses: VI (very important), I (important),U (uncertain), LI (little importance), NI (not important).

Mazor made further updates to the Newman instrument in his 1977 study. Mazor (1977) reported that in personal correspondence with Bobay, it was recommended that the column requesting the respondent to state if a task should ideally be performed be deleted. Bobay found that this column was a duplication of the third column where the respondent was asked to rank each task by circling one of the responses: VI, I, U, LI, NI (Mazor, 1977). In 1986, Sullivan, after personal conversations with Mazor, made no further revisions to the instrument when conducting his study. A sample heading of the original Newman instrument and the subsequent revisions by Bobay and Mazor may be found in Table 1 . 
Table 1

Examples of the Newman Instrument

SAMPLE OF NEWMAN'S INSTRUMENT

\begin{tabular}{c|c|c||c|c|c||c}
\hline \multicolumn{2}{c||}{ A } & \multicolumn{3}{c||}{ B } & C \\
\hline \multicolumn{2}{c||}{ ACTUALY PERFORMED } & \multicolumn{2}{|c||}{ IDEALLY PERFORMED } & RANKING \\
\hline \multirow{2}{*}{ YES } & NO & $\begin{array}{c}\text { DOES NOT } \\
\text { APPLY }\end{array}$ & YES & NO & DOES NOT \\
APPLY & $1-6$ \\
& & & & & & \\
\hline
\end{tabular}

SAMPLE OF BOBAY'S INSTRUMENT

\begin{tabular}{c|c|c||c|c|c||c}
\hline \multicolumn{2}{c||}{ A } & \multicolumn{3}{c||}{ B } & C \\
\hline \multicolumn{2}{c||}{ ACTUALY PERFORMED } & \multicolumn{2}{|c||}{ IDEALLY PERFORMED } & RANKING \\
\hline \multirow{2}{*}{ YES } & NO & $\begin{array}{c}\text { DOES NOT } \\
\text { APPLY }\end{array}$ & YES & NO & $\begin{array}{c}\text { DOES NOT } \\
\text { APPLY }\end{array}$ & VI I U LI NI \\
& & & & & & \\
\hline
\end{tabular}

\section{SAMPLE OF MAZOR'S INSTRUMENT}

\begin{tabular}{c|c|c|c}
\hline \multicolumn{2}{c|}{ A } & B \\
\hline \multicolumn{2}{c}{ ACTUALLY PERFORMED } & DEGREE OF IMPORTANCE \\
\hline YES & NO & $\begin{array}{c}\text { DOES NOT } \\
\text { APPLY }\end{array}$ & VI I U LI NI \\
\hline & & & \\
\hline
\end{tabular}


The current study was a replication of the 1986 Sullivan study. Since 1986 the Regular Education Initiative has led to more inclusive models for educating special education students (Hirth \& Valesky, 1990). More inclusive models have evoked changes in the role of the special education administrator (Lashley, 1992). The framework for the position of the special education administrator has become one that suggests collaboration and cooperation with other administrators, principals, teachers and parents (Lashley, 1992). Given that the role of the special education administrator has necessarily undergone changes as school districts move toward inclusive models, the content of the Newman instrument has been slightly changed for the current study.

An investigation of the literature surrounding the role of the special education administrator yielded two studies conducted since the Regular Education Initiative that specify tasks of the special education administrator (Frohoff, 1998; Lashley, 1992). The Lashley (1992) and Frohoff (1998) analyses of the tasks of the special education administrator were the basis of the current changes to the Newman instrument.

Lashley (1992) compiled a list of position responsibilities for the special education administrator by reviewing position descriptions and performance evaluation documents from several school systems. Lashley (1992) contended that special education should be a support system to the formal organization which retains responsibility for the education of all students. According to Lashley, as authority for special education programs expanded to the school principal it became necessary to include the school principal in evaluation systems which reflect the responsibilities and accountability which arise from the presence of students with disabilities in the school. Included in Lashley's (1992) document of position responsibilities is a section entitled Human Resource Management. It is in this section that Lashley (1992) states that the special education administrator "works with principals to supervise and evaluate school personnel in order to improve instruction" and "participates in recruitment and retention of staff" (p.18). Following Lashley's rationale regarding principals' responsibilities in the special education process, four items in the Staffing function were changed on the Newman instrument. 
In the Staffing function on the Newman instrument, item number one was changed from "recruitment of special education teachers" to "participating in recruitment of special education teachers"; item number three was changed from "selection of special education teachers" to "participating in the selection of special education teachers"; item number four was changed from "assignment of special education teachers" to "participating in assignment of special education teachers"; and item number five was changed from "evaluation of special education teachers" to "working with principals in the evaluation of special education teachers".

In 1998 Frohoff inspected the role of the special education administrator and the school principal in Kentucky public schools. Frohoff (1998) used the Newman instrument as the basis for part of her instrument on administrative functions. Frohoff (1998) utilized many of the items on the Newman instrument by changing the wording on the items to more reflect the terminology that has evolved since the Regular Education Initiative. Conforming to Frohoff's logic in relation to updating terminology, two items were changed on the Newman instrument. In the Coordinating function on the Newman instrument, item number one was changed from "integrating special education with the entire school program" to "developing inclusion model for services"; and in the Reporting function item number one was changed from "completion of state forms" to "preparation of state and federal special education reports".

Changes made to the instrument were reviewed by both the doctoral committee for the current study and four additional experts in the field of special and regular education. Suggestions and comments from these people were incorporated into the development of the instrument.

The revised instrument used in this study included 40 specific tasks assigned to seven administrative functions of special education administration. A copy of the entire instrument may be found in Appendix A. The following identifies the tasks assigned to each function:

\section{STAFFING FUNCTION}

1. Participating in recruitment of special education teachers

2. Assistance in the screening of special education teachers 
3. Participating in selection of special education teachers

4. Participating in assignment of special education teachers

5. Working with principals in evaluation of special education teachers

6. Building and maintaining special education staff morale

7. Securing consultant services for the staff

\section{DIRECTING FUNCTION}

1. Placement of children in special classes

2. Transportation schedules for exceptional children

3. Planning in-service meetings, workshops, etc.

4. Conducting research with exceptional children

5. Directing in-service meetings, workshops, etc.

6. Reevaluation of exceptional children

7. Providing counseling and guidance services for exceptional children

\section{PLANNING FUNCTION}

1. Developing policies (i.e. identification, placement, transfer)

2. Establishing special education programs

3. Surveying the district for handicapped and gifted students

4. Planning and providing facilities

5. Planning and providing special equipment and special instructional materials

6. Curriculum planning and development

\section{ORGANIZING FUNCTION}

1. Establishing channels of communication and responsibility

2. Preparing schedules for special education teachers

3. Placement of special classes within school buildings

4. Establishing psychological procedures for identifying handicapped and gifted students

5. Establishing communication with entire school staff concerning referral and diagnostic procedures 


\section{COORDINATING FUNCTION}

1. Developing inclusion model for services

2. Cooperating and communicating with school personnel

3. Communicating with parents and the public

4. Utilizing services of community agencies

5. Utilizing state department personnel as resources

6. Communication with board of education concerning special education program

\section{REPORTING FUNCTION}

1. Preparation of state and federal special education reports

2. Pupil accounting and records

3. Teacher accounting

4. Disseminating research findings

5. Periodic publications made available to parents and the public

\section{BUDGETING FUNCTION}

1. Preparation of the budget

2. Presentation of budget requests

3. Administering the budget

4. Keeping school personnel informed of budget limits

To supplement the data generated by the questionnaire, a demographic information sheet (Appendix B) was mailed to each subject along with the instrument. This sheet was used to ascertain descriptive data about respondent's training, education, and experience in both special education and administration.

\section{Collection of Data}

Each subject was mailed the revised Newman instrument, a demographic sheet, and an 
explanatory letter (Appendix C) during September of 1998. Principals, superintendents and special education administrators were requested to respond to each task as they perceive it to be actually performed by the special education administrator. Responses were placed in Column A of the instrument. The same individuals were asked to indicate the importance of the task by responding to Column B. Column B choices were:

$$
\begin{aligned}
& \text { VI - Very Important } \\
& \text { I - Important } \\
& \text { U - Uncertain } \\
& \text { LI - Little Importance } \\
& \text { NI - Not Important }
\end{aligned}
$$

A response score of four was assigned to those task identified as being very important; a response score of three was assigned if a task was identified as important; a response score of zero was assigned for those tasks identified uncertain; a response score of two was assigned to those tasks identified as having little importance; and a response score of one was assigned if a task is identified to not be of importance. The use of the Likert Scale as a reliable and useful measure in behavioral research is cited in Kerlinger (1986).

The individuals surveyed were asked to complete the demographic information sheet and the revised Newman instrument and return both in a self-addressed, stamped envelope during September1998. Two weeks after the initial mailing a second mailing with a follow up letter (Appendix D) was sent to secure a response rate of 50\%+1 from each group of superintendents, special education administrators and principals.

\section{$\underline{\text { Statistical Procedures }}$}

An analysis of variance (ANOVA) was used to answer the research questions one through fourteen of the study. An ANOVA is a statistical test of the difference of means for two or more groups (Knoke \& Bohrnstedt, 1994). This analysis is appropriate since the research questions test 
the significance of the differences between means of a number of different samples. Post hoc analyses included the Scheffe test. The Scheffe test was used in this study to differentiate the specific taks that were significant between groups of respondents. Additionally, the mean difference of responses between pairs of administrators was examined to discern the nature or dirrection of the differences found.

\section{Chapter Summary}

The role of the special education administrator as perceived by key personnel in West Virginia public schools was examined in this study. An analysis of existing differences of perceptions among and within groups of superintendents, special education administrators and school principals regarding the role of the special education administrator was pursued. 


\section{CHAPTER IV}

\section{PRESENTATION AND ANALYSIS OF DATA}

This study examined the perceptions of superintendents, principals and special education administrators within West Virginia's county school systems regarding the role of the special education administrator. Existing differences of perceptions among and within groups of superintendents, principals and special education administrators of the role expectations for the special education administrator in West Virginia were investigated. The responses analyzed included both the perceived performance and the perceived importance of specific tasks.

This chapter provides an analysis of the data generated in this study. First a summary of the descriptive data of those surveyed will be presented. Following the descriptive data will be a presentation and analysis of the 14 research questions which define the scope of this study. The presentation and analysis of the data will be organized into the seven administrative functions.

\section{Descriptive Data}

The administrative personnel from West Virginia's county school systems who were chosen to participate in this study were: (1) all 55 county superintendents of schools (2) all 55 county special education administrators and (3) a random sample of 150 West Virginia school principals. The return rate for these groups was $33(60 \%)$ superintendents, $36(65 \%)$ special education administrators, and 84 (56\%) principals. Total response rates for all three groups totaled $153(60 \%)$.

Demographic data collected from these three groups of administrative personnel included the following categories: (1) number of years in current position (2) years of experience as superintendent, assistant superintendent, special education administrator, principal, assistant principal, teacher or other (3) number of graduate courses in school administration and (4) 
number of graduate courses in special education. A fifth and final question included in the demographic data was the question "Is it your opinion the principal is the special education leader at the school level?"

The first demographic item asked for a response regarding the length of time each subject group had been in their current position. School principals had the most experience with an average tenure of 13 years. The average years of experience for superintendents was 7 years. The average years of experience for special education administrators was 8. Additional data regarding length of service in current position is presented in Appendix E.

The second demographic item was an analysis of the respondent's total years of experience as superintendent, assistant superintendent, special education administrator, principal, assistant principal, teacher or other. The range of years of experience and the mean years of experience in each category for superintendents was examined. Analysis of the data confirmed that of the superintendents $24(72 \%)$ had experience as a teacher, $23(69 \%)$ reported experience as a school principal, 15 superintendents (45\%) reported other positions, nine of the superintendents (27\%) reported time spent as assistant principals, and five (15\%) reported having experience as a special education administrator. Additional data regarding length of service in other positions is presented in Appendix E.

The range of years of experience and the mean years of experience in each category for special education administrators was examined. Of the 36 special education administrators who participated in this study, 25 (69\%) reported experience as a teacher, 16 special education administrators (44\%) reported other job experiences, eight of them $(22 \%)$ had experience as a principal, and four special education administrators (11\%) reported experience as an assistant principal.No special education administrators reported experience as a superintendent. Additional data regarding length of service in other positions is presented in Appendix E.

The range of years of experience and the mean years of experience in each category for principals was examined. In the category of experience as teachers, 64 of the principals (76\%) reported time spent in this job, 27 of them (32\%) had experience as an assistant principal, for the 
category of other job experiences, seven principals (8\%) relayed other job titles, and four (4\%) reported experience as a special education administrator. One principal responded that he had been a superintendent for one year. Additional data regarding length of service in other positions is presented in Appendix E.

The third question in the demographic information section of the survey asked the respondents as of June 1998 how many graduate courses in school administration they had taken. Of the superintendents who responded to this survey one reported taking zero administrative courses and 30 reported taking 10 and above administrative courses. Of the special education administrators who responded to this survey 26 reported taking 10 and above administrative courses. Of the principals who responded to this survey four reported taking zero administrative courses and 74 reported taking 10 and above administrative courses. Additional data regarding the amount of administration course work is presented in Appendix E.

The fourth question in the demographic information section of the survey asked the respondents as of June 1998 how many graduate and undergraduate courses in special education they had taken. Of the superintendents who responded to this survey, six reported taking zero special education courses and only four reported taking 10 and above special education courses. Of the special education administrators who responded to this survey four reported taking zero special education courses and 25 reported taking 10 and above special education courses. Of the principals who responded to this survey 24 reported taking zero special education courses and 22 reported taking 1-3 special education courses. Additional data regarding the amount of special education course work is presented in Appendix E.

The final item under demographic data asked the question "Is it your opinion that the school principal is the special education leader at the school level?" In response to this question, five superintendents (15\%) answered "No" and 28 superintendents (85\%) answered "Yes". The special education administrators relayed six (17\%) "No" answers and 30 (83\%) "Yes" answers to the final demographic question. In response to this question, 22 principals (26\%) responded "No" and $62(74 \%)$ respond "Yes". Overall, $33(22 \%)$ of these key West Virginia school administrators 
responded that the principal is not the special education leader at the school level, and $120(78 \%)$ responded that the principal is the special education leader at the school level.

\section{Scoring of the Instrument}

Data for this study were collected by the use of a questionnaire, the revised Newman instrument. The survey instrument was composed of 40 specific administrative task organized under seven administrative categories. Those surveyed were asked to respond to each task as they perceived it to be performed by the special education administrators. Response choices were Yes, No, and Does Not Apply. Respondents were also asked to indicate their perceived importance of the task on a five point Likert scale. The response choices were Very Important, Important, Uncertain, Little Importance and Not Important. A response score was assigned to both the perceived performance and the perceived importance to facilitate frequency distributions and data analyses. On the perceived performance portion of the instrument, a response score of two was assigned to Yes responses, a response score of one was assigned to No responses and a response score of zero was assigned to Does Not Apply. On the perceived importance portion of the survey instrument a response score of four was assigned to Very Important, a response score of three was assigned to Important, a response score of zero was assigned to Uncertain, a response score of two was assigned to Little Importance and a response score of one was assigned to Not Important.

\section{Analysis of Data}

An analysis of variance (ANOVA) was used to answer the research questions 1-14 of this study. An ANOVA is a statistical test of the difference of means for two or more groups (Knoke \& Bohrnstedt, 1994). An alpha level of 0.05 was set as the criterion for determining significance. This analysis was appropriate since the research questions test the significance of the differences 
between a number of different samples. A Scheffe test was performed as a form of a post hoc comparison. The Scheffe test is a post hoc analysis that is used as a comparison of differences in group means (Knoke \& Bohrnstedt, 1994). The Scheffe test was used in this study to differentiate the specific tasks that were significant between groups of respondents. Additionally, the mean difference of responses between pairs of administrators was examined to discern the nature or direction of the differences found. Analysis of these data was facilitated by use of the Statistical Package for the Social Sciences.

The presentation of the data is arranged under each of the seven administrative functions of Planning, Organizing, Staffing, Directing, Coordinating, Reporting and Budgeting. The data will be presented in pairs of research questions with the first question in each pair relating to the actual performance of the administrative function and the second question relating to the degree of importance of that administrative function.

\section{Findings}

\section{Planning Function}

\section{Question 1: Is there a significant difference in the responses among West Virginia special education administrators, principals and superintendents to the perceived performance of the special education administrative function entitled Planning as defined by the tasks on the revised Newman instrument?}

An ANOVA was computed for all possible pairings of the three groups of administrators. Based on the data received from the three groups of respondents there was a significant difference to the responses among West Virginia special education administrators, principals, and superintendents in the perceived performance of the special education administrative function entitled Planning as defined by the tasks on the revised Newman instrument. Table 2 contains the data related to Question 1. 
Table 2

Sum of Squares, Degrees of Freedom, Mean Square, F Value and Levels of

Significance for Question 1.

\begin{tabular}{lrrrrr}
\hline & $\begin{array}{c}\text { Sum of } \\
\text { Squares }\end{array}$ & df & \multicolumn{1}{c}{$\begin{array}{c}\text { Sean } \\
\text { Square }\end{array}$} & F & Sig. \\
\hline Between Groups & 5.100 & 2 & 2.550 & 14.118 & $.000^{*}$ \\
Within Groups & 27.090 & 150 & .181 & & \\
Total & 32.190 & 152 & & & \\
\hline
\end{tabular}

$* \underline{p}<.05$

In regard to specific tasks in question 1, the ANOVA indicated significant differences between groups of administrators on the perceived performance of all tasks in the Planning function. Table 3 contains the data related to the specific tasks on Question 1.

The Scheffe test indicated that responses on the revised Newman instrument in regard to the Planning function were significant (.05 level) between groups of superintendents and principals and groups of special education administrators and principals. The Scheffe yielded no significant (.05 level) differences on the Planning function between groups of special education administrators and superintendents. Utilization of the Scheffe test to differentiate the specific tasks that were significant between groups yielded the following results when applied:

1. Task 1 - Developing Policies (i.e. identification, placement, transfer): The Scheffe was computed for all possible pairings of the three groups of administrators. Responses from groups of superintendents and principals differed significantly (.05 level) on this task and special education administrators and principals differed significantly (.05 level) on this task. Responses from groups of superintendents and special education administrators did not differ significantly (.05 level) on this task.

2. Task 2 - Establishing Special Education Programs: The Scheffe was computed for all possible pairings of the three groups of administrators. Responses from groups of superintendents and principals differed significantly (.05 level) on this task and special education administrators and principals differed significantly (.05 level) on this task. 56 
Table 3

$\underline{\text { Sum of Squares, Degrees of Freedom, Mean Square, F Value and Levels of }}$

Significance for Each Task in the Planning Function as Perceived by

$\underline{\text { Special Education Administrators, Superintendents and Principals }}$

(Performance)

$\begin{array}{lllll}\text { Sum of } & \text { Mean } & & \\ \text { Squares } & \text { df } & \text { Square } & \text { F }\end{array}$

$\begin{array}{llllll}\text { 1. Developing policies } & 5.060 & 2 & 2.530 & 7.859 & .001^{*}\end{array}$ (Ex. identification, transfer)

2. Establishing special

4.510

2

2.255

7.191

$.001 *$ education programs

3. Surveying the district

13.649

2

6.824

18.762

$.000 *$ for handicapped and gifted students

4. Planning and providing facilities

3.268

2

1.634

3.772

$.025 *$

5. Planning and providing

5.159

2

2.580

11.530

$.000 *$ special equipment and special instructional materials

6. Curriculum planning

3.132

2

1.566

5.564

$.005^{*}$ and development

$* \underline{p}<.05$ 
Responses from groups of superintendents and special education administrators did not differ significantly (.05 level) on this task.

3. Task 3 - Surveying the District for Handicapped and Gifted Students: The Scheffe was computed for all possible pairings of the three groups of administrators. Responses from groups of superintendents and principals differed significantly (.05 level) on this task and special education administrators and principals differed significantly (.05 level) on this task. Responses from groups of superintendents and special education administrators did not differ significantly (.05 level) on this task.

4. Task 4 - Planning and Providing Facilities: The Scheffe was computed for all possible pairings of the three groups of administrators. Responses from groups of special education administrators and principals differed significantly (.05 level) on this task but all other pairings yielded no significant differences.

5. Task 5 - Planning and Providing special equipment and special instructional materials. The Scheffe was computed for all possible pairings of the three groups of administrators. Responses from groups of superintendents and principals differed significantly (.05 level) on this task and special education administrators and principals differed significantly (.05 level) on this task. Responses from groups of superintendents and special education administrators did not differ significantly (.05 level) on this task.

6. Task 6 - Curriculum Planning and Development: The Scheffe was computed for all possible pairings of the three groups of administrators. Responses from groups of special education administrators and principals differed significantly (.05 level) on this task but all other pairings yielded no significant (.05 level) differences.

\section{Question 8: Is there a significant difference in the responses among West Virginia special education administrators, principals and superintendents in degree of importance assigned to the special education administrative function entitled Planning as defined by the tasks on the revised Newman instrument?}


An ANOVA was computed for all possible pairings of the three groups of administrators. Based on the data received from the three groups of respondents there was a significant difference in the responses among West Virginia special education administrators, principals, and superintendents in the degree of importance of the special education administrative function entitled Planning as defined by the tasks on the revised Newman instrument. Table 4 contains the data related to Question 8.

Table 4

Sum of Squares, Degrees of Freedom, Mean Square, F Value and Levels of Significance for Question 8.

\begin{tabular}{lrrrrr}
\hline & $\begin{array}{c}\text { Sum of } \\
\text { Squares }\end{array}$ & df & $\begin{array}{c}\text { Mean } \\
\text { Square }\end{array}$ & F & Sig. \\
\hline Between Groups & 15.959 & 2 & 7.980 & 7.967 & $.001^{*}$ \\
Within Groups & 150.246 & 150 & 1.002 & & \\
Total & 166.205 & 152 & & & \\
\hline
\end{tabular}

$* \mathrm{p}<.05$

In regard to specific tasks in question 8 , the ANOVA indicated significant (.05 level) differences between groups of administrators in the following specific tasks: developing policies, establishing special education programs,surveying the district for handicapped and gifted students, and planning and providing equipment and special instructional materials. The ANOVA indicated that the following tasks did not have significant (.05 level) differences between groups of administrators: planning and providing facilities and curriculum planning and development. Table 5 contains the data related to the specific tasks on Question 8.

The Scheffe test indicated that responses on the revised Newman instrument in regard to the degree of importance of the Planning function were significant (.05 level) between groups of superintendents and principals and groups of special education administrators and principals. The Scheffe yielded no significant (.05 level) differences on the degree of importance of the Planning function between groups of special education administrators and superintendents. Utilization of 
Table 5

Sum of Squares, Degrees of Freedom, Mean Square, F Value and Levels of

Significance for Each Task in the Planning Function as Perceived by

$\underline{\text { Special Education Administrators, Superintendents and Principals }}$

$\underline{\text { (Degree of Importance) }}$

$\begin{array}{ccccc}\begin{array}{c}\text { Sum of } \\ \text { Squares }\end{array} & \text { df } & \begin{array}{c}\text { Mean } \\ \text { Square }\end{array} & \text { F } & \text { Sig. } \\ 38.056 & 2 & 19.028 & 12.841 & .000^{*}\end{array}$

(Ex. identification, transfer)

2. Establishing specia education programs

35.65

2

17.829

11.272

$.000 *$

3. Surveying the district

16.837

2

8.418

3.938

$.022 *$ for handicapped and gifted students

4. Planning and providing

10.373

2

5.186

2.216

.113

facilities

5. Planning and providing

16.631

2

8.315

6.937

$.001 *$ special equipment and special instructional materials

6. Curriculum planning

6.371

2

3.186

2.399

.094 and development

$* \underline{p}<.05$ 
the Scheffe test to differentiate the specific tasks that were significant between groups yielded the following results when applied:

1. Task 1 - Developing Policies (i.e. identification, placement, transfer): The Scheffe was computed for all possible pairings of the three groups of administrators. Responses from groups of superintendents and principals differed significantly (.05 level) on this task and special education administrators and principals differed significantly (.05 level) on this task. Responses from groups of superintendents and special education administrators did not differ significantly (.05 level) on this task.

2. Task 2 - Establishing Special Education Programs: The Scheffe was computed for all possible pairings of the three groups of administrators. Responses from groups of superintendents and principals differed significantly (.05 level) on this task and special education administrators and principals differed significantly (.05 level) on this task. Responses from groups of superintendents and special education administrators did not differ significantly (.05 level) on this task.

3. Task 3 - Surveying the District for Handicapped and Gifted Students: The Scheffe was computed for all possible pairings of the three groups of administrators. Responses from the three groups of administrators yielded no significant (.05 level) differences between groups of administrators.

4. Task 4 - Planning and Providing Facilities: The Scheffe was computed for all possible pairings of the three groups of administrators. Responses from the three groups of administrators yielded no significant (.05 level) differences between groups of administrators.

5. Task 5 - Planning and Providing special equipment and special instructional materials. The Scheffe was computed for all possible pairings of the three groups of administrators. Responses from groups of superintendents and principals differed significantly (.05 level) on this task and special education administrators and principals differed significantly (.05 level) on this task. Responses from groups of superintendents and special education 
administrators did not differ significantly (.05 level) on this task.

6. Task 6 - Curriculum Planning and Development: The Scheffe was computed for all possible pairings of the three groups of administrators. Responses from the three groups of administrators yielded no significant (.05 level) differences between groups of administrators.

\section{Nature of the difference.}

The mean difference between pairings of administrators was examined. Relative to the pairing of the superintendent and the principal, the superintendents responded "yes", it was actually performed, and the principal responded "no", it was not performed, on the following tasks: developing policies, establishing special education programs, surveying the district for handicapped and gifted students and planning and providing special equipment and special instructional materials. Regarding the degree of importance, the superintendents responded "yes", it was important, and the principal responded "no", it was not important, on the following tasks: developing policies, establishing special education programs, and providing special equipment and special instructional materials. Table 6 contains data related to the mean differences between superintendents and principals. 
Table 6

Mean Differences Between Superintendents and Principals

in the Planning Function

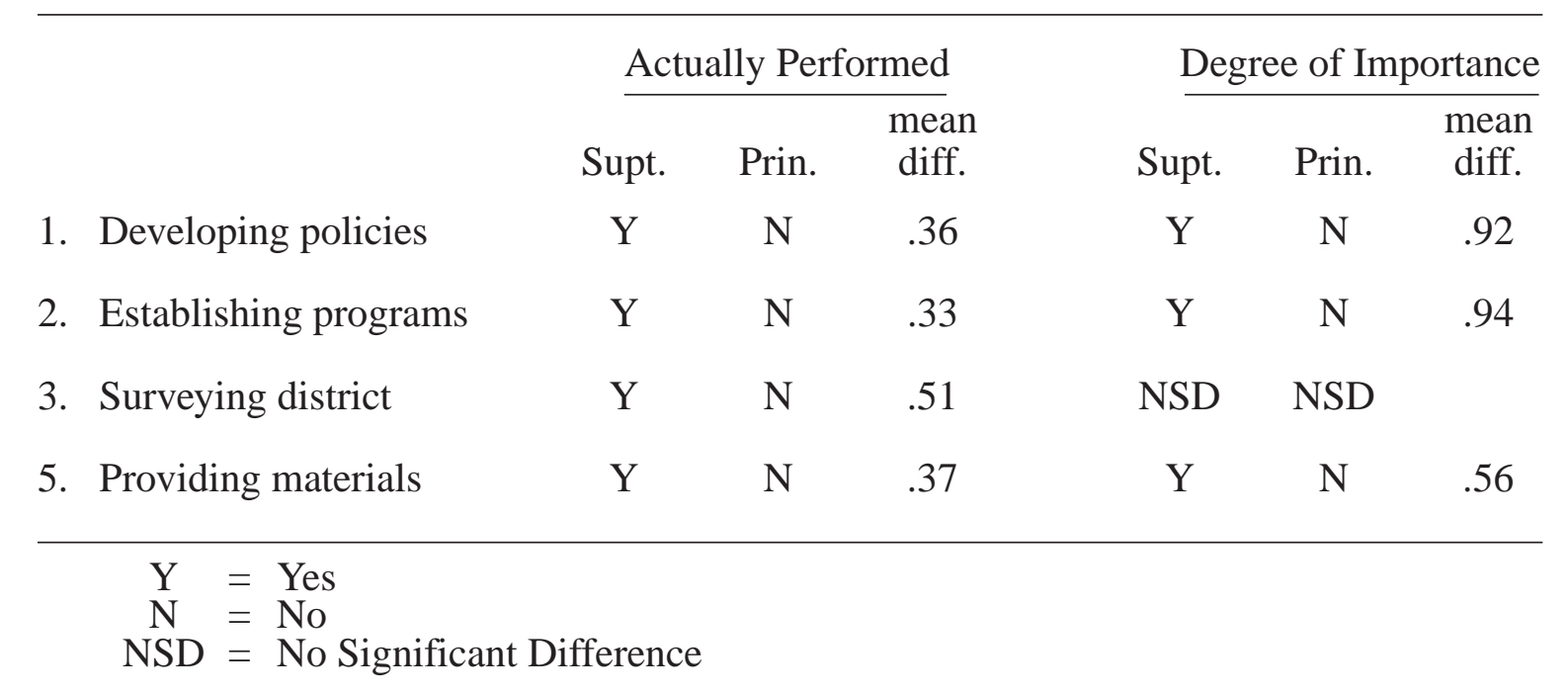

Relative to the pairing of the special education administrator and the principal, the special education administrator responded "yes", it was actually performed, and the principal responded "no", it was not performed, on the following tasks: developing policies, establishing special education programs, surveying the district for handicapped and gifted students and planning, planning and providing facilities, providing special equipment and special instructional materials and curriculum planning and development. Regarding the degree of importance, the special education administrators responded "yes", it was important, and the principal responded "no", it was not important, on the following tasks: developing policies, establishing special education programs, and providing special equipment and special instructional materials. Table 7 contains data related to the mean differences between special education administrators and principals. 
Table 7

Mean Difference Between Special Education Administrators and Principals in the Planning Function

Actually Performed
Sp. Ed.
Ad. $\quad$ Prin. $\quad$ diff.

Degree of Importance Sp. Ed. mean Ad. Prin. diff.

1. Developing policies $\begin{array}{lll}\mathrm{Y} & \mathrm{N} & .37\end{array}$ $\begin{array}{lll}\mathrm{Y} & \mathrm{N} & 1.07\end{array}$

2. Establishing programs

$\begin{array}{lll}\mathrm{Y} & \mathrm{N} & .36\end{array}$

3. Surveying district Y N .67 $\begin{array}{lll}\mathrm{Y} & \mathrm{N} & 1.00\end{array}$

4. Providing facilities $\begin{array}{lll}\mathrm{Y} & \mathrm{N} & .36\end{array}$ NSD NSD

5. Providing materials Y N .37

6. Curriculum planning

Y N

.31

Y N

$\begin{aligned} \mathrm{Y} & =\text { Yes } \\ \mathrm{N} & =\text { No } \\ \mathrm{NSD} & =\text { No Significant Difference }\end{aligned}$

There were no significant differences between the pairing of the superintendent and the special education administrator in the Planning function.

\section{Organizing Function}

Question 2: Is there a significant difference in the responses among West Virginia special education administrators, principals, and superintendents to the perceived performance of the special education administrative function entitled Organizing as defined by tasks on the revised Newman instrument?

An ANOVA was computed for all possible pairings of the three groups of administrators. Based on the data received from the three groups of respondents there was a significant difference in responses among West Virginia special education administrators, principals, and superintendents to the perceived performance of the special education administrative function 
entitled Organizing as defined by tasks on the revised Newman instrument. Table 8 contains the data related to Question 2.

Table 8

$\underline{\text { Sum of Squares, Degrees of Freedom, Mean Square, F Value and Levels of }}$

Significance for Question 2.

\begin{tabular}{lrrrrr}
\hline & $\begin{array}{c}\text { Sum of } \\
\text { Squares }\end{array}$ & df & $\begin{array}{c}\text { Mean } \\
\text { Square }\end{array}$ & F & Sig. \\
\hline Between Groups & .545 & 2 & .273 & 3.695 & $.027^{*}$ \\
Within Groups & 11.073 & 150 & $7.382 \mathrm{E}-02$ & & \\
Total & 11.619 & 152 & & & \\
\hline
\end{tabular}

$* \underline{p}<.05$

In regard to specific tasks in question 2, the ANOVA indicated significant (.05 level) differences between groups of administrators in the following specific task: establishing communication with entire school staff concerning referral and diagnostic procedures. The ANOVA indicated that the following tasks did not have significant (.05 level) differences between groups of administrators: establishing channels of communication and responsibility, preparing schedules for special education teachers, placement of special classes within school buildings, and establishing psychological procedures for identifying handicapped and gifted students. Table 9 contains the data related to the specific tasks on Question 2.

The Scheffe test indicated that responses on the revised Newman instrument in regard to the Organizing function were significant (.05 level) between groups of superintendents and principals.The Scheffe yielded no significant (.05 level) differences on the Organizing function between groups of special education administrators and principals and groups of special education administrators and superintendents. Utilization of the Scheffe test to differentiate the specific tasks that were significant between groups yielded the following results when applied: 1. Task 1 - Establishing Channels of Communication and Responsibility: The Scheffe was computed for all possible pairings of the three groups of administrators. This test yielded 
Table 9

Sum of Squares, Degrees of Freedom, Mean Square, F Value and Levels of

Significance for Each Task in the Organizing Function as Perceived by

$\underline{\text { Special Education Administrators, Superintendents and Principals }}$

(Performance)

$\begin{array}{ccccc}\begin{array}{c}\text { Sum of } \\ \text { Squares }\end{array} & \text { df } & \begin{array}{c}\text { Mean } \\ \text { Square }\end{array} & \text { F } & \text { Sig. } \\ .551 & 2 & .276 & 2.286 & .105\end{array}$

of communication and

.763

2

.381

$1.509 \quad .225$

special education teachers

3. Placement of special

2

.266

.848

.430

classes within school

buildings

4. Establishing psychological

2.268

2

1.134

2.922

.057

procedures for identifying

handicapped and gifted

students

5. Establishing communication 1.565

2

.782

3.217

$.043 *$

with entire school staff

concerning referral and

diagnostic procedures

$* \underline{p}<.05$ 
no significant (.05 level) differences between groups of administrators.

2. Task 2 - Preparing Schedules for Special education Teachers: The Scheffe was computed for all possible pairings of the three groups of administrators. This test yielded no significant (.05 level) differences between groups of administrators.

3. Task 3 - Placement of Special Classes within School Buildings: The Scheffe was computed for all possible pairings of the three groups of administrators. This test yielded no significant (.05 level) differences between groups of administrators.

4. Task 4 - Establishing Psychological Procedures for Identifying Handicapped and Gifted Students: The Scheffe was computed for all possible pairings of the three groups of administrators. Superintendents and principals differed significantly (.05 level) on this task but all other pairings yielded no significant differences.

5. Task 5 - Establishing Communication with Entire School Staff Concerning Referral and Diagnostic Procedures: The Scheffe was computed for all possible pairings of the three groups of administrators. This test yielded no significant (.05 level) differences between groups of administrators.

\section{Question 9: Is there a significant difference in the responses among West Virginia special education administrators, principals, and superintendents in degree of importance assigned to the special education administrative function entitled Organizing as defined by tasks on the revised Newman instrument?}

An ANOVA was computed for all possible pairings of the three groups of administrators. Based on the data received from the three groups of respondents there was a not a significant difference in responses among West Virginia special education administrators, principals, and superintendents to the perceived degree of importance of the special education administrative function entitled Organizing as defined by tasks on the revised Newman instrument. Table 10 contains the data related to Question 9. 
Table 10

Sum of Squares, Degrees of Freedom, Mean Square, F Value and Levels of

Significance for Question 9.

\begin{tabular}{lrrrrr}
\hline & $\begin{array}{c}\text { Sum of } \\
\text { Squares }\end{array}$ & df & $\begin{array}{c}\text { Mean } \\
\text { Square }\end{array}$ & F & Sig. \\
\hline Between Groups & .401 & 2 & .201 & .281 & .755 \\
Within Groups & 106.996 & 150 & .713 & & \\
Total & 107.398 & 152 & & \\
\hline
\end{tabular}

$* \underline{p}<.05$

In regard to specific tasks in question 9, the ANOVA indicated significant (.05 level) differences between groups of administrators in the following specific task: establishing psychological procedures for identifying handicapped and gifted students. The ANOVA indicated that the following tasks did not have significant (.05 level) differences between groups of administrators: establishing channels of communication and responsibility, preparing schedules for special education teachers, placement of special classes within school buildings, and establishing communication with entire school staff concerning referral and diagnostic procedures. Table 11 contains the data related to the specific tasks on Question 9.

The Scheffe yielded no significant (.05 level) differences on the Organizing function between groups of special education administrators and principals, groups of special education administrators and superintendents, and groups of superintendents and principals. Utilization of the Scheffe test to differentiate the specific tasks that were significant between groups yielded the following results when applied:

1. Task 1 - Establishing Channels of Communication and Responsibility: The Scheffe was computed for all possible pairings of the three groups of administrators. Responses from the three groups of administrators yielded no significant (.05 level) differences between 
Table 11

Sum of Squares, Degrees of Freedom, Mean Square, F Value and Levels of

Significance for Each Task in the Organizing Function as Perceived by

Special Education Administrators, Superintendents and Principals

(Degree of Importance)

\begin{tabular}{|c|c|c|c|c|c|}
\hline & $\begin{array}{l}\text { Sum of } \\
\text { Squares }\end{array}$ & $\mathrm{df}$ & $\begin{array}{l}\text { Mean } \\
\text { Square }\end{array}$ & $\mathrm{F}$ & Sig. \\
\hline $\begin{array}{l}\text { 1. Establishing channels } \\
\text { of communication and } \\
\text { responsibility }\end{array}$ & .467 & 2 & .233 & .289 & .750 \\
\hline $\begin{array}{l}\text { 2. Preparing schedules for } \\
\text { special education teachers }\end{array}$ & 4.137 & 2 & 2.069 & .931 & .397 \\
\hline $\begin{array}{l}\text { 3. Placement of special } \\
\text { classes within school } \\
\text { buildings }\end{array}$ & 3.001 & 2 & 1.501 & .727 & .485 \\
\hline $\begin{array}{l}\text { 4. Establishing psychological } \\
\text { procedures for identifying } \\
\text { handicapped and gifted } \\
\text { students }\end{array}$ & 16.016 & 2 & 8.008 & 4.020 & $.020^{*}$ \\
\hline $\begin{array}{l}\text { 5. Establishing communication } \\
\text { with entire school staff } \\
\text { concerning referral and } \\
\text { diagnostic procedures }\end{array}$ & .263 & 2 & .132 & .117 & .890 \\
\hline
\end{tabular}

$* \mathrm{p}<.05$ 
groups of administrators.

2. Task 2 - Preparing Schedules for Special education Teachers: The Scheffe was computed for all possible pairings of the three groups of administrators. Responses from the three groups of administrators yielded no significant (.05 level) differences between groups of administrators.

3. Task 3 - Placement of Special Classes within School Buildings: The Scheffe was computed for all possible pairings of the three groups of administrators. Responses from the three groups of administrators yielded no significant (.05 level) differences between groups of administrators.

4. Task 4 - Establishing Psychological Procedures for Identifying Handicapped and Gifted Students: The Scheffe was computed for all possible pairings of the three groups of administrators. Superintendents and special education administrators differed significantly (.05 level) on this task but all other pairings yielded no significant differences.

5. Task 5 - Establishing Communication with Entire School Staff Concerning Referral and Diagnostic Procedures: The Scheffe was computed for all possible pairings of the three groups of administrators. Responses from the three groups of administrators yielded no significant (.05 level) differences between groups of administrators.

\section{Nature of the difference.}

The mean difference between pairings of administrators was examined. Relative to the pairing of the superintendent and the principal, the superintendents responded "yes", it was actually performed, and the principal responded "no", it was not performed, on the following task: establishing psychological procedures for identifying handicapped and gifted students. Regarding the degree of importance there were no significant differences between superintends and principals in regard to the Organizing function. Table 12 contains data related to the mean 
differences between superintendents and principals.

Table 12

$\underline{\text { Mean Differences Between Superintendents and Principals }}$

in the Organizing Function

\begin{tabular}{|c|c|c|c|c|c|c|}
\hline \multirow{3}{*}{$\begin{array}{l}\text { Establishing psychological } \\
\text { procedures }\end{array}$} & \multicolumn{3}{|c|}{ Actually Performed } & \multicolumn{3}{|c|}{ Degree of Importance } \\
\hline & Supt. & Prin. & $\begin{array}{c}\text { mean } \\
\text { diff. }\end{array}$ & Supt. & Prin. & $\begin{array}{l}\text { mean } \\
\text { diff. }\end{array}$ \\
\hline & Y & $\mathrm{N}$ & .31 & NSD & NSD & \\
\hline
\end{tabular}

$$
\begin{aligned}
\mathrm{Y} & =\text { Yes } \\
\mathrm{N} & =\text { No } \\
\mathrm{NSD} & =\text { No Significant Difference }
\end{aligned}
$$

Regarding the pairing of the superintendent and the special education administrator relative to actual performance of tasks, there were no significant differences between these two groups of administrators. Regarding the degree of importance, the superintendents responded "yes", it was important, and the special education administrators responded "no", it was not important, on the following task: establishing psychological procedures for identifying handicapped and gifted students. Table 13 contains data related to the mean differences between special education administrators and principals.

\section{Table 13}

Mean Differences Between Superintendents and Special Education Administrators in the Organizing Function

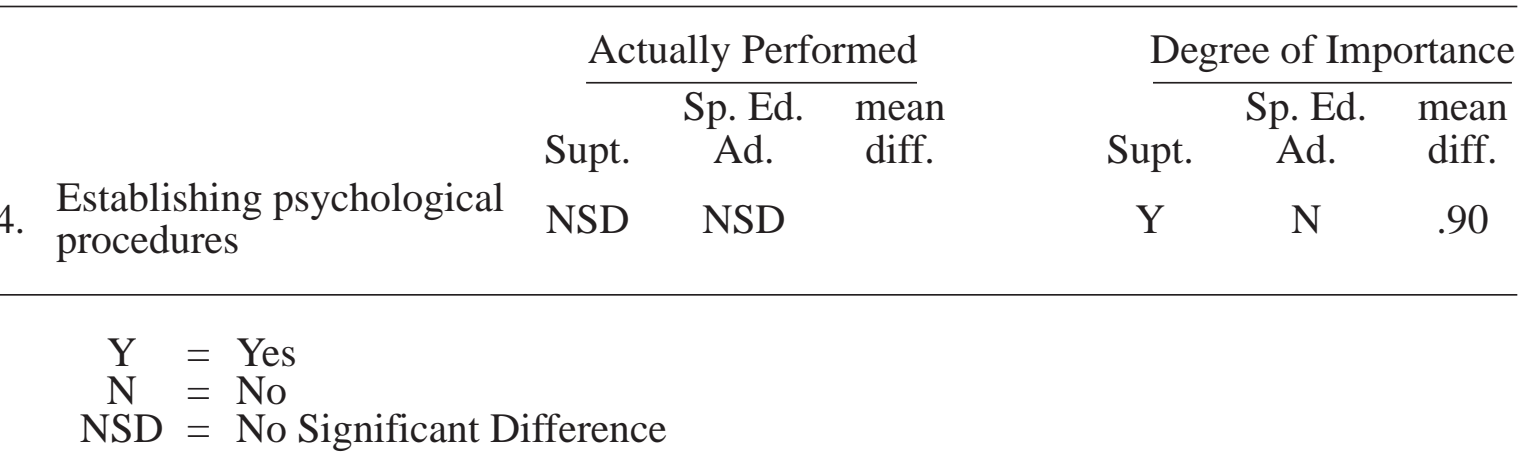


There were no significant differences between the pairing of the special education administrator and the principal in the Organizing function.

\section{Staffing Function}

Question 3: Is there a significant difference in the responses among West Virginia special education administrators, principals, and superintendents to the perceived performance of the special education administrative function entitled Staffing as defined by tasks on the revised Newman instrument?

An ANOVA was computed for all possible pairings of the three groups of administrators. Based on the data received from the three groups of respondents there was a significant difference in responses among West Virginia special education administrators, principals, and superintendents to the perceived performance of the special education administrative function entitled Staffing as defined by tasks on the revised Newman instrument. Table 14 contains the data related to Question 3.

Table 14

Sum of Squares, Degrees of Freedom, Mean Square, F Value and Levels of Significance for Question 3.

\begin{tabular}{lrrrrr}
\hline & $\begin{array}{c}\text { Sum of } \\
\text { Squares }\end{array}$ & \multicolumn{1}{c}{ df } & $\begin{array}{c}\text { Mean } \\
\text { Square }\end{array}$ & F & Sig. \\
\hline Between Groups & 2.793 & 2 & 1.397 & 14.420 & $.000^{*}$ \\
Within Groups & 14.528 & 150 & $9.685 \mathrm{E}-02$ & & \\
Total & 17.321 & 152 & & & \\
\hline
\end{tabular}

$* \underline{p}<.05$ 
In regard to specific tasks in question 3, the ANOVA indicated significant differences between groups of administrators on the perceived performance of all tasks in the Staffing function. Table 15 contains the data related to the specific tasks on Question 3.

The Scheffe test indicated that responses on the revised Newman instrument in regard to the Staffing function were significant (.05 level) between groups of superintendents and principals and groups of special education administrators and principals. The Scheffe yielded no significant (.05 level) differences on the Staffing function between groups of special education administrators and superintendents. Utilization of the Scheffe test to differentiate the specific tasks that were significant between groups yielded the following results when applied:

1. Task 1 - Participating in Recruitment of Special Education Teachers: The Scheffe was computed for all possible pairings of the three groups of administrators. Responses from groups of superintendents and principals differed significantly (.05 level) on this task and special education administrators and principals differed significantly (.05 level) on this task. Responses from groups of superintendents and special education administrators did not differ significantly (.05 level) on this task.

2. Task 2 - Assistance in the Screening of Special Education Teachers: The Scheffe was computed for all possible pairings of the three groups of administrators. Responses from groups of superintendents and principals differed significantly (.05 level) on this task and special education administrators and principals differed significantly (.05 level) on this task. Responses from groups of superintendents and special education administrators did not differ significantly (.05 level) on this task.

3. Task 3 - Participating in the Selection of Special Education Teachers: The Scheffe was computed for all possible pairings of the three groups of administrators. Responses from groups of superintendents and principals differed significantly (.05 level) on this task and special education administrators and principals differed significantly (.05 level) on this task. Responses from groups of superintendents and special education administrators did not differ significantly (.05 level) on this task. 
Table 15

Sum of Squares, Degrees of Freedom, Mean Square, F Value and Levels of

Significance for Each Task in the Staffing Function as Perceived by

$\underline{\text { Special Education Administrators, Superintendents and Principals }}$

(Performance)

Sum of

Mean

Squares

df Square

F Sig.

1. Participating in recruitment 3.522

2

1.761

$5.849 \quad .004 *$

of special education teachers

2. Assistance in the screening 2.886

of special education teachers

1.443

$4.983 \quad .008 *$

3. Participating in selection of 3.492 special education teachers

2

1.746

$7.587 \quad .001 *$

4. Participating in assignment 2.465

2

1.233

4.732

$.010^{*}$

of special education teachers

5. Working with principals

4.047

2

2.023

6.314

$.002 *$

in evaluation of special

education teachers

6. Building and maintaining $\quad 1.571$

2

.785

4.127

$.018 *$ special education staff morale

7. Securing consultant

3.085

2

1.542

6.761

$.002 *$ services for the staff

$* \mathrm{p}<.05$ 
4. Task 4 - Participating in Assignment of Special Education Teachers: The Scheffe was computed for all possible pairings of the three groups of administrators. Responses from groups superintendents and principals differed significantly (.05 level) on this task but all other pairings yielded no significant differences.

5. Task 5 - Working with Principals in Evaluation of Special Education Teachers: The Scheffe was computed for all possible pairings of the three groups of administrators. Responses from groups special education administrators and principals differed significantly (.05 level) on this task but all other pairings yielded no significant differences.

6. Task 6 - Building and Maintaining Special Education Staff Morale: The Scheffe was computed for all possible pairings of the three groups of administrators. Responses from groups special education administrators and principals differed significantly (.05 level) on this task but all other pairings yielded no significant differences.

7. Task 7 - Securing consultant Services for the Staff: The Scheffe was computed for all possible pairings of the three groups of administrators. Responses from groups superintendents and principals differed significantly (.05 level) on this task but all other pairings yielded no significant differences.

\section{Question 10: Is there a significant difference in the responses among West Virginia special education administrators, principals, and superintendents in degree of importance assigned to the special education administrative function entitled Staffing as defined by tasks on the revised Newman instrument?}

An ANOVA was computed for all possible pairings of the three groups of administrators. Based on the data received from the three groups of respondents there was not a significant difference in responses among West Virginia special education administrators, principals, and superintendents to the perceived degree of importance of the special education administrative function entitled Staffing as defined by tasks on the revised Newman instrument. Table 16 
contains the data related to Question 10.

Table 16

Sum of Squares, Degrees of Freedom, Mean Square, F Value and Levels of

Significance for Question 10.

\begin{tabular}{lrrrrr}
\hline & $\begin{array}{c}\text { Sum of } \\
\text { Squares }\end{array}$ & df & $\begin{array}{c}\text { Mean } \\
\text { Square }\end{array}$ & F & Sig. \\
\hline Between Groups & 2.634 & 2 & 1.317 & 2.566 & .080 \\
Within Groups & 76.988 & 150 & .513 & & \\
Total & 79.632 & 152 & & & \\
\hline
\end{tabular}

$* \mathrm{p}<.05$

In regard to specific tasks in question 10, the ANOVA indicated significant (.05 level) differences between groups of administrators in the following specific task: securing consultant services for the staff. The ANOVA indicated that the following tasks did not have significant (.05 level) differences between groups of administrators: participating in recruitment of special education teachers, assistance in the screening of special education teachers, participating in selection of special education teachers, working with principals in evaluation of special education teachers, building and maintaining special education staff morale. Table 17 contains the data related to the specific tasks on Question 10.

The Scheffe yielded no significant (.05 level) differences on the Staffing function between groups of special education administrators and superintendents, special education administrators and principals, and superintendents and principals. Utilization of the Scheffe test to differentiate the specific tasks that were significant between groups yielded the following results when applied:

1. Task 1 - Participating in Recruitment of Special Education Teachers: The Scheffe was computed for all possible pairings of the three groups of administrators. Responses from the three groups of administrators yielded no significant (.05 level) differences between groups of administrators. 
Table 17

$\underline{\text { Sum of Squares, Degrees of Freedom, Mean Square, F Value and Levels of }}$

Significance for Each Task in the Staffing Function as Perceived by

$\underline{\text { Special Education Administrators, Superintendents and Principals }}$

$\underline{\text { (Degree of Importance) }}$

Sum of

Mean

Squares

df Square

F Sig.

1. Participating in recruitment 4.840

$2 \quad 2.420$

1.931

.149

of special education teachers

2. Assistance in the screening

1.453

2

.727

.552

.577

of special education teachers

3. Participating in selection of 5.438

2

2.719

2.643

.074 special education teachers

4. Participating in assignment $\quad 6.687$

2

3.344

2.359

.098

of special education teachers

5. Working with principals

.908

2

.454

.221

.802

in evaluation of special

education teachers

6. Building and maintaining $\quad 1.065$

2

.533

.447

.640

special education staff morale

7. Securing consultant

7.705

2

3.852

3.213

$.043 *$ services for the staff

$* \mathrm{p}<.05$ 
2. Task 2 - Assistance in the Screening of Special Education Teachers: The Scheffe was computed for all possible pairings of the three groups of administrators. Responses from the three groups of administrators yielded no significant (.05 level) differences between groups of administrators.

3. Task 3 - Participating in the Selection of Special Education Teachers: The Scheffe was computed for all possible pairings of the three groups of administrators. Responses from the three groups of administrators yielded no significant (.05 level) differences between groups of administrators.

4. Task 4 - Participating in Assignment of Special Education Teachers: The Scheffe was computed for all possible pairings of the three groups of administrators. Responses from the three groups of administrators yielded no significant (.05 level) differences between groups of administrators.

5. Task 5 - Working with Principals in Evaluation of Special Education Teachers: The Scheffe was computed for all possible pairings of the three groups of administrators. Responses from the three groups of administrators yielded no significant (.05 level) differences between groups of administrators.

6. Task 6 - Building and Maintaining Special Education Staff Morale: The Scheffe was computed for all possible pairings of the three groups of administrators. Responses from the three groups of administrators yielded no significant (.05 level) differences between groups of administrators.

7. Task 7 - Securing consultant Services for the Staff: The Scheffe was computed for all possible pairings of the three groups of administrators. Responses from the three groups of administrators yielded no significant (.05 level) differences between groups of administrators. 


\section{Nature of the difference.}

The mean difference between pairings of administrators was examined. Relative to the pairing of the superintendent and the principal, the superintendents responded "yes", it was actually performed, and the principal responded "no", it was not performed, on the following tasks: participating in the recruitment of teachers, assistance in the screening of teachers, participating in the selection of teachers, participating in assignment of teachers and securing consultant services for the staff. Regarding the degree of importance there were no significant differences between superintends and principals in regard to the Staffing function. Table 18 contains data related to the mean differences between superintendents and principals.

Table 18

Mean Differences Between Superintendents and Principals in the Staffing Function

\begin{tabular}{|c|c|c|c|c|c|c|}
\hline & \multicolumn{3}{|c|}{ Actually Performed } & \multicolumn{3}{|c|}{ Degree of Importance } \\
\hline & Supt. & Prin. & $\begin{array}{l}\text { mean } \\
\text { diff. }\end{array}$ & Supt. & Prin. & $\begin{array}{c}\text { mean } \\
\text { diff. }\end{array}$ \\
\hline 1. Recruiting teachers & $\mathrm{Y}$ & $\mathrm{N}$ & .32 & NSD & NSD & \\
\hline 2. Screening teachers & Y & $\mathrm{N}$ & .28 & NSD & NSD & \\
\hline 3. Selecting teachers & $\mathrm{Y}$ & $\mathrm{N}$ & .31 & NSD & NSD & \\
\hline 4. Assigning teachers & $\mathrm{Y}$ & $\mathrm{N}$ & .31 & NSD & NSD & \\
\hline 7. Securing consultants & $\mathrm{Y}$ & $\mathrm{N}$ & .33 & NSD & NSD & \\
\hline
\end{tabular}

Relative to the pairing of the special education administrator and the principal, the special education administrator responded "yes", it was actually performed, and the principal responded "no", it was not performed, on the following tasks: participating in the recruitment of teachers, assistance in the screening of teachers, participating in the selection of teachers, 
working with principals in evaluation of special education teachers, and building and maintaining special education staff morale. Regarding the degree of importance there were no significant differences between special education administrators and principals in regard to the Staffing function. Table 19 contains data related to the mean differences between special education administrators and principals.

Table 19

$\underline{\text { Mean Differences Between Special Education Administrators and Principals }}$ in the Staffing Function

\begin{tabular}{|c|c|c|c|c|c|}
\hline \multicolumn{3}{|c|}{ Actually Performed } & \multicolumn{3}{|c|}{ Degree of Importance } \\
\hline $\begin{array}{l}\text { Sp. Ed. } \\
\text { Ad. }\end{array}$ & Prin. & $\begin{array}{l}\text { mean } \\
\text { diff. }\end{array}$ & $\begin{array}{l}\text { Sp. Ed. } \\
\text { Ad. }\end{array}$ & Prin. & $\begin{array}{c}\text { mean } \\
\text { diff. }\end{array}$ \\
\hline $\mathrm{Y}$ & $\mathrm{N}$ & .29 & NSD & NSD & \\
\hline Y & $\mathrm{N}$ & .27 & NSD & NSD & \\
\hline Y & $\mathrm{N}$ & .29 & NSD & NSD & \\
\hline $\mathrm{Y}$ & $\mathrm{N}$ & .39 & NSD & NSD & \\
\hline $\mathrm{Y}$ & $\mathrm{N}$ & .23 & NSD & NSD & \\
\hline
\end{tabular}

$\begin{aligned} \mathrm{Y} & =\text { Yes } \\ \mathrm{N} & =\text { No } \\ \mathrm{NSD} & =\text { No Significant Difference }\end{aligned}$

There were no significant differences between the pairing of the superintendent and the special education administrator in the Staffing function. 


\section{Directing Function}

Question 4: Is there a significant difference in the responses among West Virginia special education administrators, principals, and superintendents to the perceived performance of the special education administrative function entitled Directing as defined by tasks on the revised Newman instrument?

An ANOVA was computed for all possible pairings of the three groups of administrators. Based on the data received from the three groups of respondents there was a significant difference in responses among West Virginia special education administrators, principals, and superintendents to the perceived performance of the special education administrative function entitled Directing as defined by tasks on the revised Newman instrument. Table 20 contains the data related to Question 4.

Table 20

$\underline{\text { Sum of Squares, Degrees of Freedom, Mean Square, F Value and Levels of }}$ Significance for Question 4.

\begin{tabular}{lrrrrr}
\hline & $\begin{array}{c}\text { Sum of } \\
\text { Squares }\end{array}$ & \multicolumn{1}{c}{ df } & $\begin{array}{c}\text { Mean } \\
\text { Square }\end{array}$ & F & Sig. \\
\hline Between Groups & 2.075 & 2 & 1.038 & 8.923 & $.000^{*}$ \\
Within Groups & 17.444 & 150 & .116 & & \\
Total & 19.520 & 152 & & & \\
\hline
\end{tabular}

$* \underline{p}<.05$

In regard to specific tasks in question 4 , the ANOVA indicated significant (.05 level) differences between groups of administrators in the following specific tasks: planning in-service meetings, workshops, etc., conducting research with exceptional children, and directing in service meetings, workshops, etc. The ANOVA indicated that the following tasks did not have significant (.05 level) differences between groups of administrators: placement of children in special classes, transportation schedules for exceptional children, reevaluation of exceptional 
children, and providing counseling and guidance services for exceptional children. Table 21 contains the data related to the specific tasks on Question 4.

The Scheffe test indicated that responses on the revised Newman instrument in regard to the Directing function were significant (.05 level) between groups of superintendents and principals and groups of special education administrators and principals. The Scheffe yielded no significant (.05 level) differences on the Directing function between groups of special education administrators and superintendents. Utilization of the Scheffe test to differentiate the specific tasks that were significant between groups yielded the following results when applied:

1. Task 1 - Placement of Children in Special Classes: The Scheffe was computed for all possible pairings of the three groups of administrators. This test yielded no significant (.05 level) differences between groups of administrators.

2. Task 2 - Transportation Schedules for Exceptional Children: The Scheffe was computed for all possible pairings of the three groups of administrators. This test yielded no significant (.05 level) differences between groups of administrators.

3. Task 3 - Planning In-service Meetings, Workshops, etc.: The Scheffe was computed for all possible pairings of the three groups of administrators. Responses from groups superintendents and principals differed significantly (.05 level) on this task but all other pairings yielded no significant differences.

4. Task 4 - Conducting Research with Exceptional Children: The Scheffe was computed for all possible pairings of the three groups of administrators. Responses from groups special education administrators and principals differed significantly (.05 level) on this task but all other pairings yielded no significant differences.

5. Task 5 - Directing In-service Meetings, Workshops, etc.: The Scheffe was computed for all possible pairings of the three groups of administrators. Responses from groups of superintendents and principals differed significantly (.05 level) on this task and special education administrators and principals differed significantly (.05 level) on this task. Responses from groups of superintendents and special education administrators did not 
Table 21

Sum of Squares, Degrees of Freedom, Mean Square, F Value and Levels of

Significance for Each Task in the Directing Function as Perceived by

Special Education Administrators, Superintendents and Principals

(Performance)

Sum of

Squares

1. Placement of children in special classes

2. Transportation schedules for exceptional children

3. Planning in-service meetings, workshops, etc.

4. Conducting research with exceptional children

5. Directing in-service meetings, workshops, etc.

6. Re-evaluation of exceptional children

7. Providing counseling and guidance services for exceptional children

.681

1.529

2.446

5.327

7.104

1.134

.477
2

3.552

12.743

$.000 *$

2

.567

1.545

.217

2

.239

.587

.558

$* \underline{p}<.05$ 
differ significantly (.05 level) on this task.

6. Task 6 - Reevaluation of Exceptional Children: The Scheffe was computed for all possible pairings of the three groups of administrators. This test yielded no significant (.05 level) differences between groups of administrators.

7. Task 7 - Providing Counseling and Guidance Services for Exceptional Children: The Scheffe was computed for all possible pairings of the three groups of administrators. This test yielded no significant (.05 level) differences between groups of administrators.

\section{Question 11: Is there a significant difference in the responses among West Virginia special education administrators, principals, and superintendents in degree of importance assigned to the special education administrative function entitled Directing as defined by tasks on the revised Newman instrument?}

An ANOVA was computed for all possible pairings of the three groups of administrators. Based on the data received from the three groups of respondents there was not a significant difference in responses among West Virginia special education administrators, principals, and superintendents to the perceived degree of importance of the special education administrative function entitled Directing as defined by tasks on the revised Newman instrument. Table 22 contains the data related to Question 11.

Table 22

Sum of Squares, Degrees of Freedom, Mean Square, F Value and Levels of Significance for Question 11.

\begin{tabular}{lrrrrr}
\hline & $\begin{array}{c}\text { Sum of } \\
\text { Squares }\end{array}$ & \multicolumn{1}{c}{ df } & \multicolumn{1}{c}{ Mean } \\
& Square & F & Sig. \\
\hline Between Groups & 3.031 & 2 & 1.516 & 2.003 & .139 \\
Within Groups & 113.495 & 150 & .757 & & \\
Total & 116.526 & 152 & & & \\
\hline
\end{tabular}

$* \mathrm{p}<.05$ 
In regard to specific tasks in question 11, the ANOVA indicated significant (.05 level) differences between groups of administrators in the following specific tasks: planning in-service meetings, workshops, etc. and directing in service meetings, workshops, etc. research with exceptional children, and directing in service meetings, workshops, etc. The ANOVA indicated that the following tasks did not have significant (.05 level) differences between groups of administrators: conducting research with exceptional children, placement of children in special classes, transportation schedules for exceptional children, reevaluation of exceptional children, and providing counseling and guidance services for exceptional children. Table 23 contains the data related to the specific tasks on Question 11.

The Scheffe yielded no significant (.05 level) differences on the Directing function between groups of special education administrators and superintendents, special education administrators and principals, and superintendents and principals. Utilization of the Scheffe test to differentiate the specific tasks that were significant between groups yielded the following results when applied:

1. Task 1 - Placement of Children in Special Classes: The Scheffe was computed for all possible pairings of the three groups of administrators. Responses from the three groups of administrators yielded no significant (.05 level) differences between groups of administrators.

2. Task 2 - Transportation Schedules for Exceptional Children: The Scheffe was computed for all possible pairings of the three groups of administrators. Responses from the three groups of administrators yielded no significant (.05 level) differences between groups of administrators.

3. Task 3 - Planning In-service Meetings, Workshops, etc.: The Scheffe was computed for all possible pairings of the three groups of administrators. Responses from groups superintendents and principals differed significantly (.05 level) on this task but all other pairings yielded no significant differences.

4. Task 4 - Conducting Research with Exceptional Children: The Scheffe was computed for 85 
Table 23

Sum of Squares, Degrees of Freedom, Mean Square, F Value and Levels of

$\underline{\text { Significance for Each Task in the Directing Function as Perceived by }}$

Special Education Administrators, Superintendents and Principals

(Degree of Importance)

Sum of

Mean

Squares

df Square

F Sig.

1. Placement of children in

.397

2

.198

.109

.897

special classes

2. Transportation schedules

1.133

2

.567

.246

.782

for exceptional children

3. Planning in-service

13.830

2

6.915

5.606

$.004 *$

meetings, workshops, etc.

4. Conducting research with

4.464

2

2.232

.896

.410

exceptional children

5. Directing in-service

18.921

2

9.460

6.432

$.002 *$

meetings, workshops, etc.

6. Re-evaluation of

7.337

2

3.668

1.700

.186

exceptional children

7. Providing counseling and

1.164

2

.582

.310

.734

guidance services for

exceptional children

$* \mathrm{p}<.05$ 
all possible pairings of the three groups of administrators. Responses from the three groups of administrators yielded no significant (.05 level) differences between groups of administrators.

5. Task 5 - Directing In-service Meetings, Workshops, etc.: The Scheffe was computed for all possible pairings of the three groups of administrators. Responses from groups of superintendents and principals differed significantly (.05 level) on this task and special education administrators and principals differed significantly (.05 level) on this task. Responses from groups of superintendents and special education administrators did not differ significantly (.05 level) on this task.

6. Task 6 - Reevaluation of Exceptional Children: The Scheffe was computed for all possible pairings of the three groups of administrators. Responses from the three groups of administrators yielded no significant (.05 level) differences between groups of administrators.

7. Task 7 - Providing Counseling and Guidance Services for Exceptional Children: The Scheffe was computed for all possible pairings of the three groups of administrators. Responses from the three groups of administrators yielded no significant (.05 level) differences between groups of administrators.

\section{Nature of the difference.}

The mean difference between pairings of administrators was examined. Relative to the pairing of the superintendent and the principal, the superintendents responded "yes", it was actually performed, and the principal responded "no", it was not performed, on the following tasks: planning in-service meetings and directing in-service meetings. Regarding the degree of importance, the superintendents responded "yes", it was important, and the principal responded "no", it was not important, on the following tasks: planning in-service meetings and directing inservice meetings. Table 24 contains data related to the mean differences between superintendents 
and principals.

Table 24

Mean Differences Between Superintendents and Principals

in the Directing Function

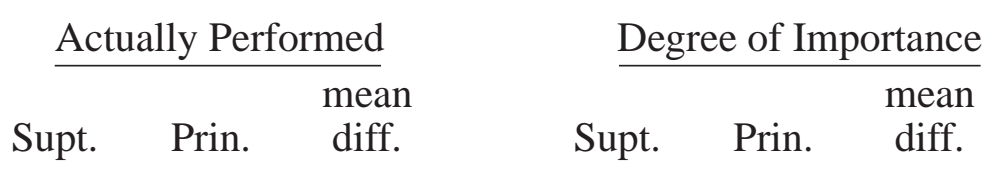

$\begin{array}{lllllll}\text { 3. Planning in-service } & \mathrm{Y} & \mathrm{N} & .28 & \mathrm{Y} & \mathrm{N} & .69\end{array}$

$\begin{array}{llllllll}\text { 5. Directing in-service } & \text { Y } & \text { N } & .45 & \text { Y } & \text { N } & .72\end{array}$

$\begin{aligned} \mathrm{Y} & =\text { Yes } \\ \mathrm{N} & =\text { No } \\ \mathrm{NSD} & =\text { No Significant Difference }\end{aligned}$

Relative to the pairing of the special education administrator and the principal, the special education administrator responded "yes", it was actually performed, and the principal responded "no", it was not performed, on the following tasks: conducting research with exceptional children and directing in-service meetings. Regarding the degree of importance, the special education administrators responded "yes", it was important, and the principal responded "no", it was not important, on the following task: directing in-service meetings. Table 25 contains data related to the mean differences between special education administrators and principals.

Table 25

Mean Differences Between Special Education Administrators and Principals in the Directing Function

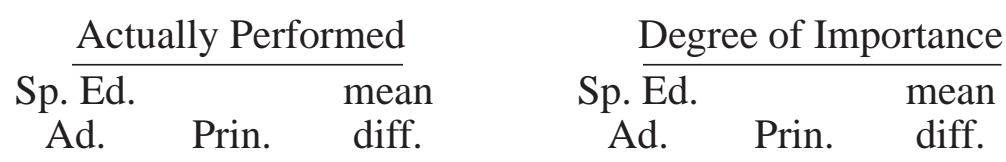

$\begin{array}{llllll}\text { 4. Conducting research } & \mathrm{Y} & \mathrm{N} & .43 & \mathrm{NSD} & \text { NSD }\end{array}$

$\begin{array}{lllllll}\text { 5. Directing in-service } & \mathrm{Y} & \mathrm{N} & .42 & \mathrm{Y} & \mathrm{N} & .69\end{array}$

$\begin{aligned} \mathrm{Y} & =\text { Yes } \\ \mathrm{N} & =\text { No } \\ \mathrm{NSD} & =\text { No Significant Difference }\end{aligned}$


There were no significant differences between the pairing of the superintendent and the special education administrator in the Directing function.

\section{Coordinating Function}

Question 5: Is there a significant difference in the responses among West Virginia special education administrators, principals, and superintendents to the perceived performance of the special education administrative function entitled Coordinating as defined by tasks on the revised Newman instrument?

An ANOVA was computed for all possible pairings of the three groups of administrators. Based on the data received from the three groups of respondents there was a significant difference in responses among West Virginia special education administrators, principals, and superintendents to the perceived performance of the special education administrative function entitled Coordinating as defined by tasks on the revised Newman instrument. Table 26 contains the data related to Question 5.

Table 26

Sum of Squares, Degrees of Freedom, Mean Square, F Value and Levels of Significance for Question 5.

\begin{tabular}{lrrrrr}
\hline & $\begin{array}{c}\text { Sum of } \\
\text { Squares }\end{array}$ & df & $\begin{array}{c}\text { Mean } \\
\text { Square }\end{array}$ & F & Sig. \\
\hline Between Groups & 1.410 & 2 & .705 & 15.132 & $.000^{*}$ \\
Within Groups & 6.988 & 150 & $4.653 \mathrm{E}-02$ & & \\
Total & 8.398 & 152 & & & \\
\hline
\end{tabular}

$* \underline{p}<.05$ 
In regard to specific tasks in question 5, the ANOVA indicated significant (.05 level) differences between groups of administrators in the following specific tasks: developing inclusion model for services, cooperating and communicating with school personnel, communicating with parents and the public and utilizing state department personnel as resources. The ANOVA indicated that the following tasks did not have significant (.05 level) differences between groups of administrators: utilizing services of community agencies and communication with board of education concerning special education program. Table 27 contains the data related to the specific tasks on Question 5.

The Scheffe test indicated that responses on the revised Newman instrument in regard to the Coordinating function were significant (.05 level) between groups of superintendents and principals and groups of special education administrators and principals. The Scheffe yielded no significant (.05 level) differences on the Coordinating function between groups of special education administrators and superintendents. Utilization of the Scheffe test to differentiate the specific tasks that were significant between groups yielded the following results when applied:

1. Task 1 - Developing Inclusion Model for Services: The Scheffe was computed for all possible pairings of the three groups of administrators. Responses from groups superintendents and principals differed significantly (.05 level) on this task but all other pairings yielded no significant differences.

2. Task 2 - Cooperating and Communicating with School Personnel: The Scheffe was computed for all possible pairings of the three groups of administrators. This test yielded no significant (.05 level) differences between groups of administrators.

3. Task 3 - Communicating with Parents and the Public: The Scheffe was computed for all possible pairings of the three groups of administrators. This test yielded no significant (.05 level) differences between groups of administrators.

4. Task 4 - Utilizing Services of Community Agencies: The Scheffe was computed for all possible pairings of the three groups of administrators. This test yielded no significant (.05 level) differences between groups of administrators. 
Table 27

Sum of Squares, Degrees of Freedom, Mean Square, F Value and Levels of

$\underline{\text { Significance for Each Task in the Coordinating Function as Perceived by }}$

$\underline{\text { Special Education Administrators, Superintendents and Principals }}$

(Performance)

$\begin{array}{lllcr}\begin{array}{c}\text { Sum of } \\ \text { Squares }\end{array} & \text { df } & \begin{array}{c}\text { Mean } \\ \text { Square }\end{array} & \text { F } & \text { Sig. } \\ 2.466 & 2 & 1.233 & 5.055 & .008^{*}\end{array}$

model for services

2. Cooperating and

$\begin{array}{lllll}.650 & 2 & .325 & 4.215 & .017 *\end{array}$
communicating with school personnel

3. Communicating with

1.353

2

.677

$4.943 \quad .008 *$ parents and the public

4. Utilizing services of .586

2

.239

2.141

.121 community agencies

5. Utilizing state

2

2.066

$9.343 \quad .000 *$

department personnel as resources

6. Communication with

.666

2

.333

2.019

.136

board of education

concerning special

education program

$* \mathrm{p}<.05$ 
5. Task 5 - Utilizing State Department Personnel as Resources: The Scheffe was computed for all possible pairings of the three groups of administrators. Responses from groups of superintendents and principals differed significantly (.05 level) on this task and special education administrators and principals differed significantly (.05 level) on this task. Responses from groups of superintendents and special education administrators did not differ significantly (.05 level) on this task.

6. Task 6 - Communication with Board of Education Concerning Special Education Program: The Scheffe was computed for all possible pairings of the three groups of administrators. This test yielded no significant (.05 level) differences between groups of administrators.

\section{Question 12: Is there a significant difference in the responses among West Virginia special education administrators, principals, and superintendents in degree of importance assigned to the special education administrative function entitled Coordinating as defined by tasks on the revised Newman instrument?}

An ANOVA was computed for all possible pairings of the three groups of administrators. Based on the data received from the three groups of respondents there was not a significant difference in responses among West Virginia special education administrators, principals, and superintendents to the perceived degree of importance of the special education administrative function entitled Coordinating as defined by tasks on the revised Newman instrument. Table 28 contains the data related to Question 12. 
Table 28

Sum of Squares, Degrees of Freedom, Mean Square, F Value and Levels of

Significance for Question 12.

\begin{tabular}{lrrrrr}
\hline & $\begin{array}{c}\text { Sum of } \\
\text { Squares }\end{array}$ & df & $\begin{array}{c}\text { Mean } \\
\text { Square }\end{array}$ & F & Sig. \\
\hline Between Groups & 2.639 & 2 & 1.319 & 2.251 & .109 \\
Within Groups & 87.920 & 150 & .586 & & \\
Total & 90.559 & 152 & & & \\
\hline
\end{tabular}

$* \mathrm{p}<.05$

In regard to specific tasks in question 12, the ANOVA indicated significant (.05 level) differences between groups of administrators in the following specific task: utilizing state department personnel as resources. The ANOVA indicated that the following tasks did not have significant (.05 level) differences between groups of administrators: developing inclusion model for services, cooperating and communicating with school personnel, communicating with parents and the public, utilizing services of community agencies and communication with board of education concerning special education program. Table 29 contains the data related to the specific tasks on Question 12.

The Scheffe yielded no significant (.05 level) differences on the Coordinating function between groups of special education administrators and superintendents, special education administrators and principals, and superintendents and principals.. Utilization of the Scheffe test to differentiate the specific tasks that were significant between groups yielded the following results when applied:

1. Task 1 - Developing Inclusion Model for Services: The Scheffe was computed for all possible pairings of the three groups of administrators. Responses from the three groups of administrators yielded no significant (.05 level) differences between groups of administrators.

2. Task 2 - Cooperating and Communicating with School Personnel: The Scheffe was 
Table 29

Sum of Squares, Degrees of Freedom, Mean Square, F Value and Levels of

$\underline{\text { Significance for Each Task in the Coordinating Function as Perceived by }}$

$\underline{\text { Special Education Administrators, Superintendents and Principals }}$

(Degree of Importance)

$\begin{array}{lllll}\begin{array}{c}\text { Sum of } \\ \text { Squares }\end{array} & \text { df } & \begin{array}{c}\text { Mean } \\ \text { Square }\end{array} & \text { F } & \text { Sig. } \\ 3.240 & 2 & 1.620 & .842 & .433\end{array}$

model for services

2. Cooperating and

2

.217

.267

.766

communicating with

school personnel

3. Communicating with

.848

2

.424

.643

.527

parents and the public

4. Utilizing services of

1.453

2

.727

.536

.586

community agencies

5. Utilizing state

22.238

2

11.119

$7.043 \quad .001 *$

department personnel as resources

6. Communication with

.780

2

.390

.250

.779

board of education

concerning special

education program

$* \mathrm{p}<.05$ 
computed for all possible pairings of the three groups of administrators. Responses from the three groups of administrators yielded no significant (.05 level) differences between groups of administrators.

3. Task 3 - Communicating with Parents and the Public: The Scheffe was computed for all possible pairings of the three groups of administrators. This test yielded no significant (.05 level) differences between groups of administrators.

4. Task 4 - Utilizing Services of Community Agencies: The Scheffe was computed for all possible pairings of the three groups of administrators. Responses from the three groups of administrators yielded no significant (.05 level) differences between groups of administrators.

5. Task 5 - Utilizing State Department Personnel as Resources: The Scheffe was computed for all possible pairings of the three groups of administrators. Responses from groups superintendents and principals differed significantly (.05 level) on this task but all other pairings yielded no significant differences.

6. Task 6 - Communication with Board of Education Concerning Special Education Program: The Scheffe was computed for all possible pairings of the three groups of administrators. Responses from the three groups of administrators yielded no significant (.05 level) differences between groups of administrators.

\section{Nature of the difference.}

The mean difference between pairings of administrators was examined. Relative to the pairing of the superintendent and the principal, the superintendents responded "yes", it was actually performed, and the principal responded "no", it was not performed, on the following tasks: developing inclusion model for services and utilizing state department personnel as resources. Regarding the degree of importance there were no significant differences between superintends and principals in regard to the Coordinating function. Table 30 contains data related 
to the mean differences between superintendents and principals.

Table 30

Mean Differences Between Superintendents and Principals

in the Coordinating Function

\section{Actually Performed \\ Supt. Prin. diff.}

$\frac{\text { Degree of Importance }}{\text { mean }}$

Supt. Prin. diff.

$\begin{array}{llllll}\text { 1. Developing inclusion } & \text { Y } & \text { N } & .28 & \text { NSD } & \text { NSD } \\ \text { 5. Utilizing State Department } & \text { Y } & \text { N } & .36 & \text { NSD } & \text { NSD }\end{array}$

$\begin{aligned} \mathrm{Y} & =\text { Yes } \\ \mathrm{N} & =\text { No } \\ \mathrm{NSD} & =\text { No Significant Difference }\end{aligned}$

Relative to the pairing of the special education administrator and the principal, the special education administrator responded "yes", it was actually performed, and the principal responded "no", it was not performed, on the following tasks:communicating with parents and public and utilizing state department personnel as resources. Regarding the degree of importance, the special education administrators responded "yes", it was important, and the principal responded "no", it was not important, on the following task: utilizing state department personnel as resources. Table 31 contains data related to the mean differences between special education administrators and principals.

Table 31

Mean Differences Between Special Education Administrators and Principals in the Coordinating Function

\begin{tabular}{|c|c|c|c|c|c|c|}
\hline & \multicolumn{3}{|c|}{ Actually Performed } & \multicolumn{3}{|c|}{ Degree of Importance } \\
\hline & $\begin{array}{c}\text { Sp. Ed. } \\
\text { Ad. }\end{array}$ & Prin. & $\begin{array}{l}\text { mean } \\
\text { diff. }\end{array}$ & $\begin{array}{c}\text { Sp. Ed. } \\
\text { Ad. }\end{array}$ & Prin. & $\begin{array}{c}\text { mean } \\
\text { diff. }\end{array}$ \\
\hline 3. Communicating with public & $\mathrm{Y}$ & $\mathrm{N}$ & .20 & NSD & NSD & \\
\hline 5. Utilizing State Department & Y & $\mathrm{N}$ & .30 & $\mathrm{Y}$ & $\mathrm{N}$ & .86 \\
\hline $\begin{aligned} \mathrm{Y} & =\text { Yes } \\
\mathrm{N} & =\text { No } \\
\mathrm{NSD} & =\text { No Significant Di }\end{aligned}$ & ifference & & & & & \\
\hline
\end{tabular}


There were no significant differences between the pairing of the superintendent and the special education administrator in the Coordinating function.

\section{Reporting Function}

Question 6: Is there a significant difference in the responses among West Virginia special education administrators, principals, and superintendents to the perceived performance of the special education administrative function entitled Reporting as defined by tasks on the revised Newman instrument?

An ANOVA was computed for all possible pairings of the three groups of administrators. Based on the data received from the three groups of respondents there was a significant difference in responses among West Virginia special education administrators, principals, and superintendents to the perceived performance of the special education administrative function entitled Reporting as defined by tasks on the revised Newman instrument. Table 32 contains the data related to Question 6.

Table 32

Sum of Squares, Degrees of Freedom, Mean Square, F Value and Levels of Significance for Question 6.

\begin{tabular}{lrrrrr}
\hline & $\begin{array}{c}\text { Sum of } \\
\text { Squares }\end{array}$ & df & $\begin{array}{c}\text { Mean } \\
\text { Square }\end{array}$ & F & Sig. \\
\hline Between Groups & 1.542 & 2 & .771 & 6.105 & $.003^{*}$ \\
Within Groups & 18.945 & 150 & .126 & & \\
Total & 20.487 & 152 & & & \\
\hline
\end{tabular}

$* \mathrm{p}<.05$ 
In regard to specific tasks in question 6, the ANOVA indicated significant (.05 level) differences between groups of administrators in the following specific tasks: preparation of state and federal special education reports, disseminating research findings, and periodic publications made available to parents and the public. The ANOVA indicated that the following tasks did not have significant (.05 level) differences between groups of administrators: pupil accounting and records and teacher accounting. Table 33 contains the data related to the specific tasks on Question 6.

The Scheffe test indicated that responses on the revised Newman instrument in regard to the Reporting function were significant (.05 level) between groups of special education administrators and principals. The Scheffe yielded no significant (.05 level) differences on the Reporting function between groups of superintendents and principals and groups of superintendents and special education administrators. Utilization of the Scheffe test to differentiate the specific tasks that were significant between groups yielded the following results when applied:

1. Task 1 - Preparation of State and Federal Special Education Reports: The Scheffe was computed for all possible pairings of the three groups of administrators. This test yielded no significant (.05 level) differences between groups of administrators.

2. Task 2 - Pupil Accounting and Records: The Scheffe was computed for all possible pairings of the three groups of administrators. This test yielded no significant (.05 level) differences between groups of administrators.

3. Task 3 - Teacher Accounting: The Scheffe was computed for all possible pairings of the three groups of administrators. This test yielded no significant (.05 level) differences between groups of administrators.

4. Task 4 - Disseminating Research Findings: The Scheffe was computed for all possible pairings of the three groups of administrators. Responses from groups of superintendents and principals differed significantly (.05 level) on this task and special education administrators and principals differed significantly (.05 level) on this task. Responses 
Table 33

Sum of Squares, Degrees of Freedom, Mean Square, F Value and Levels of

Significance for Each Task in the Reporting Function as Perceived by

$\underline{\text { Special Education Administrators, Superintendents and Principals }}$

(Performance)

\begin{tabular}{|c|c|c|c|c|c|}
\hline & $\begin{array}{l}\text { Sum of } \\
\text { Squares }\end{array}$ & df & $\begin{array}{l}\text { Mean } \\
\text { Square }\end{array}$ & $\mathrm{F}$ & Sig. \\
\hline $\begin{array}{l}\text { 1. Preparation of state and } \\
\text { federal special education } \\
\text { reports }\end{array}$ & 1.298 & 2 & .649 & 3.363 & $.037 *$ \\
\hline $\begin{array}{l}\text { 2. Pupil accounting and } \\
\text { records }\end{array}$ & .809 & 2 & .404 & 1.821 & .165 \\
\hline 3. Teacher accounting & $5.305 \mathrm{E}-02$ & 2 & $2.653 \mathrm{E}-02$ & .070 & .933 \\
\hline $\begin{array}{l}\text { 4. Disseminating research } \\
\text { findings }\end{array}$ & 6.224 & 2 & 3.112 & 7.300 & $.001 *$ \\
\hline $\begin{array}{l}\text { 5. Periodic publications } \\
\text { made available to parents } \\
\text { and the public }\end{array}$ & 2.212 & 2 & 1.106 & 3.397 & $.036 *$ \\
\hline
\end{tabular}


from groups of superintendents and special education administrators did not differ significantly (.05 level) on this task.

5. Task 5 - Periodic Publication Made Available to Parents and the Public: The Scheffe was computed for all possible pairings of the three groups of administrators. Responses from groups special education administrators and principals differed significantly (.05 level) on this task but all other pairings yielded no significant differences.

Question 13: Is there a significant difference in the responses among West Virginia special education administrators, principals, and superintendents in degree of importance assigned to the special education administrative function entitled Reporting as defined by tasks on the revised Newman instrument?

An ANOVA was computed for all possible pairings of the three groups of administrators. Based on the data received from the three groups of respondents there was not a significant difference in responses among West Virginia special education administrators, principals, and superintendents to the perceived degree of importance of the special education administrative function entitled Reporting as defined by tasks on the revised Newman instrument. Table 34 contains the data related to Question 13.

Table 34

Sum of Squares, Degrees of Freedom, Mean Square, F Value and Levels of Significance for Question 13.

\begin{tabular}{lrrrrr}
\hline & $\begin{array}{c}\text { Sum of } \\
\text { Squares }\end{array}$ & df & $\begin{array}{c}\text { Mean } \\
\text { Square }\end{array}$ & F & Sig. \\
\hline Between Groups & 2.944 & 2 & 1.472 & 1.432 & .242 \\
Within Groups & 154.236 & 150 & 1.028 & & \\
Total & 157.180 & 152 & & & \\
\hline
\end{tabular}

$* \underline{p}<.05$ 
In regard to specific tasks in question 13, the ANOVA indicated significant (.05 level) differences between groups of administrators in the following specific tasks:preparation of state and federal special education reports and pupil accounting and records. The ANOVA indicated that the following tasks did not have significant (.05 level) differences between groups of administrators: teacher accounting, disseminating research findings, and periodic publications made available to parents and the public. Table 35 contains the data related to the specific tasks on Question 13.

The Scheffe yielded no significant (.05 level) differences on the Reporting function between groups of superintendents and principals, groups of superintendents and special education administrators, and groups of special education administrators and principals. Utilization of the Scheffe test to differentiate the specific tasks that were significant between groups yielded the following results when applied:

1. Task 1 - Preparation of State and Federal Special Education Reports: The Scheffe was computed for all possible pairings of the three groups of administrators. Responses from groups special education administrators and principals differed significantly (.05 level) on this task but all other pairings yielded no significant differences.

2. Task 2 - Pupil Accounting and Records: The Scheffe was computed for all possible pairings of the three groups of administrators. Responses from the three groups of administrators yielded no significant (.05 level) differences between groups of administrators.

3. Task 3 - Teacher Accounting: The Scheffe was computed for all possible pairings of the three groups of administrators. Responses from the three groups of administrators yielded no significant (.05 level) differences between groups of administrators.

4. Task 4 - Disseminating Research Findings: The Scheffe was computed for all possible pairings of the three groups of administrators. Responses from the three groups of administrators yielded no significant (.05 level) differences between groups of administrators. 
Table 35

Sum of Squares, Degrees of Freedom, Mean Square, F Value and Levels of

Significance for Each Task in the Reporting Function as Perceived by

Special Education Administrators, Superintendents and Principals

(Degree of Importance)

Sum of

Mean

Squares

df Square

F Sig.

1. Preparation of state and

17.993

2

8.997

5.782

$.004 *$

federal special education

reports

2. Pupil accounting and

10.894

2

5.447

3.204

$.043 *$

records

3. Teacher accounting

.739

2

.370

.149

.862

4. Disseminating research

2.206

2

1.103

.439

.645

findings

5. Periodic publications

9.129E-02

2

$4.565 \mathrm{E}-02$

.020

.980 made available to parents and the public

$* \underline{p}<.05$ 
5. Task 5 - Periodic Publication Made Available to Parents and the Public: The Scheffe was computed for all possible pairings of the three groups of administrators. Responses from the three groups of administrators yielded no significant (.05 level) differences between groups of administrators.

\section{Nature of the difference.}

The mean difference between pairings of administrators was examined. Relative to the pairing of the superintendent and the principal, the superintendents responded "yes", it was actually performed, and the principal responded "no", it was not performed, on the following task: disseminating research findings. Regarding the degree of importance there were no significant differences between superintendents and principals in regard to the Reporting function. Table 36 contains data related to the mean differences between superintendents and principals.

Table 36

Mean Differences Between Superintendents and Principals in the Reporting Function

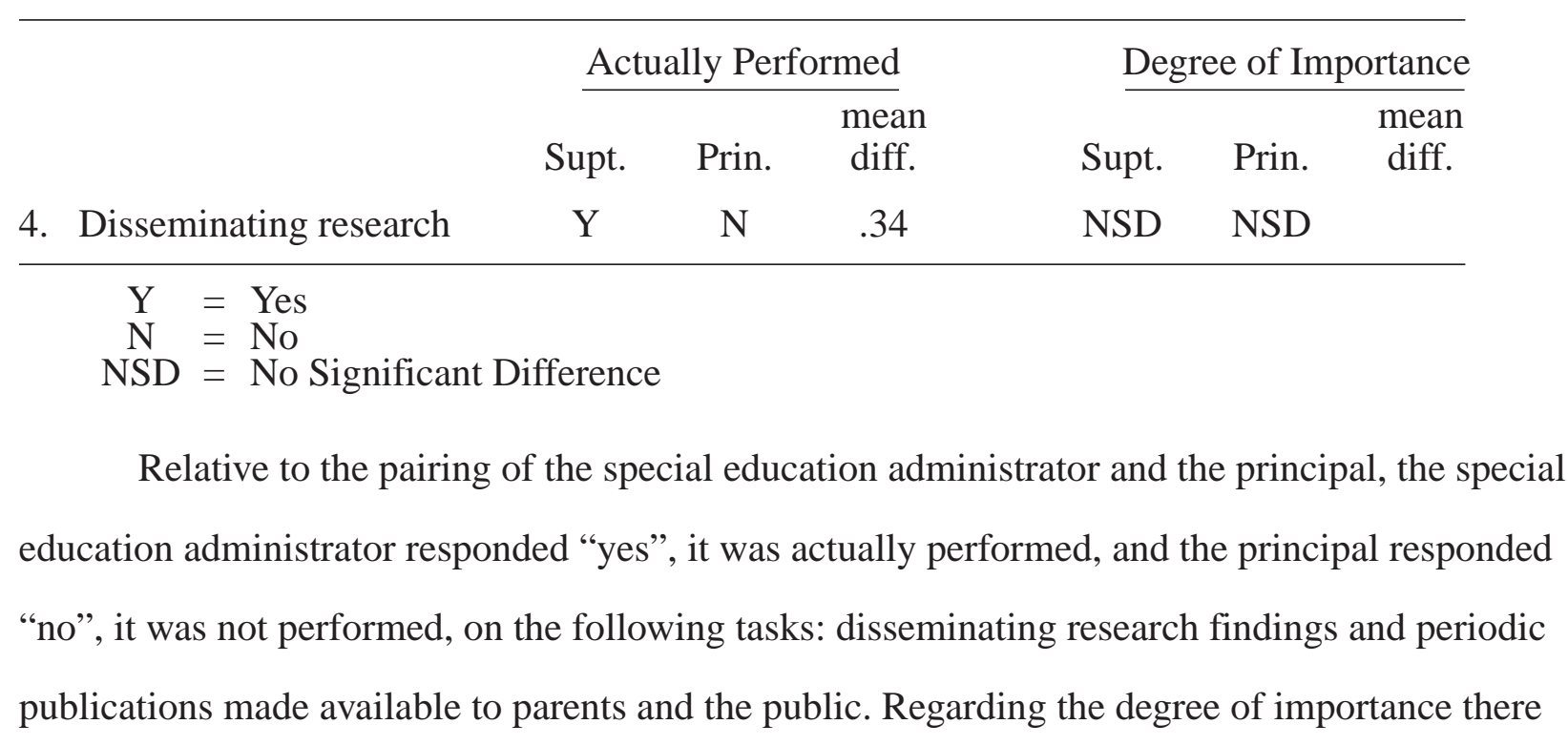


were no significant differences between special education administrators and principals in regard to the Reporting function. Table 37 contains data related to the mean differences between special education administrators and principals.

Table 37

Mean Differences Between Special Education Administrators and Principals in the Reporting Function

\begin{tabular}{|c|c|c|c|c|c|c|}
\hline & \multicolumn{3}{|c|}{ Actually Performed } & \multicolumn{3}{|c|}{ Degree of Importance } \\
\hline & $\begin{array}{l}\text { Sp. Ed. } \\
\text { Ad. }\end{array}$ & Prin. & $\begin{array}{l}\text { mean } \\
\text { diff. }\end{array}$ & $\begin{array}{l}\text { Sp. Ed. } \\
\text { Ad. }\end{array}$ & Prin. & $\begin{array}{c}\text { mean } \\
\text { diff. }\end{array}$ \\
\hline 4. Disseminating research & $\mathrm{Y}$ & $\mathrm{N}$ & .45 & NSD & NSD & \\
\hline 5. Publications to parents & $\mathrm{Y}$ & $\mathrm{N}$ & .29 & NSD & NSD & \\
\hline
\end{tabular}

There were no significant differences between the pairing of the superintendent and the special education administrator in the Reporting function.

\section{Budgeting Function}

\section{Question 7: Is there a significant difference in the responses among West Virginia special education administrators, principals, and superintendents to the perceived performance of the special education administrative function entitled Budgeting as defined by tasks on the revised Newman instrument?}

An ANOVA was computed for all possible pairings of the three groups of administrators. Based on the data received from the three groups of respondents there was a significant difference in responses among West Virginia special education administrators, principals, and superintendents to the perceived performance of the special education administrative function entitled Budgeting as defined by tasks on the revised Newman instrument. Table 38 contains the 
data related to Question 7.

Table 38

Sum of Squares, Degrees of Freedom, Mean Square, F Value and Levels of $\underline{\text { Significance for Question } 7 .}$

\begin{tabular}{lrrrrr}
\hline & $\begin{array}{c}\text { Sum of } \\
\text { Squares }\end{array}$ & \multicolumn{1}{c}{ df } & $\begin{array}{c}\text { Mean } \\
\text { Square }\end{array}$ & F & Sig. \\
\hline Between Groups & 4.936 & 2 & 2.468 & 12.709 & $.000^{*}$ \\
Within Groups & 29.126 & 150 & .194 & & \\
Total & 34.062 & 152 & & & \\
\hline
\end{tabular}

$* \mathrm{p}<.05$

In regard to specific tasks in question 7, the ANOVA indicated significant differences between groups of administrators on the perceived performance of all tasks in the Budgeting function. Table 39 contains the data related to the specific tasks on Question 7.

The Scheffe test indicated that responses on the revised Newman instrument in regard to the Budgeting function were significant (.05 level) between groups of superintendents and principals and groups of special education administrators and principals. The Scheffe yielded no significant (.05 level) differences on the Budgeting function between groups of special education administrators and superintendents. Utilization of the Scheffe test to differentiate the specific tasks that were significant between groups yielded the following results when applied:

1. Task 1- Preparation of the Budget: The Scheffe was computed for all possible pairings of the three groups of administrators. Responses from groups of superintendents and principals differed significantly (.05 level) on this task and special education administrators and principals differed significantly (.05 level) on this task. Responses from groups of superintendents and special education administrators did not differ significantly (.05 level) on this task.

2. Task 2 - Presentation of Budget Requests: The Scheffe was computed for all possible 
Table 39

Sum of Squares, Degrees of Freedom, Mean Square, F Value and Levels of

Significance for Each Task in the Budgeting Function as Perceived by

$\underline{\text { Special Education Administrators, Superintendents and Principals }}$

(Performance)

Sum of

Mean

Squares

df Square

F Sig.

1. Preparation of the budget $\quad \begin{array}{lllll}6.844 & 2 & 3.422 & 12.612 & .000 *\end{array}$

2. Presentation of budget

3.391

$2 \quad 1.696$

$6.512 \quad .002 *$ requests

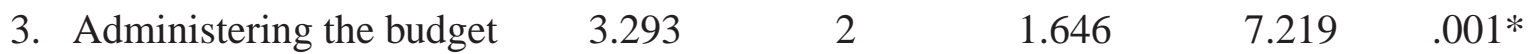

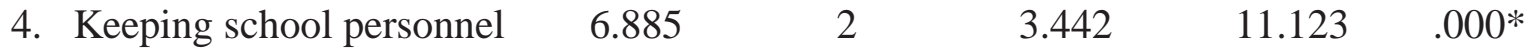
informed of budget limits

$* \underline{p}<.05$ 
pairings of the three groups of administrators. Responses from groups of superintendents and principals differed significantly (.05 level) on this task and special education administrators and principals differed significantly (.05 level) on this task. Responses from groups of superintendents and special education administrators did not differ significantly (.05 level) on this task.

3. Task 3 - Administering the Budget: The Scheffe was computed for all possible pairings of the three groups of administrators. Responses from groups of superintendents and principals differed significantly (.05 level) on this task and special education administrators and principals differed significantly (.05 level) on this task. Responses from groups of superintendents and special education administrators did not differ significantly (.05 level) on this task.

4. Task 4 - Keeping School Personnel Informed of Budget Limits: The Scheffe was computed for all possible pairings of the three groups of administrators. Responses from groups of superintendents and principals differed significantly (.05 level) on this task and special education administrators and principals differed significantly (.05 level) on this task. Responses from groups of superintendents and special education administrators did not differ significantly (.05 level) on this task.

\section{Question 14: Is there a significant difference in the responses among West Virginia special education administrators, principals, and superintendents in degree of importance assigned to the special education administrative function entitled Budgeting as defined by tasks on the revised Newman instrument?}

An ANOVA was computed for all possible pairings of the three groups of administrators. Based on the data received from the three groups of respondents there was a significant difference in responses among West Virginia special education administrators, principals, and superintendents to the perceived degree of importance of the special education administrative function entitled Budgeting as defined by tasks on the revised Newman instrument. Table 40 
contains the data related to Question 14.

Table 40

Sum of Squares, Degrees of Freedom, Mean Square, F Value and Levels of

Significance for Question 14.

\begin{tabular}{lrrrrr}
\hline & $\begin{array}{c}\text { Sum of } \\
\text { Squares }\end{array}$ & df & $\begin{array}{c}\text { Mean } \\
\text { Square }\end{array}$ & F & Sig. \\
\hline Between Groups & 16.536 & 2 & 8.268 & 7.904 & $.001^{*}$ \\
Within Groups & 156.905 & 150 & 1.046 & & \\
Total & 173.441 & 152 & & & \\
\hline
\end{tabular}

$* \mathrm{p}<.05$

In regard to specific tasks in question 14, the ANOVA indicated significant (.05 level) differences between groups of administrators in the following specific tasks: preparation of the budget, presentation of budget requests, and administering the budget. The ANOVA indicated that the following task did not have significant (.05 level) differences between groups of administrators: keeping school personnel informed of budget limits. Table 41 contains the data related to the specific tasks on Question 14.

The Scheffe test indicated that responses on the revised Newman instrument in regard to the Budgeting function were significant (.05 level) between groups of superintendents and principals and groups of special education administrators and principals. The Scheffe yielded no significant (.05 level) differences on the Budgeting function between groups of special education administrators and superintendents. Utilization of the Scheffe test to differentiate the specific tasks that were significant between groups yielded the following results when applied:

1. Task 1- Preparation of the Budget: The Scheffe was computed for all possible pairings of the three groups of administrators. Responses from groups of superintendents and principals differed significantly (.05 level) on this task and special education administrators and principals differed significantly (.05 level) on this task. Responses 
Table 41

Sum of Squares, Degrees of Freedom, Mean Square, F Value and Levels of

Significance for Each Task in the Budgeting Function as Perceived by

$\underline{\text { Special Education Administrators, Superintendents and Principals }}$

(Degree of Importance)

Sum of

Mean

Squares

df Square

F Sig.

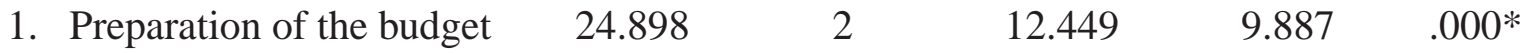

2. Presentation of budget

13.930

2

6.965

$4.878 \quad .009 *$ requests

$\begin{array}{llllll}\text { 3. Administering the budget } & 19.992 & 2 & 9.996 & 7.358 & .001 *\end{array}$

$\begin{array}{llllll}\text { 4. Keeping school personnel } & 10.011 & 2 & 5.006 & 2.522 & .084\end{array}$ informed of budget limits

$* \underline{p}<.05$ 
from groups of superintendents and special education administrators did not differ significantly (.05 level) on this task.

2. Task 2 - Presentation of Budget Requests: The Scheffe was computed for all possible pairings of the three groups of administrators. Responses from groups special education administrators and principals differed significantly (.05 level) on this task but all other pairings yielded no significant differences.

3. Task 3 - Administering the Budget: The Scheffe was computed for all possible pairings of the three groups of administrators. Responses from groups special education administrators and principals differed significantly (.05 level) on this task but all other pairings yielded no significant differences.

4. Task 4 - Keeping School Personnel Informed of Budget Limits: The Scheffe was computed for all possible pairings of the three groups of administrators. Responses from the three groups of administrators yielded no significant (.05 level) differences between groups of administrators.

\section{Nature of the difference.}

The mean difference between pairings of administrators was examined. Relative to the pairing of the superintendent and the principal, the superintendents responded "yes", it was actually performed, and the principal responded "no", it was not performed, on the following tasks: preparation of the budget, presentation of budget requests, administering the budget, keeping school personnel informed of budget limits. Regarding the degree of importance, the superintendents responded "yes", it was important, and the principal responded "no", it was not important, on the following task: preparation of the budget. Table 42 contains data related to the mean differences between superintendents and principals. 
Table 42

Mean Differences Between Superintendents and Principals

in the Budgeting Function

\begin{tabular}{|c|c|c|c|c|c|}
\hline \multicolumn{3}{|c|}{ Actually Performed } & \multicolumn{3}{|c|}{ Degree of Importance } \\
\hline Supt. & Prin. & $\begin{array}{l}\text { mean } \\
\text { diff. }\end{array}$ & Supt. & Prin. & $\begin{array}{c}\text { mean } \\
\text { diff. }\end{array}$ \\
\hline $\mathrm{Y}$ & $\mathrm{N}$ & .45 & Y & $\mathrm{N}$ & .80 \\
\hline $\mathrm{Y}$ & $\mathrm{N}$ & .30 & NSD & NSD & \\
\hline Y & $\mathrm{N}$ & .32 & NSD & NSD & \\
\hline Y & $\mathrm{N}$ & .45 & NSD & NSD & \\
\hline
\end{tabular}

$\begin{aligned} \text { 4. Informing budget limits } & \mathrm{Y} \\ \mathrm{Y} & =\text { Yes } \\ \mathrm{N} & =\text { No } \\ \mathrm{NSD} & =\text { No Significant Difference }\end{aligned}$

Relative to the pairing of the special education administrator and the principal, the special education administrator responded "yes", it was actually performed, and the principal responded "no", it was not performed, on the following tasks: preparation of the budget, presentation of budget requests, administering the budget, keeping school personnel informed of budget limits. Regarding the degree of importance, the special education administrators responded "yes", it was important, and the principal responded "no", it was not important, on the following tasks: preparation of the budget, presentation of budget requests, and administering the budget. Table 43 contains data related to the mean differences between special education administrators and principals. 
Table 43

Mean Differences Between Special Education Administrators and Principals in the Budgeting Function

\begin{tabular}{|c|c|c|c|c|c|c|}
\hline & \multicolumn{3}{|c|}{ Actually Performed } & \multicolumn{3}{|c|}{ Degree of Importance } \\
\hline & $\begin{array}{c}\text { Sp. Ed. } \\
\text { Ad. }\end{array}$ & Prin. & $\begin{array}{c}\text { mean } \\
\text { diff. }\end{array}$ & $\begin{array}{c}\text { Sp. } \overline{\text { Ed. }} \\
\text { Ad. }\end{array}$ & Prin. & $\begin{array}{c}\text { mean } \\
\text { diff. }\end{array}$ \\
\hline 1. Preparing budget & $\mathrm{Y}$ & $\mathrm{N}$ & .40 & $\mathrm{Y}$ & $\mathrm{N}$ & .82 \\
\hline 2. Presenting budget & $\mathrm{Y}$ & $\mathrm{N}$ & .30 & $\mathrm{Y}$ & $\mathrm{N}$ & .68 \\
\hline 3. Administering budget & Y & $\mathrm{N}$ & .27 & $\mathrm{Y}$ & $\mathrm{N}$ & .83 \\
\hline 4. Informing budget limits & $\mathrm{Y}$ & $\mathrm{N}$ & .40 & NSD & NSD & \\
\hline $\begin{aligned} \mathrm{Y} & =\text { Yes } \\
\mathrm{N} & =\text { No } \\
\mathrm{NSD} & =\text { No Significan }\end{aligned}$ & ifference & & & & & \\
\hline
\end{tabular}

There were no significant differences between the pairing of the superintendent and the special education administrator in the Budgeting function.

\section{Summary Data}

A final approach to analyzing the data generated by this study was to analyze both the perceived performance and perceived degree of importance between groups of principals, superintendents, and special education administrators regarding the special education administrative functions. This analysis revealed that in regard to the 40 tasks on the survey instrument, on 12 tasks there were significant differences in responses among the three groups of administrators for both the perceived performance and the perceived degree of importance of the special education administrative tasks. These tasks were from all of the administrative functions except for the organizing function. Table 44 contains the data related to summary data. 
Table 44

Tasks in Which Significant* Differences Occurred Among Principals, Superintendents and Special Education Administrators Regarding Perceived Performance and Perceived Degree of Importance Assigned to Tasks

1. securing consultant services for the staff

2. developing policies (i.e. identification, placement, transfer)

3. establishing special education programs

4. surveying the district for handicapped and gifted students

5. planing and providing special equipment and special instructional materials

6. planning in-service meetings, workshops, etc.

7. directing in-service meetings, workshops, etc.

8. utilizing state department personnel as resources

9. preparation of state and federal special education reports

10. preparation of the budget

11. presentation of budget requests

12. administering the budget

$* \underline{p}<.05$ 


\section{Chapter Summary}

The purpose of this study was to examine expectations held by key administrative personnel within West Virginia's county school system with regard to the role of the special education administrator. Specifically what was examined were the existing differences, if any, among and within groups of superintendents, principals, and special education administrators of the role expectations of the special education administrator in West Virginia.

Thirty three West Virginia superintendents, 36 special education administrators and 84 principals participated in this study. Data collected in this study related to 40 administrative tasks organized into seven administrative functions. The first seven research questions related to the extent of agreement among the three groups as to whether the special education administrators actually performed the specific tasks, while research question eight through fourteen related to the extent of agreement among the three groups of respondents around the degree of importance of the specific tasks.

An analysis of variance (ANOVA) was used to answer the research questions $1-14$ of this study. An alpha level of 0.05 was set as the criterion for determining significance. A Scheffe test was performed as a form of a post hoc comparison. The Scheffe test was used in this study to differentiate the specific tasks that were significant between groups of respondents. Additionally, the mean difference of responses between pairs of administrators was examined to discern the nature or direction of the differences found.

The results of these statistical analyses indicated that nine out of the fourteen research questions were significant. This indicated that in regard to the administrative functions named in research questions one through fourteen, groups of superintendents, special education administrators and principals differed in their perceptions of performance or importance of nine of these fourteen special education administrative functions. 


\section{Chapter V}

\section{Summary, Conclusions, and Recommendations}

This investigation was designed to discover potential misunderstandings of the role of the special education administrator between principals, superintendents and special education administrators. This chapter provides a summary of the study. The chapter is organized around seven sections: (1) purpose, (2) procedures, (3) descriptive data, (4) summary of findings, (5) conclusions, (6) discussion and implications, and (7) recommendations for further research.

\section{Purpose}

This study examined the expectations held by key administrative personnel within West Virginia public schools regarding the role of the special education administrator. Existing differences in perception of the administrative functions of the special education administrator in West Virginia among and within groups of superintendents, principals, and special education administrators were investigated. Forty administrative tasks organized into seven administrative activities identified by Urwick's (1937) POSDCoRB Theory (Planning, Organizing, Staffing, Directing, Coordinating, Reporting, and Budgeting) were examined in order to identify potential areas of conflict between the school system administrators. The responses analyzed pertained to both the perceived performance and the perceived importance of each administrative task.

Demographic data were requested and analyzed to provide descriptive data for the three groups of administrators surveyed. The first seven research questions addressed the perceived performance of functions by the special education administrators. Research questions eight through fourteen addressed the perceived importance of the administrative functions by the special education administrators. The following specific research questions guided the study:

1. Is there a significant difference in responses among West Virginia special education 
administrators, principals and superintendents to the perceived performance of the special education administrative function entitled Planning as defined by the tasks on the revised Newman instrument?

2. Is there a significant difference in responses among West Virginia special education administrators, principals, and superintendents to the perceived performance of the special education administrative function entitled Organizing as defined by tasks on the revised Newman instrument?

3. Is there a significant difference in responses among West Virginia special education administrators, principals, and superintendents to the perceived performance of the special education administrative function entitled Staffing as defined by tasks on the revised Newman instrument?

4. Is there a significant difference in responses among West Virginia special education administrators, principals, and superintendents to the perceived performance of the special education administrative function entitled Directing as defined by tasks on the revised Newman instrument?

5. Is there a significant difference in responses among West Virginia special education administrators, principals, and superintendents to the perceived performance of the special education administrative function entitled Coordinating as defined by tasks on the revised Newman instrument?

6. Is there a significant difference in responses among West Virginia special education administrators, principals, and superintendents to the perceived performance of the special education administrative function entitled Reporting as defined by tasks on the revised Newman instrument?

7. Is there a significant difference in responses among West Virginia special education administrators, principals, and superintendents to the perceived performance of the special education administrative function entitled Budgeting as defined by tasks on the revised Newman instrument? 
8. Is there a significant difference in responses among West Virginia special education administrators, principals and superintendents in the degree of importance assigned to the special education administrative function entitled Planning as defined by the tasks on the revised Newman instrument?

9. Is there a significant difference in responses among West Virginia special education administrators, principals, and superintendents in the degree of importance assigned to the special education administrative function entitled Organizing as defined by tasks on the revised Newman instrument?

10. Is there a significant difference in responses among West Virginia special education administrators, principals, and superintendents in the degree of importance assigned to the special education administrative function entitled Staffing as defined by tasks on the revised Newman instrument?

11. Is there a significant difference in responses among West Virginia special education administrators, principals, and superintendents in the degree of importance assigned to the special education administrative function entitled Directing as defined by tasks on the revised Newman instrument?

12. Is there a significant difference in responses among West Virginia special education administrators, principals, and superintendents in the degree of importance assigned to the special education administrative function entitled Coordinating as defined by tasks on the revised Newman instrument?

13. Is there a significant difference in responses among West Virginia special education administrators, principals, and superintendents in the degree of importance assigned to the special education administrative function entitled Reporting as defined by tasks on the revised Newman instrument?

14. Is there a significant difference in responses among West Virginia special education administrators, principals, and superintendents in the degree of importance assigned to the special education administrative function entitled Budgeting as defined by tasks on 
the revised Newman instrument?

\section{Procedures}

The West Virginia school personnel who were chosen to participate in this study included: (1) all 55 county superintendents of schools, (2) all 55 persons identified as special education administrators in the Directory of Special education administrative Personnel (1997) published by the West Virginia Department of Education and (3) a random sample of 150 West Virginia public school principals. The return rate for these groups was $33(60 \%)$ superintendents, $36(65 \%)$ special education administrators, and $84(56 \%)$ principals. Total response rates for all three groups totaled $153(60 \%)$.

The survey instrument used was the revised Newman instrument. This survey instrument was employed in three other research studies examining the perceived role of the special education administrator. For the current study, the Newman instrument was revised to reflect changes in special education that have occurred since the instrument was used 12 years ago in the Sullivan (1986) study. A survey instrument was mailed to each participant in the study. The survey instrument consisted of forty administrative tasks organized into seven types of administrative functioning and six questions concerned with demographic data.

Data generated in this study were assigned response codes and processed using the Statistical Package for the Social Sciences. An Analysis of Variance (ANOVA) was used to answer research questions one through fourteen. An alpha level of 0.05 was set as the criteria for determining significance. A Scheffe test was performed as a form of post hoc comparison. The Scheffe was used to differentiate the specific tasks that were significant between groups of administrators. Additionally, the mean difference of responses between pairs of administrators was examined to discern the nature or direction of differences found. 


\section{Descriptive Data}

An analysis of the demographic data collected in this study formed the basis for the development of a profile for each of the three respondent groups of school administrators. Data in regard to superintendents revealed that they had an average tenure of 7.48 years. Of the 33 superintendents who participated in this study, 24 reported experience as a teacher and 23 reported experience as a school principal.

In regard to graduate classes in administration, 30 superintendents reported taking 10 or more administrative courses and one superintendent reported taking no administrative courses. In regard to special education courses, four superintendents reported taking 10 or more special education courses. Sixteen superintendents reported taking 1-3 special education courses and six reported taking no special education courses. On the demographic question asking "Is it your opinion that the principal is the special education leader at the school level?", five superintendents answered "No" and 28 superintendents answered "Yes".

Data gathered in regard to special education administrators revealed that they had served an average of 8.05 years in this position. Of the 36 special education administrators who participated in this study, 25 reported experience as a teacher. Eight special education administrators reported serving time as a principal and four reported experience as an assistant principal. Sixteen special education administrators reported serving time in other positions.

When asked about the number of graduate courses in administration taken, all special education administrators reported taking some administration courses and 26 reported taking 10 or more administrative courses. In responding to the number of special education courses taken, 25 special education administrators provided information that they had taken 10 or above special education courses. Four special education administrators revealed that they had taken no special education courses. In regard to the demographic question asking "Is it your opinion that the principal is the special education leader at the school level?", six special education administrators answered "No" and 30 special education administrators answered "Yes". 
Data gathered in regard to principals revealed that they had an average tenure in position of 13.16 years. Of the 84 principals responding to the survey, 20 revealed that they had no experience as a teacher. Twenty-seven principals reported that they had served as assistant principal and one principal reported serving as a superintendent. No principals reported time spent as a special education administrator.

In regard to number of administrative courses, 74 reported taking 10 or above administrative courses. Four principals responded that they had taken 7-9 administrative courses and two reported taking 1-3 administrative courses. Four principals reported taking no administrative courses. In regard to special education courses, 24 principals reported taking no special education courses and 22 reported taking 1-3 special education courses. Fourteen principals reported taking 10 and above special education courses. On the demographic question asking "Is it your opinion that the principal is the special education leader at the school level?", 22 principals answered "No" and 62 principals answered "Yes".

\section{$\underline{\text { Summary of Findings }}$}

\section{Planning Function}

Question 1: Is there a significant difference in the responses among West Virginia special education administrators, principals and superintendents to the perceived performance of the special education administrative function entitled Planning as defined by the tasks on the revised Newman instrument?

\section{Question 8: Is there a significant difference in the responses among West Virginia special education administrators, principals and superintendents in degree of importance assigned to the special education administrative function entitled Planning as defined by the tasks on the revised Newman instrument?}


Based on the data received from the three groups of respondents there was a significant difference to the responses among West Virginia special education administrators, principals, and superintendents in the perceived performance of the special education administrative function entitled Planning as defined by the tasks on the revised Newman instrument. Regarding the degree of importance of the Planning function, data received from the three groups of respondents indicted significant differences in the responses among West Virginia special education administrators, principals, and superintendents on the tasks on the revised Newman instrument.

The mean difference between pairings of administrators indicated that relative to the pairing of the superintendent and the principal, the superintendents responded that it was actually performed, and the principal responded that it was not performed, on the four tasks. Regarding the degree of importance, the superintendents responded that it was important, and the principal responded that it was not important, on three tasks.

Relative to the pairing of the special education administrator and the principal, the special education administrator responded that it was actually performed, and the principal responded that it was not performed, on six tasks. Regarding the degree of importance, the special education administrators responded that it was important, and the principal responded that it was not important, on three tasks. There were no significant differences between the pairing of the superintendent and the special education administrator in the Planning function.

\section{Organizing Function}

\section{Question 2: Is there a significant difference in the responses among West Virginia special education administrators, principals, and superintendents to the perceived performance of the special education administrative function entitled Organizing as defined by tasks on the revised Newman instrument?}


Question 9: Is there a significant difference in the responses among West Virginia special education administrators, principals, and superintendents in degree of importance assigned to the special education administrative function entitled Organizing as defined by tasks on the revised Newman instrument?

Data received from the three groups of respondents indicated there was a significant difference in responses among West Virginia special education administrators, principals, and superintendents to the perceived performance of the special education administrative function entitled Organizing as defined by tasks on the revised Newman instrument. Based on the data received from the three groups of administrators there was a not a significant difference in responses among West Virginia special education administrators, principals, and superintendents to the perceived degree of importance of the special education administrative function entitled Organizing as defined by tasks on the revised Newman instrument.

The mean difference between pairings of administrators was examined. Information regarding the pairing of the superintendent and the principal indicated the superintendents responded that it was actually performed, and the principal responded that it was not performed, on one task. Regarding the degree of importance there were no significant differences between superintendents and principals in regard to the Organizing function.

Information generated concerning the pairing of the superintendent and the special education administrator relative to actual performance of tasks indicated no significant differences between these two groups of administrators. Regarding the degree of importance, the superintendents responded that it was important, and the special education administrators responded that it was not important, on only one task. There were no significant differences between the pairing of the special education administrator and the principal in the Organizing function. 


\section{Staffing Function}

Question 3: Is there a significant difference in the responses among West Virginia special education administrators, principals, and superintendents to the perceived performance of the special education administrative function entitled Staffing as defined by tasks on the revised Newman instrument?

Question 10: Is there a significant difference in the responses among West Virginia special education administrators, principals, and superintendents in degree of importance assigned to the special education administrative function entitled Staffing as defined by tasks on the revised Newman instrument?

Based on the data received from the three groups of respondents, there was a significant difference in responses among West Virginia special education administrators, principals, and superintendents to the perceived performance of the special education administrative function entitled Staffing as defined by tasks on the revised Newman instrument. Data received from the three groups of respondents, relative to the degree of importance of the Staffing function, indicated there was not a significant difference in responses among the three groups of administrators on tasks on the revised Newman instrument.

By examining the mean difference between pairings of administrators was findings indicated that relative to the pairing of the superintendent and the principal, the superintendents responded that it was actually performed, and the principal responded that it was not performed, on four tasks Regarding the degree of importance there were no significant differences between superintends and principals in regard to the Staffing function.

Relative to the pairing of the special education administrator and the principal, the special education administrator responded that it was actually performed, and the principal responded that it was not performed, on five tasks. Regarding the degree of importance there were no significant differences between special education administrators and principals in regard 
to the Staffing function. There were no significant differences between the pairing of the superintendent and the special education administrator in the Staffing function.

\section{Directing Function}

Question 4: Is there a significant difference in the responses among West Virginia special education administrators, principals, and superintendents to the perceived performance of the special education administrative function entitled Directing as defined by tasks on the revised Newman instrument?

Question 11: Is there a significant difference in the responses among West Virginia special education administrators, principals, and superintendents in degree of importance assigned to the special education administrative function entitled Directing as defined by tasks on the revised Newman instrument?

Based on the data received from the three groups of respondents there was a significant difference in responses among West Virginia special education administrators, principals, and superintendents to the perceived performance of the special education administrative function entitled Directing as defined by tasks on the revised Newman instrument. Based on the data received from the three groups of respondents there was not a significant difference in responses among West Virginia special education administrators, principals, and superintendents to the perceived degree of importance of the special education administrative function entitled Directing as defined by tasks on the revised Newman instrument.

By examining the mean difference between pairings of administrators some findings were generated. Relative to the pairing of the superintendent and the principal, the superintendents responded that it was actually performed, and the principal responded that it was not performed, on two tasks. Regarding the degree of importance, the superintendents responded that it was important, and the principal responded that it was not important, on the same two tasks. 
Relative to the pairing of the special education administrator and the principal, the special education administrator responded that it was actually performed, and the principal responded that it was not performed, on two tasks Regarding the degree of importance, the special education administrators responded that it was important, and the principal responded that it was not important, on one task.There were no significant differences between the pairing of the superintendent and the special education administrator in the Directing function.

\section{Coordinating Function}

Question 5: Is there a significant difference in the responses among West Virginia special education administrators, principals, and superintendents to the perceived performance of the special education administrative function entitled Coordinating as defined by tasks on the revised Newman instrument?

Question 12: Is there a significant difference in the responses among West Virginia special education administrators, principals, and superintendents in degree of importance assigned to the special education administrative function entitled Coordinating as defined by tasks on the revised Newman instrument?

Responses from the three groups of administrators revealed significant difference in responses among West Virginia special education administrators, principals, and superintendents to the perceived performance of the special education administrative function entitled Coordinating as defined by tasks on the revised Newman instrument. Based on the data received from the three groups of respondents there was not a significant difference in responses among the West Virginia administrators to the perceived degree of importance of the special education administrative function entitled Coordinating as defined by tasks on the revised Newman instrument.

The mean difference between pairings of administrators was examined. Relative to the 
pairing of the superintendent and the principal, the superintendents responded that it was actually performed, and the principal responded that it was not performed, on two tasks. Regarding the degree of importance there were no significant differences between superintendents and principals in regard to the Coordinating function.

On the pairing of the special education administrator and the principal, the special education administrator responded that it was actually performed, and the principal responded that it was not performed, on two tasks. Regarding the degree of importance, the special education administrators responded that it was important, and the principal responded that it was not important, on one task. There were no significant differences between the pairing of the superintendent and the special education administrator in the Coordinating function.

\section{Reporting Function}

Question 6: Is there a significant difference in the responses among West Virginia special education administrators, principals, and superintendents to the perceived performance of the special education administrative function entitled Reporting as defined by tasks on the revised Newman instrument?

\section{Question 13: Is there a significant difference in the responses among West Virginia special} education administrators, principals, and superintendents in degree of importance assigned to the special education administrative function entitled Reporting as defined by tasks on the revised Newman instrument?

There was a significant difference in responses among West Virginia special education administrators, principals, and superintendents to the perceived performance of the special education administrative function entitled Reporting as defined by tasks on the revised Newman instrument. Based on the data received from the three groups of respondents there was not a significant difference in responses among the three groups to the perceived degree of importance 
of the special education administrative function entitled Reporting as defined by tasks on the revised Newman instrument.

The mean difference relative to the pairing of the superintendent and the principal indicted that the superintendents responded that it was actually performed, and the principal responded that it was not performed, on only one task. Regarding the degree of importance there were no significant differences between superintendents and principals in regard to the Reporting function.

Relative to the pairing of the special education administrator and the principal, the special education administrator responded that it was actually performed, and the principal responded that it was not performed, on two tasks. Regarding the degree of importance there were no significant differences between special education administrators and principals in regard to the Reporting function. There were no significant differences between the pairing of the superintendent and the special education administrator in the Reporting function.

\section{Budgeting Function}

Question 7: Is there a significant difference in the responses among West Virginia special education administrators, principals, and superintendents to the perceived performance of the special education administrative function entitled Budgeting as defined by tasks on the revised Newman instrument?

Question 14: Is there a significant difference in the responses among West Virginia special education administrators, principals, and superintendents in degree of importance assigned to the special education administrative function entitled Budgeting as defined by tasks on the revised Newman instrument?

There was a significant difference in responses among West Virginia special education administrators, principals, and superintendents to the perceived performance of the special 
education administrative function entitled Budgeting as defined by tasks on the revised Newman instrument. Regarding the degree of importance of the Budgeting function, there was a significant difference in responses among the three groups administrators on the tasks on the revised Newman instrument

The mean difference between pairing of the superintendent and the principal indicated that the superintendents responded that it was actually performed, and the principal responded that it was not performed, on all tasks on the Budgeting function. Regarding the degree of importance, the superintendents responded that it was important, and the principal responded that it was not important, on only one task.

Relative to the pairing of the special education administrator and the principal, the special education administrator responded that it was actually performed, and the principal responded that it was not performed, on all tasks on the Budgeting function. Regarding the degree of importance, the special education administrators responded that it was important, and the principal responded that it was not important, on three tasks. There were no significant differences between the pairing of the superintendent and the special education administrator in the Budgeting function.

\section{Summary Data}

A final approach to examining the data generated by this study was to analyze both the perceived performance and perceived degree of importance among the three groups of administrators regarding the special education administrative functions. This analysis revealed that in regard to the 40 tasks on the survey instrument, on 12 tasks there were significant differences in responses among the three groups of administrators for both the perceived performance and the perceived degree of importance of the special education administrative tasks. These tasks were from all of the administrative functions except for the organizing function. These tasks were: (1) securing consultant services for the staff, (2) developing policies 
(i.e. identification, placement, transfer), (3) establishing special education programs, (4) surveying the district for handicapped and gifted students, (5) planning and providing special equipment and special instructional materials (6) planning in-service meetings, workshops, etc., (7) directing in-service meetings, workshops, etc., (8) utilizing state department personnel as resources, (9) preparation of state and federal special education reports, (10) preparation of the budget, (11) presentation of budget requests, and (12) administering the budget.

\section{$\underline{\text { Conclusions }}$}

\section{Actual Performance of Tasks}

\section{Major functions.}

In this study, research questions one through seven referred to the perceived actual performance of tasks on the revised Newman instrument. The study's findings supported the conclusion that groups of superintendents, special education administrators and principals differed in their perceptions of actual performance of special education administrative functions on all seven of the first seven research questions.

Regarding specific tasks on the revised Newman instrument, the study's findings supported the conclusion that among the three groups of administrators there were significant differences in responses on the perceived performance of 28 out of the 40 tasks on the survey instrument. These tasks included all those on the staffing, planning and budgeting functions, as well as some tasks from all of the other functions. By comparing the number of tasks in which there were differences among groups in regard to the perceived actual performance of tasks, it could be stated that the current study is much like Sullivan's (1986) in regard to responses on the perceived performance of the administrative functions. Sullivan's (1986) findings indicated differencesamong the three group of administrators on perceived performance of 21 of the 40 
tasks on the survey instrument. The significant tasks revealed in the Sullivan study were from all of the administrative functions except for the directing function.

Two other studies by Mazor (1977) and Bobay (1974) have employed the Newman instrument to examine the perceived role of the special education administrator. These two studies differed from the current study in the number of tasks in which significant differences occurred among groups of administrators. Mazor (1977) studied principals, superintendents and special education administrators and discovered that relative to the perceived performance of the special education administrator, there were significant differences among the three groups of administrators on 10 of the 40 tasks on the survey instrument. Bobay (1974) examined special education directors, special education supervisors and general program supervisors. The three groups of administrators in Bobay's study indicated differences in perceptions of performance on 4 of the 40 tasks on the survey instrument.

\section{The special education administrator and the principal.}

In the current study, findings supported the conclusion that the pairing of the special education administrator and the principal had significant differences in perception of the performance of 20 of the 40 tasks on the survey. These 20 tasks included ones from all of the administrative functions except for organizing. Sullivan (1986) reported information about the pairing of the special education administrator and the principal that indicated a difference in perceived performance on 19 of the 40 tasks on the instrument. The specific tasks in the Sullivan study that were significant for special education administrators and principals were from all seven administrative functions on the survey instrument. Information provided by the Mazor study (1977) specifies that on the pairing of the special education administrator and the principal, only 6 of the 40 tasks revealed significant differences in regard to perceived performance of the special education administrator. 


\section{The special education administrator and the superintendent.}

Information provided by the study's findings supported the conclusion that the dyad of the special education administrator and the superintendents indicated that there were no significant differences between superintendents and special education administrators in regard to perceived performance on any of the 40 tasks on the survey instrument. This information is much like previous studies. Sullivan's (1986) inspection of these two administrative roles acknowledged only two tasks had significant differences between groups of special education administrators and superintendents. Mazor (1977) confirmed no differences in his investigation between special education administrators and superintendents.

\section{The superintendent and the principal.}

Data collected in regard to the pairing of the superintendent and the principal in the current study supported the conclusion that there were differences relative to this pairing from previous studies utilizing the Newman instrument. Information gathered in the current study indicated that the pairing of the superintendent and the principal had significant differences in regard to perceived performance of the special education administrator on 19 of the 40 survey tasks. The Sullivan (1986) study confirmed only 2 tasks were significant in differences between superintendents and principals. Mazor's (1977) investigation revealed differences between superintendents and principals on 6 out of the 40 survey tasks.

\section{Degree of importance of tasks.}

\section{Major functions.}

In this study research questions eight through fourteen referred to the perceived degree of 131 
importance of tasks on the revised Newman instrument. The study's findings supported the conclusion that groups of superintendents, special education administrators and principals differed in their perceptions of degree of importance of special education administrative functions on research questions eight and fourteen. Research question eight referred to the Planning function and research question fourteen referred to the Budgeting function. On all other functions, regarding perceived degree of importance, there were no differences among the three groups of administrators.

Regarding specific tasks on the revised Newman instrument, the study's findings supported the conclusion that among the three groups of administrators, there were significant differences in responses on the perceived degree of importance of tasks performed by the special education administrator on 14 out of the 40 tasks on the survey instrument. These tasks were from each of the seven administrative functions on the Newman instrument. The data from the current study were much like the Sullivan (1986) study in that information provided by the Sullivan study disclosed 18 out of the 40 tasks on the survey instrument had significant differences on degree of importance among the trio of administrators studied. This information was in contrast to data reported by Mazor (1977) and Bobay (1974). Mazor reported differences among the three groups of administrators in perceived degree of importance of 8 out of 40 tasks on the survey instrument. Regarding the three groups of administrators scrutinized by Bobay (1974), there were differences in perception of the degree of importance on 4 of the 40 survey tasks.

\section{The special education administrator and the principal.}

The study's findings supported the conclusion that the match of the special education administrator and the principal in the current study provided information that revealed differences in perceived degree of importance on 9 of the 40 tasks on the Newman instrument. Sullivan's (1986) examination confirmed that for the combination of the special education 
administrator and the principal there were differences on perceived degree of importance on 17 of the 40 survey tasks. The Mazor (1977) investigation disclosed that, between groups of special education administrators and the principals, there were differences in perception of the degree of importance on 5 of the 40 tasks.

\section{The special education administrator and the superintendent.}

In regard to the pairing of the special education administrator and the superintendent relative to degree of importance of tasks, the study's findings supported the conclusion that there were significant differences between the two groups of administrators on only one task. This task was from the organizing function and was: establishing psychological procedures for identifying handicapped and gifted students. Relative to these two groups of administrators, the Sullivan (1986) study also found differences on only one of the survey tasks. The significant task from the

Sullivan study was from the coordinating function and was: cooperating and communicating with school personnel. Mazor (1977) affirmed no differences in his investigation between special education administrators and superintendents.

\section{The superintendent and the principal.}

The study's findings supported the conclusion that the pairing of the superintendent and the principal relative to degree of importance of tasks in the current study were consistent with the Sullivan study. Information gathered in the current study indicated that the pairing of the superintendent and the principal had significant differences in regard to the degree of importance of the special education administrator functions on 6 of the 40 survey tasks. The Sullivan (1986) study confirmed three tasks that were significant in differences between superintendents and principals. Mazor's (1977) investigation revealed no differences between superintendents and principals on the survey tasks. 


\section{Summary of conclusions.}

A final approach to analyzing data generated from this study was to identify the specific tasks among the three groups of administrators that were significant for both perceived performance and perceived degree of importance. The study's findings supported the conclusion that there were 12 of these tasks. These tasks were from all of the administrative functions except for the organizing function. Analysis of data in the Sullivan study (1986) indicated significant differences regarding both the perceived performance and the perceived degree of importance on ten of the forty tasks. Five of the tasks in the Sullivan study that were significant for both the perceived performance and the perceived degree of importance were the same as the tasks

identified in the current study. These tasks were: (1) developing policies, (2) establishing special education programs, (3) utilizing state department personnel as resources, (4) preparation of the budget, and (5) presentation of budget requests.

To summarize the comparison between this study and the Sullivan study, the two sets of study results were much alike. The pairing of administrators which was most different between the current study and the Sullivan study, was the pairing of the superintendents and the principal on the perceived performance of tasks on the survey instrument. The current study indicated significant differences on 19 of the 40 survey tasks and data from the Sullivan study revealed differences between these groups of administrators on only two of the administrative tasks.

Information generated from the current study indicated that special education administrators, superintendents and principals have considerable differences in perceptions of the role of the special education administrator. This confirms related research from Duncan \& Hill (1979), Robson (1980), and Hartley (1991). The current study is contradictory to findings from other research conducted by Bobay (1974), Mazor (1977), Anastasio \& Sage (1982), and Berry \& Sistrunk (1989). Information presented from these studies indicated that there were little differences in perceptions of the role of the special education administrator from groups of other 
educators.

\section{$\underline{\text { Discussion and Implications }}$}

In an organization, an administrator's behavior is affected not only by his personal needs, but also by the expectations that other relevant individuals have of his role (Getzels \& Guba, 1957). Unless roles are clearly defined and understood, considerable dissatisfaction may result (Getzels\& Guba, 1957). The presence of role conflict is frequently signaled by the existence of incompatible behavioral performance expectations by other key individuals in the system (Getzels\& Guba, 1957). Data presented in this study clearly imply a potential for role conflict to exist for the special education administrator in West Virginia.

In this study, the greatest potential for conflict existed between the principal and the special education administrator and the principal and the superintendent. The role of the school principal seemed to be the position that was least aware of the special education administrative functions. Given that this finding was consistent with Sullivan's findings from 1986, it appears that in West Virginia not much progress has been made in the past twelve years in regard to principals being more aware of the role of the special education administrator.

Findings and conclusions in this study imply that communication between these key administrators in West Virginia has not improved in a day when the literature clearly indicates integrated regular and special education programs. Given the research presented in this study relative to the increased role by the principal in special education, the principal's lack of knowledge of the role of the special education administrator is especially troubling.

When the administrative functions were studied, the main differences occured between groups of special education administrators and the principals and the superintendents and the principals were the functions of staffing, planning and budgeting. The staffing function has been described as those activities which include the methods for accomplishing the purposes of the enterprise (Bobay, 1974). The planning function has been described as being involved with the 
recruiting and training of personnel and the budgeting function as the one dealing with the fiscal planning and accounting (Bobay, 1974). Although all of the administrative functions on the revised Newman instrument can be viewed as significant, it could be argued that the staffing, planning and budgeting functions could be the most important functions to the operation of the educational system. Findings generated in this study imply that, given that these were the three administrative functions in which the pairings of special education administrators and principals and superintendents and principals indicated the most differences in the perceived role of the special education administrator, there is the potential for a reduction in efficiency and effectiveness in, if not the entire educational system, at least the special education system.

Findings and conclusions in this study imply that the school principal is largely unaware of the role of the special education administrator. The implication of these findings of the principal's lack of knowledge of the role of the special education administrator is significant given that, of the three administrative roles scrutinized in this study, the principal is the only role that manages the special education program on an implementation level. A closer inspection of the specific tasks of the special education administrator that influence the school level special education programs would be warranted to ensure that special education programs are not being affected by the lack of communication between the principal and the special education administrator.

Data presented in this study confirmed a difference of perception of the role of the special education administrator between the superintendent and the principal. This finding was in contrast to Sullivan's findings of very little conflict between the superintendent and the principal. The implication of this finding is that the pairing of the superintendent and the principals, in regard to the perceived role of the special education administrator, are further apart than they were twelve years ago. Perhaps, as the roles of both of these administrators themselves have become more complicated, it is difficult to maintain knowledge across the system in regard to the roles other administrators maintain.

Information gathered in this study could help West Virginia school systems avoid conflict 136 
between special education and regular education. One way to alleviate role conflict would be to have a vehicle for increased communication among the three groups of administrators, such as roundtable discussions or presentations, to keep all groups aware of what the other groups are doing. Another way to avoid conflict would be more special education training provided to school principals. This training could be provided through school systems or institutions of higher education.

Since the Sullivan study, the special education system has become more complicated due to the inclusion movement, increased litigation, more legislation and the trend on the federal level toward more accountability for quality special education programs. This comes at a time when the public education system as a whole has become more complicated. It is understandable that the complexity of the education system has hindered a clear view of the role of the special education administrator. It is precisely these complex changes in special education that make it more crucial for all administrators in the education system to be aware of the role of the special education administrator.

Information garnered in this study revealed that the potential for role conflict exists for the special education administrator in West Virginia. This conflict could cause job dissatisfaction which would ultimately weaken the system as a whole. If one is to minimize conflict, it is necessary to identify and understand potential conflicting situations. This study has done much to help identify and understand the potential conflict situations in West Virginia in regard to the special education administrator. The information provided in this study could be utilized to strengthen the special education program in West Virginia and ultimately, the education system as a whole.

\section{$\underline{\text { Recommendations for Further Research }}$}

An analysis of the descriptive data and the findings in this investigation have formed the basis for the following recommendations: 
1. It is recommended that additional research be developed to determine to what extent additional tasks might be added to further clarify the special education administrative tasks in the survey instrument.

2. It is recommended that a study be conducted to determine if tasks identified as being performed by special education administrators in this study are included in any existing course content in the training of special education administrators.

3. It is recommended that identification of tasks actually performed by special education administrators be conducted periodically to ascertain the actual functions of the role.

4. It is recommended that additional research be developed to isolate potential conflict between special education administrators and principals at different programmatic levels (early, middle and adolescent).

5. It is recommended that similar research be extended to include classroom teachers to determine possible conflict of roles that may effect services at the classroom level.

6. It is recommended that the findings from this study be examined on a task by task basis to determine whether additional program objectives should be added to principalship and superintendency certifications. 


\section{REFERENCES}

Anastasio, J.T., \& Sage, D.D. (1982). Role expectations for the director of special education. Paper presented at the Annual Meeting of the American Educational Research Association. (ERIC document Reproduction Service No. ED 218 859)

Arick, J.R. and Krug D.A. (1993). Special education administrators in the United States: Perceptions on policy and personnel issues. The Journal of Special Education, 27(3), 348-364.

Ayer, F. C., \& Barr, A. S. (1928). The organization of supervision. New York: Harper and Row.

Baker, H. J. (1944). Administration of special education. Review of Educational Research, 14, 209-216.

Berry B.C., \& Sistrunk, W.E. (1989). The relationship between actual and preferred supervisory behaviors as perceived by special education teachers and as self-perceived by special education supervisors in Louisiana. Paper presented at the Annual Meeting of the Mid-South Educational Research Association (ERIC document Reproduction Service No. ED 312 766)

Bobay, R. B. (1973). Tasks of the chief administrator of special education at the district level in Florida, as perceived by supervisors and the chief administrator of special education. unpublished doctoral dissertation, Florida State University.

Bruno, L. (1961). Handbook of special education for school administrators. Superintendent of Public Instruction, State of Washington, Olympia.

Buka, S. L. (1998). A researcher's view: Learning-disabled children get lost in definitions. Brown University Child and Adolescent Behavior Letter, 14(2), 2-4.

Burnett, E. (1994). Next steps: Adaptation and use of an established model in training principals. Journal of School Leadership, 4(5), 529-542. 
Burnett, E., \& Pankake, A. M. (1990). The effective elementary school principal: Theoretical bases, research findings and practical implications. Paper presented at the Annual Meeting of the Mid-South Educational Research Association (ERIC document Reproduction Service No. ED 333 591)

Campbell, R. F., Bridges, E. N., Corbally, J. E. Jr., Nystrand, R. O., \& Ramseyer, J. A. (1971). Introduction to educational administration. Boston MA: Allyn and Bacon.

Cline, R. (1981). Principal's attitudes and knowledge about handicapped children. Exceptional Children, 48, 172-176.

Clouse, R.W.(1989). A review of educational role theory: A teaching guide for administrative theory. Unpublished report (ERIC Document Reproduction Service No. ED 314 824)

Connor, L. E. (1963). Preliminaries to a theory of administration for special education. Exceptional Children, 29, 431-436.

Davis, W. J., Wholeben, B. E., \& Ellis, N. (1979). A role theory perspective of the system of delivering services to exceptional children. Paper presented at the 57th Annual International Conference of the Council for Exceptional Children, Dallas, TX.

Downey, R. D. (1970). A study of the leader behavior of special education administrators in Illionios public schools. Unpublished doctoral dissertation, Southern Illinois University.

Downing, J.E., Eichinger, J. and Williams, L. J.(1997). Inclusive education for students with severe disabilities. Remedial and Special Education, 18(3), 133-142.

Duncan, R.R., \& Hill, R. L. (1979). Expectations for the role of cooperative special education director. University of North Dakota, Grand Rapids, North Dakota: Bureau of Education Research and Services (ERIC document Reproduction Service No. ED 176 522)

Elliot, B., and Riddle, M.(1989). An effective interface between regular and special education: A synopsis of issues and successful practices. Bloomington, IN: Council of Administrators of Special Education, Inc. 
Finkenbinder, R. L. (1981). Special education administration and supervision: The state of the art. Journal of Special Education, 15(4), 485-495.

Forgone, C., and Collings, G.(1975). State certification endorsement in special education administration. Journal of Special Education, 26, 5-10.

Frohoff, K. (1998) The roles of special education administrators and principals in Kentucky. unpublished doctoral dissertation, University of Kentucky.

Fullen, M. (1982). The meaning of educational change. New York: Teachers College Press.

Fullen, M. with S. Stiegelbauer (1991). The new meaning of educational change, 2nd ed. New York: Teacher's College Press.

Furman, G. C. (1988). The work of the special education director: A field study. Paper presented at the Annual Meeting of the American Educational Research Association (ERIC document Reproduction Service No. ED 300 943)

Gearheart, B.R. (1967). Administration of Special Education. Springfield: Charles C. Thomas.

Getzels, J.W., and Guba, E.G.(1954). Role, role conflict, and effectiveness: An empirical study. American Sociological Review, 19, 164-175.

Getzels, J.W., and Guba, E.G.(1957). Social behavior and the administrative process. School Review, 64, 423-441.

Getzels, J. W., Lipman, J. M., \& Campbell, R. F. (1968). Educational administration as a social process. New York: Harper and Row.

Gibbs, G. K. (1990). General systems theory: Implications for educational organizations and administration. Unpublished doctoral dissertation, State University of New York, Buffalo, New York.

Gillung, T.B., Spears, J., Campbell, T., Rucker, C. N. (1992). Competencies for administrators of special education. Journal of Personnel Evaluation in Education, 6, 71-90. 
Gmelch W. H., \& Torelli, J. A. (1993). The association of role conflict and ambiguity with administrator stress and burnout. Paper presented at the Annual Meeting of the American Educational Research Association (ERIC document Reproduction Service No. ED 359631 )

Gmelch W. H., \& Torelli, J. A. (1993). The association of role conflict and ambiguity with administrator stress and burnout. Journal of School Leadership, 4, 341-356.

Goor, M. B., Schwenn, J. O., \& Boyer, L. (1997). Preparing principals for leadership in special education. Intervention in School and Clinic, 32(3), 133-141.

Gorton, R. A. (1972). Conflict, controversy and crisis in school administration and supervision: issues, cases and concepts for the 70s. Dubuque, Iowa: Wm. C. Brown Publishers.

Graham, R. (1956). A guide - directing the education for exceptional children in a local school district. Springfield, IL: Office of the superintendent of Public Instruction.

Grebner, F.D. (1989). Control of special education. Illinois Benedictine College, Lisle, Illinois (ERIC document Reproduction Service No. ED 313 865)

Grieder, C., \& Rosenstengel, W. E. (1954). Public school administration. New York: Roland Press, 1954.

Halpin, A. W. (1966). Theory and research in administration. New York: MacMillan.

Hartenian, L. S., Hadaway, F. J., Badovick, G. J. (1994). Antecedents and consequences of role perceptions: A path analysis approach. Journal of Applied Business research, 10(2), 4051.

Hartley, V. J. (1991). Perceptions of the role of special education coordinators and building principals in special education administration. Unpublished doctoral dissertation, University of Southern Mississippi.

Herbert, EA., and Miller, S. I. (1985). Role conflict and the special education supervisor: A qualitative. The Journal of Special Education, 19(2), 215- 229.

Hill, D.A. (1993). The realities of principalship. Castleton State College, Vermont (ERIC Document Reproduction Service No. ED 364-972) 
Hirth M. A., \& Valesky, T. C. (1990). Survey of universities: special education knowledge requirements in school administrator preparation programs. Planning and Changing, 21(3), 4-14.

Ho, F. N., Vitell, S. J., Barnes, J. H., \& Desborde, R. (1997). Ethical correlates of role conflict and ambiguity in marketing: The mediating role of cognitive moral development. Journal of the Academy of Marketing Science, 25(2), 117-127.

Johnson, M. m. (1971). Role expectations that supervisors, teachers and elementary school principals have for the supervisor of special classes for mentally retarded children. Unpublished doctoral dissertation, University of Maryland.

Johnson, V. L., \& Burrello, L. C. (1987). Critical success factors of rural and urban special education administration. Leadership and Supervision in Special Services, 4(1-2), 1-15.

Katz, D., \& Kahn, R. L. (1978). The social psychology of organizations (2nd ed.). New York: John Wiley.

Kerlinger, F. N. (1986). Foundations of behavioral research (3rd ed.). Fort Worth, TX: Holt, Rinehart, Winston.

Kirk, S.A.(1957). A doctor's degree program in special education. Exceptional Children, $\underline{24}, 50-52$.

Knoke, D., and Bohrnstedt, G. W.(1994). Statistics for social data analysis. Itasca, Illinois: F. E. Peacock Publishers, Inc.

Lamb, J., and Burrello, L.C.(1979). The role of the council of administrators of special education. Exceptional Children, 46(1), 42-48.

Lashley, C. A. (1991). Position responsibilities and relationships in the evaluation of district level special education administrators. Council of Administrators of Special Education, Inc.; Indiana University, Bloomington, Indiana (ERIC document Reproduction Service No. ED $358649)$

Lindeberg, E. (1987). A forecast of future tasks for special education service education administrators. Unpublished doctoral dissertation, Texas A \& M University. 
MacGregor, N. J. (1994). Role and role expectations of superintendents of a school system: An application of Getzels' and Gubas' social systems model. Unpublished doctoral dissertation, University of Toronto.

Mackie, R. \& Engel, A. (1955). Directors and supervisors of special education in local

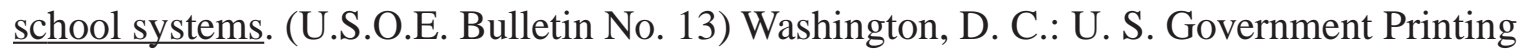
Office.

Marro, T. D., \& Kohl, J. W. (1972). Normative study of the administration position in special education. Exceptional Children, 5-13.

Mazor, G. (1977). The role of the special education administrator as viewed by principals,

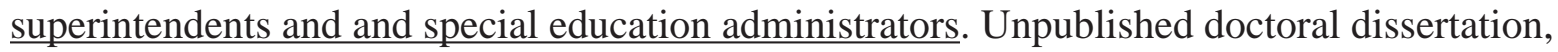
Boston College.

McLaughlin, M. J., \& Kienas, K. (1989). The administrators' roundtables: A model for increasing the leadership of elementary school principals in special education. International Journal of Disability, Development and Education, 36(2), 107-116.

Meisgeier, C. H. \& Sloat, R. (1970). Special education administration and supervision - a review of relevant literature. In C. H. Meisgeier \& J. D. King. The Process of Special Education Administration. Scranton: International Textbook Company, 390-409.

Miles, R. H. (1976). Role requirements as sources of organizational stress. Journal of Applied Psychology, 61(2), 172-179.

National Advisory Committee on the Education of the Handicapped (1976). The unfinished revolution: Education of the handicapped. Washington, D.C.:GPO.

National Association of the State Directors of Special Education(1993). Leading and managing for performance: An examination of challenges confronting special education. Viewpoints (ERIC Document Reproduction Service No. ED 389 116)

Naegley, R. L., Evans, N. D., \& Lynn, C. A. (1969). The school administrator and learning resources. New Jersey: Prentice-Hall. 
Newman, K. S. (1970). Administrative tasks in special education. Exceptional Children, $521-524$.

Nunn, M. (1998). Assistant Director, West Virginia Department of Special Education, personal interview.

Payne, R. \& Murray, C. (1974). Principals' attitudes toward integration of the handicapped. Exceptional Children, 41, 123-125.

Ponder, S. M. (1994). The differences in perception of training between Mississippi special education directors and special education directors nationwide. Unpublished doctoral dissertation, The University of Southern Mississippi.

Powell, D., \& Hyle, A. E. (1997). Principals and school reform: Barriers to inclusion in three secondary schools. Journal of School Leadership, 7, 301- 326.

Prillaman, D., and Richardson, R. (1985). State certification- endorsement requirements for special education administrators. The Journal of Special Education, 19(2), 231-236.

Robson, D. L. (1981). Administering educational services for the handicapped: role expectations and perceptions. Planning and Changing, 12(3), 183-189.

Rude, H. A., \& Sasso, G. M. (1988). Colorado special education administrative competencies. Teacher Education and Special Education, 11(4), 139-143.

School, G. T. (1968). The principal works with the visually impaired. Washington D. C.: Council for Exceptional Children.

Schultz, J. J. (1973). Integration of emotionally disturbed students: the role of the director of special education. Exceptional Children, 40, 39-41.

Scruggs, T. E. \& Mastropieri, M. A. (1994). Successful mainstreaming in elementary science classes: a qualitative study of the reputational cases. American Educational Research Journal, 31(4), 785-811.

Simpson, R. G., \& Lamb, J. R. (1979). Special education administrators. The Pointer, 23 (2), 77-80. 
Spriggs, G.M. (1972). The role of administrators of special education programs as perceived by administrators of special education programs in the state of Minnesota. unpublished doctoral dissertation, University of Minnesota.

Stile, S.W., and Pettibone, T.J.(1980). Training and certification in special education. Exceptional Children, 46(7), 530-533.

Stile, S., Abernathy, S., and Pettibone, T.(1986). Training and certification of special education administrators: A 5-year follow-up study. Exceptional Children, 53(3), 209-212.

Sullivan, M. E. (1986). The special education administrator role as perceived by principals, superintendents and special education administrators in West Virginia. Unpublished doctoral dissertation, West Virginia University.

Sullivan, M. E. (1996). Identifying challenges to rural education: Role clarification for administrators. In Rural Goals 2000: Building Programs that Work (ERIC document Reproduction Service No. ED 394 776)

Sullivan, M. E., \& Leary, P. A. (1991). Perceptions of rural school administrators of the

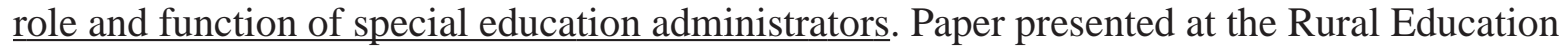
Symposium (ERIC document Reproduction Service No. ED 342 552)

Swain, C. R. \& Underwood, B. C. (1965). Arkansas guide for public school speech therapy. Arkansas State Department of Education, Special Education Division of Instructional Services.

Thouvenelle, S., Deloria, D., and Blaschke, C. (1984). Final Report: An Investigation of the dispersion among West Virginia County School districts in the percentage of exceptional children receiving free appropriate public education. Paper prepared by Education Turnkey Systems, Inc., Falls Church, Virginia.

Urwick, L. (1931). In L. Gulick and L. Urwick (Eds). Papers on the science of administration. (p. 199). New York: Institute of Public Administration, Columbia University. Valesky, T.C., and Hirth, M.A.(1992). Survey of states: Special education knowledge requirements for school administrators. Exceptional Children, 58, 399-405. 
Van Sell, M., Brief, A. P., \& Schuler, R.S. (1981). Role conflcit and role ambiguity: Integration of the literature and directions for future research. Human Relations, 34(1), 43-71.

Voelker, P. H. (1966). Administration of special education in local school systems. Proceedings of the Second Colloquium of Exceptional Children and Youth. Austin, TX: University of Texas.

Von Horn, G. P., Burrello, L. C., \& DeClue, L. (1992). An instructional leadership framework: The principal's leadership in special education. The Special Education Leadership Review, 1(1), 41-54.1

Walker, V. A. (1988). Special education administrators' perceived competencies in areas of special education administration. Unpublished doctoral dissertation, Texas A \& M University.

Washington, N. G. (1996). Special education administration: Paths of preparation and models of practice. Unpublished doctoral dissertation, Oklahoma State University.

Weatherman, R., \& Hapoz, I. (1975). A study of special education directors in Minnesota. Unpublished report, Duluth, MN: University of Minnesota.

Whitworth, J. E., \& Hatley, R. V. (1979). Certification and special education leadership personnel: analysis of state standards. The Journal of Special Education, 13, (3), 297-305.

Whitworth, J. E., \& Hatley, R. V. (1982). The role of the special education director. The Journal for Special Educators, 19(1), 38-43.

Will, M. (1986). Education students with learning problems: A shared responsibility. Washington, D.C.: U.S. Department of Education.

Williams, G. B. (1993). Managing impossible jobs: Dilemmas and decisions in special education administration. Unpublished doctoral dissertation, Boston University.

Wisconsin state Department of Special Education (1969). Guidelines for Wisconsin's directors, coordinators and supervisors of special education. Unpublished report (ERIC document Reproduction Service No. ED 036930) 
APPENDIX A

$\underline{\text { REVISED NEWMAN INSTRUMENT }}$ 


\section{THE ROLE OF THE SPECIAL EDUCATION ADMINISTRATOR IN WEST VIRGINIA}

The instrument on the following pages concerns the tasks performed in seven functional areas of administration by the individual who is designated as the administrator of special education in your county. The seven functions are staffing, directing, planning, organizing, coordinating, reporting, and budgeting.

In the first column Actually Performed: please check Yes if the person responsible for administering special education in your school system actually performs the task, or check No if the task is not performed, or check Does Not Apply if the task is not applicable to the position.

In the second column Degree of Importance: the scale has been designed so that you may indicate the importance of the various functions listed. Please circle the letters in the second column which indicate how you feel about each item: VI Very Important, I Important, $U$ Uncertain, LI Little Importance, NI Not Important.

$$
\begin{aligned}
\text { VI - Very Important } \\
\text { I }- \text { Important } \\
\text { U - Uncertain } \\
\text { LI - Little Importance } \\
\text { NI - Not Important } \\
\text { STAFFING FUNCTION: }
\end{aligned}
$$

1. Participating in recruitment of special education teachers

2. Assistance in the screening of special education teachers

3. Participating in selection of special education teachers

4. Participating in assignment of special education teachers

5. Working with principals in evaluation of special

\begin{tabular}{|c|c|c|c|c|c|c|c|}
\hline \multicolumn{3}{|c|}{$\begin{array}{c}\text { ACTUALLY } \\
\text { PERFORMED }\end{array}$} & \multicolumn{5}{|c|}{$\begin{array}{l}\text { DEGREE OF } \\
\text { IMPORTANCE }\end{array}$} \\
\hline YES & NO & $\begin{array}{c}\text { DOES NOT } \\
\text { APPLY }\end{array}$ & VI & 1 & & LI & NI \\
\hline & & & VI & I & $\mathrm{U}$ & LI & NI \\
\hline & & & VI & I & $\mathrm{U}$ & LI & NI \\
\hline & & & VI & I & $\mathrm{U}$ & LI & NI \\
\hline & & & VI & I & $\mathrm{U}$ & LI & NI \\
\hline & & & VI & I & $\mathrm{L}$ & LI & NI \\
\hline & & & VI & I & $\mathrm{U}$ & LI & NI \\
\hline & & & VI & I & $\mathrm{U}$ & LI & NI \\
\hline
\end{tabular}
education teachers

6. Building and maintaining special education staff morale

7. Securing consultant services for the staff
Please turn page 
DIRECTING FUNCTION:

1. Placement of children in special classes

2. Transportation schedules for exceptional children

3. Planning in-service meetings, workshops, etc.

4. Conducting research with exceptional children

5. Directing in-service meetings, workshops, etc.

6. Re-evaluation of exceptional children

7. Providing counseling and guidance services for exceptional children

\begin{tabular}{|c|c|c|c|c|c|c|c|}
\hline \multicolumn{3}{|c|}{$\begin{array}{c}\text { ACTUALLY } \\
\text { PERFORMED }\end{array}$} & \multicolumn{5}{|c|}{$\begin{array}{l}\text { DEGREE OF } \\
\text { IMPORTANCE }\end{array}$} \\
\hline \multirow[t]{8}{*}{ YES } & $\mathrm{NO}$ & $\begin{array}{c}\text { DOES NOT } \\
\text { APPLY }\end{array}$ & VI & I & $\mathrm{U}$ & LI & NI \\
\hline & & & VI & I & $\mathrm{U}$ & LI & NI \\
\hline & & & VI & I & $\mathrm{U}$ & LI & NI \\
\hline & & & VI & I & $\mathrm{U}$ & LI & NI \\
\hline & & & VI & I & $\mathrm{U}$ & LI & NI \\
\hline & & & VI & I & $\mathrm{U}$ & LI & NI \\
\hline & & & VI & I & $\mathrm{U}$ & LI & NI \\
\hline & & & VI & I & $\mathrm{U}$ & LI & NI \\
\hline
\end{tabular}

PLANNING FUNCTION:

1. Developing policies (i.e identification, placement, transfer)

2. Establishing special education programs

3. Surveying the district for handicapped and gifted students

4. Planning and providing facilities

5. Planning and providing special equipment and special instructional materials

6. Curriculum planning and development

\begin{tabular}{|l|l|llllll|}
\hline & & & & & & \\
VI & I & U & LI & NI \\
& VI & I & U & LI & NI \\
& VI & I & U & LI & NI \\
VI & I & U & LI & NI \\
& & & & & \\
& VI & I & U & LI & NI \\
& & & & & \\
VI & I & U & LI & NI \\
\hline
\end{tabular}

Page 2 
ORGANIZING FUNCTION:

1. Establishing channels of communication and responsibility

2. Preparing schedules for special education teachers

3. Placement of special classes within school buildings

4. Establishing psychological procedures for identifying handicapped and gifted students

5. Establishing communication with entire school staff concerning referral and diagnostic procedures

\begin{tabular}{|c|c|c|c|c|c|c|c|}
\hline \multicolumn{3}{|c|}{$\begin{array}{c}\text { ACTUALLY } \\
\text { PERFORMED }\end{array}$} & \multicolumn{5}{|c|}{$\begin{array}{l}\text { DEGREE OF } \\
\text { IMPORTANCE }\end{array}$} \\
\hline \multirow[t]{6}{*}{ YES } & NO & $\begin{array}{c}\text { DOES NOT } \\
\text { APPLY }\end{array}$ & VI & I & $\mathrm{U}$ & LI & NI \\
\hline & & & VI & I & $\mathrm{U}$ & LI & NI \\
\hline & & & VI & I & $\mathrm{U}$ & LI & $\mathrm{NI}$ \\
\hline & & & VI & I & $\mathrm{U}$ & LI & NI \\
\hline & & & VI & I & $\mathrm{U}$ & LI & NI \\
\hline & & & VI & I & $\mathrm{U}$ & LI & NI \\
\hline
\end{tabular}

\section{COORDINATING FUNCTION:}

1. Developing inclusion model for services

2. Cooperating and communicating with school personnel

3. Communicating with parents and the public

4. Utilizing services of community agencies

5. Utilizing state department personnel as resources

6. Communication with board of education concerning special education program

Page 3

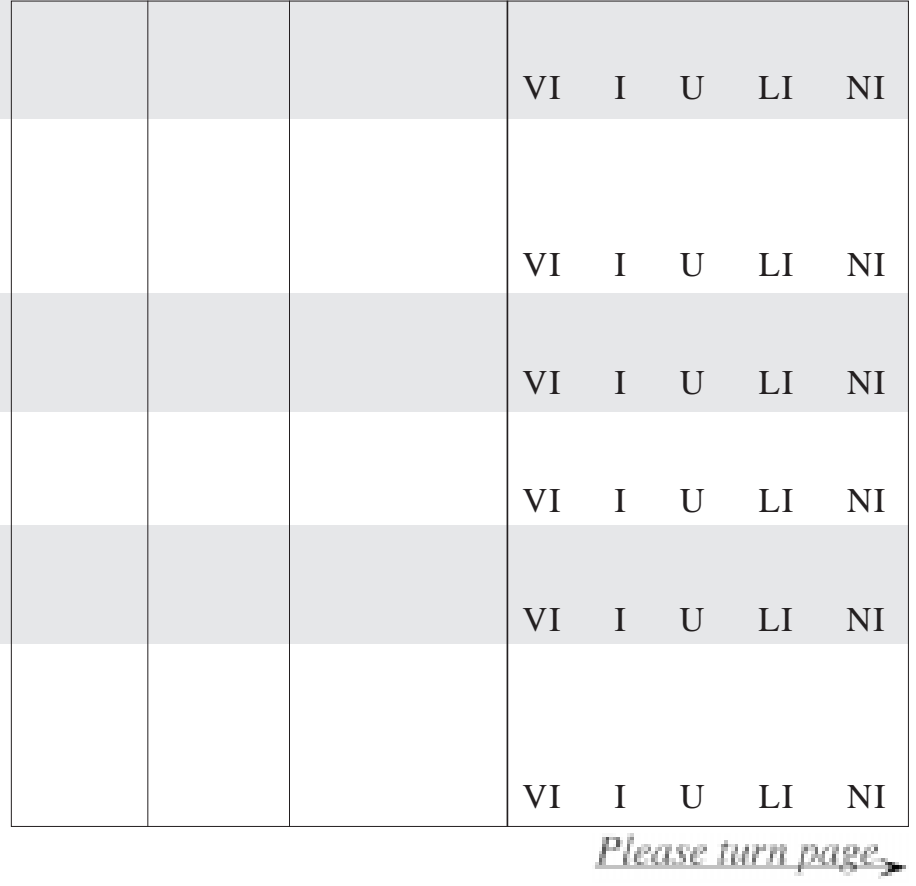




\section{REPORTING FUNCTION:}

1. Preparation of state and federal special education reports

2. Pupil accounting and records

3 . Teacher accounting

4. Disseminating research findings

5. Periodic publications made available to parents and the public

\begin{tabular}{|c|c|c|ccccc|}
\hline \multicolumn{3}{|c|}{ ACTUALLY } & \multicolumn{5}{c|}{ DEGREE OF } \\
IMPORTANCE
\end{tabular}

BUDGETING FUNCTION:

1. Preparation of the budget

2. Presentation of budget requests

3. Administering the budget

4. Keeping school personnel informed of budget limits

\begin{tabular}{|l|l|lllll|}
\hline & & VI & I & U & LI & NI \\
VI & I & U & LI & NI \\
VI & I & U & LI & NI \\
& & & & & & \\
& & VI & I & U & LI & NI \\
\hline
\end{tabular}




\section{APPENDIX B}

DEMOGRAPHIC INFORMATION SHEET 


\section{Demographic Information Sheet}

1. As of June, 1998, how many years have you been in your currents position? (Complete appropriate category)

__ Superintendent

Principal

___ Special Education Administrator

2. As of June, 1998, how many years of experience have you had in the following position(s)? (complete appropriate categories)

Superintendent

__ Special Education Administrator

Principal

__ Assistant Principal

Teacher

Other (specify)

3. As of June, 1998, how many graduate courses in school administration have you taken? (Check one)
$-0$
$1-3$
4-6
7-9
10 and above

4. As of June, 1998, how many graduate and undergraduate courses have you taken in the area of special education? (Check one)
0
$1-3$
4-6
7-9
10 and above

5. Is it your opinion that the school principal is the special educatio leader at the school level? Yes No 
APPENDIX C

INITIAL LETTER 


\section{Education Administration \\ West Virginia University \\ College of Human Resources and Education}

September 11, 1998

APPROVED BY THE COULEE OF

HUMAN RESOURCES \& EDUCATION

ERNEST R. GOERES

Dear Educator,

I am seeking your participation in a study regarding the perceived role of the special education administrator in West Virginia. As part of my dissertation for an Ed. D. in Educational Leadership from West Virginia University, this study will examine perceptions among groups of superintendents, principals and special education administrators, regarding the role of the special education administrator. Your help in furnishing information about role expectations of the county administrator of special education will make this study valuable to those who work with, employ, or train special education administrators. Specifically, this study should identify tasks which may be sources of potential conflict among administrators of special education and other educational leaders.

The survey does not ask for names, completion is voluntary, and you do not have to respond to every item. The data gathered will be reported in aggregate form and your responses will remain anonymous.

You can assist in this research by taking approximately ten minutes to complete the enclosed survey instrument. Please return the document in the enclosed envelope by September 21,1998 . Your cooperation in completing the survey instrument is greatly appreciated.

Sincerely,

Katherine L. Porter

304 293-3707/2467 व 606 Allen Hall 口 P.O. Box 6122 a Morgantown, WV 26506-6122 Equal Opportunity / Affirmative Action Institution 
APPENDIX D

FOLLOW-UP LETTER 


\section{Education Administration \\ College of Human Resources and Education}

Dear Educator,

October 1, 1998

Your help is needed very badly at this time. You may have misplaced or overlooked my initial mailing to you requesting your participation in a study of the perceived role of the special education administrator in West Virginia. Specifically, the results of this study should identify existing tasks which may be sources of potential conflict among administrators of special education and other educational leaders.

Although a large number of individuals completed and returned the attached instrument, I need your cooperation to make the sampling of this study more complete, and therefore, the results more valid. Please take the approximately five minutes necessary to complete the enclosed survey instrument and return it in the enclosed envelope.

If our letters have crossed in the mail and you have already returned the questionnaire, please disregard this letter and accept my appreciation for your cooperation.

Sincerely,

Katherine L. Porter

Doctoral Candidate

304 293-3707/2467 606 Allen Hall 口 P.O. Box 6122 口 Morgantown, WV 26506-6122

Equal Opportunity / Affirmative Action Institution 
APPENDIX E

$\underline{\text { DEMOGRAPHIC TABLES }}$ 
Range and Mean Years of Experience in Current Position

\begin{tabular}{ccc}
\hline position & range of years & $\begin{array}{c}\text { mean years } \\
\text { of experience }\end{array}$ \\
\hline $\begin{array}{c}\text { Superintendents } \\
(\mathrm{N}=33)\end{array}$ & $1-28$ & 7.48 \\
$\begin{array}{c}\text { Special Education } \\
\text { Administrators } \\
(\mathrm{N}=36)\end{array}$ & $1-28$ & \\
$\quad$ & $1-36$ & \\
Principals \\
$(\mathrm{N}=84)$
\end{tabular}


Experiential Data for Superintendents* by Current and Prior Positions

\begin{tabular}{|c|c|c|}
\hline position & range of years & $\begin{array}{l}\text { mean years } \\
\text { of experience }\end{array}$ \\
\hline $\begin{array}{l}\text { Superintendents } \\
\qquad(\mathrm{N}=33)\end{array}$ & $1-28$ & 7.48 \\
\hline $\begin{array}{l}\text { Special Education } \\
\text { Administrators } \\
\qquad(\mathrm{N}=5)\end{array}$ & $1-16$ & 8.20 \\
\hline $\begin{array}{l}\text { Principals } \\
\qquad(\mathrm{N}=23)\end{array}$ & $1-19$ & 8.43 \\
\hline $\begin{array}{l}\text { Assistant Principals } \\
\qquad(\mathrm{N}=9)\end{array}$ & $1-10$ & 9.6 \\
\hline $\begin{array}{l}\text { Teachers } \\
\qquad(\mathrm{N}=24)\end{array}$ & $1-24$ & 8.08 \\
\hline $\begin{array}{l}\text { Others } \\
\qquad(\mathrm{N}=15)\end{array}$ & $1-18$ & 8.53 \\
\hline
\end{tabular}


Experiential Data for Special Education Administrators* by Current and Prior Positions

\begin{tabular}{|c|c|c|}
\hline position & range of years & $\begin{array}{l}\text { mean years } \\
\text { of experience }\end{array}$ \\
\hline
\end{tabular}

Superintendents

$(\mathrm{N}=0)$

Special Education

Administrators

$1-28$

8.05

$(\mathrm{N}=36)$

Principals

$1-32$

11.5

$(\mathrm{N}=8)$

Assistant Principals

$1-5$

5

$(\mathrm{N}=4)$

Teachers

1-24

10.4

$(\mathrm{N}=25)$

Others

1-23

10.81

$(\mathrm{N}=16)$

* N=36 
Experiential Data for Principals* by Current and Prior Positions

\begin{tabular}{|c|c|c|}
\hline position & range of years & $\begin{array}{l}\text { mean years } \\
\text { of experience }\end{array}$ \\
\hline $\begin{array}{l}\text { Superintendents } \\
\qquad(\mathrm{N}=1)\end{array}$ & 1 & 1 \\
\hline $\begin{array}{l}\text { Special Education } \\
\text { Administrators } \\
\qquad(\mathrm{N}=4)\end{array}$ & $1-14$ & 7.25 \\
\hline $\begin{array}{l}\text { Principals } \\
\qquad(\mathrm{N}=84)\end{array}$ & $1-36$ & 13.16 \\
\hline $\begin{array}{l}\text { Assistant Principals } \\
\qquad(\mathrm{N}=27)\end{array}$ & $1-24$ & 6.44 \\
\hline $\begin{array}{l}\text { Teachers } \\
\qquad(\mathrm{N}=64)\end{array}$ & $1-32$ & 10.25 \\
\hline $\begin{array}{l}\text { Others } \\
\qquad(\mathrm{N}=7)\end{array}$ & $1-10$ & 3.85 \\
\hline
\end{tabular}


Number of Graduate Courses Taken in School Administration by Position

\begin{tabular}{|c|c|c|c|c|c|}
\hline \multirow[t]{2}{*}{ position } & \multicolumn{5}{|c|}{ number of graduate courses } \\
\hline & 0 & $1-3$ & $4-6$ & $7-9$ & $\begin{array}{l}10 \text { and } \\
\text { above }\end{array}$ \\
\hline $\begin{array}{l}\text { Superintendents } \\
\qquad(N=33)\end{array}$ & 1 & 1 & 0 & 1 & 30 \\
\hline $\begin{array}{l}\text { Special Education } \\
\text { Administrators } \\
\qquad(\mathrm{N}=36)\end{array}$ & 0 & 5 & 2 & 3 & 26 \\
\hline $\begin{array}{l}\text { Principals } \\
\qquad(\mathrm{N}=84)\end{array}$ & 4 & 2 & 0 & 4 & 74 \\
\hline
\end{tabular}


Number of Undergraduate and Graduate Courses Taken in Special Education by Position

\begin{tabular}{|c|c|c|c|c|c|}
\hline \multirow[t]{2}{*}{ position } & \multicolumn{5}{|c|}{ number of undergraduate and graduate courses } \\
\hline & 0 & $1-3$ & $4-6$ & $7-9$ & $\begin{array}{l}10 \text { and } \\
\text { above }\end{array}$ \\
\hline $\begin{array}{l}\text { Superintendents } \\
\qquad(\mathrm{N}=33)\end{array}$ & 6 & 16 & 3 & 4 & 4 \\
\hline $\begin{array}{l}\text { Special Education } \\
\text { Administrators } \\
\qquad(\mathrm{N}=36)\end{array}$ & 4 & 0 & 5 & 2 & 25 \\
\hline $\begin{array}{l}\text { Principals } \\
\qquad(\mathrm{N}=84)\end{array}$ & 24 & 22 & 19 & 5 & 14 \\
\hline
\end{tabular}


Answers by Position to the Question

"Is it your opinion that the school principal is the special education leader at the school level?"

\begin{tabular}{lll}
\hline Position & Yes & No \\
\hline $\begin{array}{c}\text { Superintendents } \\
(\mathrm{N}=33)\end{array}$ & 28 & 5 \\
$\begin{array}{l}\text { Special Education } \\
\text { Administrators } \\
(\mathrm{N}=36)\end{array}$ & 30 & 6 \\
$\begin{array}{c}\text { Principals } \\
(\mathrm{N}=84)\end{array}$ & 62 & \\
\hline
\end{tabular}

